NBER WORKING PAPER SERIES

\title{
BUSINESS CYCLES AND CURRENCY RETURNS
}

\author{
Riccardo Colacito \\ Steven J. Riddiough \\ Lucio Sarno \\ Working Paper 26299 \\ http://www.nber.org/papers/w26299 \\ NATIONAL BUREAU OF ECONOMIC RESEARCH \\ 1050 Massachusetts Avenue \\ Cambridge, MA 02138 \\ September 2019
}

We are grateful for comments and suggestions to Antje Berndt, Magnus Dahlquist, Pasquale Della Corte, Antonio Gargano, Federico Gavazzoni, Michael Halling, Kai Li, Matteo Maggiori, Nelson Mark, Thomas Maurer, Michael Moore, Anella Munro, Dagfinn Rime, Maik Schmeling, Bill Schwert, Thomas Stolper, Andrea Tamoni, Raman Uppal, Adrien Verdelhan, Mungo Wilson, Josef Zechner and to other participants at presentations held at: 2018 American Finance Association; 2017 Auckland Finance Conference; 2017 China International Conference in Finance; 2017 Wellington Finance Summit; 2017 FIRN Annual Conference; 6th Workshop on 'Financial Determinants of Exchange Rates,' Bank of England; 2016 Australian National University Annual Summer Camp; the 9th INQUIRE Business School Workshop, Cass Business School; BI Norwegian Business School, Oslo; University of Geneva; University of Melbourne. We also thank Sidharth Dube, Harvey Huang and Rachel Quan for excellent research assistance. Steven Riddiough gratefully acknowledges financial support from the Faculty of Business and Economics, University of Melbourne. The paper was the recipient of the CFA Institute Best Paper Prize 2017 FIRN Annual Conference, and the Runner-up Best Paper Prize 2017 Vienna Symposium on Foreign Exchange Markets. All errors are ours. The views expressed herein are those of the authors and do not necessarily reflect the views of the National Bureau of Economic Research.

NBER working papers are circulated for discussion and comment purposes. They have not been peer-reviewed or been subject to the review by the NBER Board of Directors that accompanies official NBER publications.

(C) 2019 by Riccardo Colacito, Steven J. Riddiough, and Lucio Sarno. All rights reserved. Short sections of text, not to exceed two paragraphs, may be quoted without explicit permission provided that full credit, including $(\odot$ notice, is given to the source. 
Business Cycles and Currency Returns

Riccardo Colacito, Steven J. Riddiough, and Lucio Sarno

NBER Working Paper No. 26299

September 2019

JEL No. F31,G12,G15

\section{$\underline{\text { ABSTRACT }}$}

We find a strong link between currency excess returns and the relative strength of the business cycle. Buying currencies of strong economies and selling currencies of weak economies generates high returns both in the cross section and time series of countries. These returns stem primarily from spot exchange rate predictability, are uncorrelated with common currency investment strategies, and cannot be understood using traditional currency risk factors in either unconditional or conditional asset pricing tests. We also show that a business cycle factor implied by our results is priced in a broad currency cross section.

Riccardo Colacito

Kenan-Flagler Business School

University of North Carolina at Chapel Hill

Campus Box \#3490

Chapel Hill, NC 27559

and NBER

ric@unc.edu

Steven J. Riddiough

Department of Finance

University of Melbourne

Level 12, 198 Berkeley Street

Melbourne, VIC 3010

Australia

steven.riddiough@unimelb.edu.au
Lucio Sarno

Cass Business School

106 Bunhill Row

London, EC1Y 8TZ, UK

United Kingdom

lucio.sarno@city.ac.uk 


\section{Introduction}

A core issue in asset pricing is the need to understand the relationship between fundamental macroeconomic conditions and asset market returns (Cochrane, 2005, 2017). Nowhere is this more central, and yet consistently difficult to establish, than in the foreign exchange (FX) market, in which currency returns and country-level fundamentals are highly correlated in theory, and yet the empirical relationship is typically found to be weak (Rossi, 2013). A recent literature in macro-finance has documented, however, that the behaviour of exchange rates becomes easier to explain once exchange rates are studied relative to one another in the cross section, rather than in isolation (Lustig et al., 2011; Lustig and Richmond, 2019; Verdelhan, 2018). This insight offers the tantalizing prospect that new empirical tests focusing on relative macroeconomic conditions across countries could reveal a stronger relationship between currency market returns and macroeconomic fundamentals.

In this paper, we take this empirical step by investigating the cross-sectional properties of currency returns to provide novel evidence on the relationship between currency returns and country-level macroeconomic conditions. We focus on the broadest measure of aggregate macroeconomic conditions - the business cycle - which constitutes a key building block in theoretical models of exchange rates. We find that business cycles are a key driver and powerful predictor of both currency excess returns and spot exchange rate fluctuations in the cross section, and that this predictability can be understood from a risk-based perspective. This allows us to connect our findings to a broad literature that has analyzed the linkages between macro fundamentals and currency risk premia (see, inter alia, Colacito and Croce, 2011; Hassan, 2013; Gabaix and Maggiori, 2015; Ready et al., 2017; Berg and Mark, 2018; Colacito et al., 2018).

We measure macroeconomic conditions using the output gap, defined as the difference between a country's actual and potential level of output, for a broad sample of 27 developed- and emergingmarket economies. Since it is not directly observable, we measure the output gap using industrial production data and apply several commonly adopted methods in the literature, including the filters proposed by Hodrick and Prescott (HP, 1980) and Baxter and King (1999), the quadratic time trend used by Clarida et al. (1998), and the linear projection method recently introduced by 
Hamilton (2018). We define the relative strength of the economy based on its position within the business cycle, i.e. whether it is nearer the trough (weak) or peak (strong) in the cycle. Using monthly data from 1983 to 2016, we find that sorting currencies into portfolios on the basis of the differential in output gaps relative to the US generates a monotonic increase in excess returns as we move from portfolios of 'weak' to 'strong' economy currencies. Thus our results imply that currency excess returns are higher for strong economies, a finding that we document to be robust to various ways of constructing currency portfolios.

Importantly, the predictability stemming from business cycles is quite different from other sources of cross-sectional predictability observed in the literature. Sorting currencies by output gaps is not equivalent, for example, to the currency carry trade that requires sorting currencies by their differentials in nominal interest rates. We highlight this point in Figure 1 using two common carry trade currencies - the Australian dollar and Japanese yen. The interest rate differential is highly persistent and consistently positive between the two countries in recent decades. A carry trade investor would have thus always been long the Australian dollar and short the Japanese yen. In contrast the output gap differential varies substantially over time, and an output-gap investor would have thus taken both long and short positions in the Australian dollar and Japanese yen as their relative business cycles fluctuated. Moreover, we find that the cross-sectional predictability arising from business cycles stems primarily from the spot exchange rate component, rather than from interest rate differentials. That is, currencies of strong economies tend to appreciate and those of weak economies tend to depreciate over the subsequent month. This feature makes the returns from exploiting business cycle information different from the returns delivered by most canonical currency investment strategies, and most notably distinct from the carry trade, which generates a negative exchange rate return.

We initially calculate output gaps using the full time-series of industrial production data observed in 2016. This exercise allows us to carefully document the relationship between relative macroeconomic conditions and exchange rates by exploiting the longest sample of data to formulate the most precise estimates of the output gap over time. Indeed, in the international economics literature it has been difficult to uncover a predictive link between macro fundamentals and exchange rates even when the econometrician is assumed to have perfect foresight of future macro 


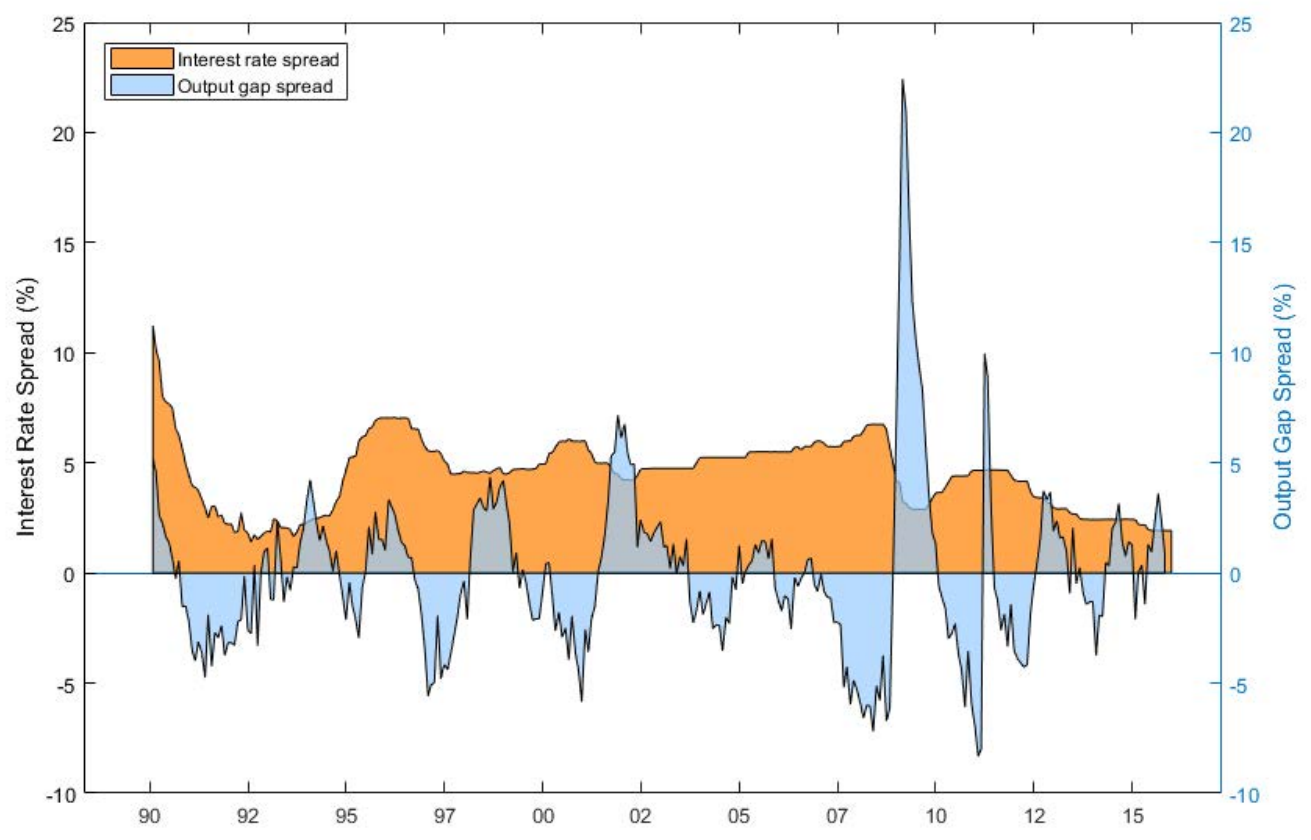

Figure 1: Output Gap and Interest Rate Spreads between Australia and Japan

The figure plots the interest-rate- and output-gap-spread between Australia and Japan. The interest rates reflect one-month euro-deposit rates, while the output gaps are calculated using the Hodrick-Prescott filter. When a series is above the origin, it indicates the Australian value is higher (i.e. either a higher interest rate or output gap).

fundamentals (Meese and Rogoff, 1983). However, the use of two-sided filters and revised data in the long sample also raises questions as to whether the relationship is exploitable in real time. We explore this question using a shorter sample of 'vintage' data beginning in 1999 and find that the results are qualitatively identical. The 'vintage' data mimics the information set available to investors and thus sorting is conditional only on information available at the time. Between 1999 and 2016, a high-minus-low cross-sectional strategy that sorts on relative output gaps across countries, which we denote as $G A P_{C S}$, generates a Sharpe ratio of 0.72 before transaction costs, and 0.50 after costs. The result also holds when assigning linear or rank weights (and thus trading all currencies simultaneously), which reassures us that the cross-sectional results are not driven by a few outlier currencies but apply generally to the broader cross section. Moreover, a time series strategy, which goes long (short) currencies issued by countries with output gaps above (below) the US, denoted as $G A P_{T S}$, generates a Sharpe ratio of 0.65 before costs and 0.50 after costs. 
The two strategies, $G A P_{C S}$ and $G A P_{T S}$, exhibit a correlation of around $35 \%$ and thus the investment performance increases further once these strategies are combined. ${ }^{1}$ Furthermore, the time series correlations between the output gap strategies and the currency carry trade are found to be essentially zero, while the correlations with other canonical currency investment strategies - including "dollar carry" (Lustig et al., 2014), momentum (Menkhoff et al., 2012b), and value (Menkhoff et al., 2017) - are also low and close to zero. ${ }^{2}$ This apparent lack of correlation implies that the output gap strategy offers useful diversification gains to an investor who adds it to a conventional menu of currency portfolios, and we quantify these gains in the empirical analysis.

We investigate whether the returns of output-gap-sorted portfolios reflect compensation for risk. Specifically, we test the pricing power of conventional risk factors using a battery of linear asset pricing models, and do not find evidence that these pricing kernels can price the cross section of currency returns sorted on output gaps. We then consider the possibility that business cycles proxy for a priced state variable as implied by many macro-finance models, giving rise to a 'GAP risk premium'. To do so, we consider the pricing power of a business cycle factor, taken to equal the returns on the $G A P_{C S}$ strategy, and test whether it is priced in the cross section of currencies. We find that the pricing power of the factor is strong and not confined to portfolios sorted on output gaps, extending to other popular currency cross sections, including portfolios sorted on carry (interest rate differentials), momentum, and value.

We analyze these empirical findings in the context of the international long-run risk model of Colacito and Croce (2011). We make two assumptions concerning the correlation of the shocks in the model. First, we allow for an imperfect degree of correlation between shocks to volatility and

\footnotetext{
${ }^{1}$ Moskowitz et al. (2012) study the performance of a time-series momentum strategy, while Baz et al. (2015) consider combinations of time-series and cross-sectional strategies across asset classes using carry, value, and momentum signals. Goyal and Jegadeesh (2018) show that, unlike cross-sectional strategies, time-series strategies are not zero-cost and that once scaled, cross-sectional portfolio performance is substantially stronger.

${ }^{2}$ Lustig et al. (2014) propose a "dollar carry trade" strategy which trades a basket of currencies against the US dollar on the basis of the average forward discount relative to the US. Their strategy is different from the standard carry trade, and the returns compensate US investors for taking on aggregate risk by shorting the dollar in bad times, when the US price of risk is high. Our strategy is distinct conceptually - in that it directly sorts on relative business cycles across all countries rather than on interest rate (forward discount) information relative to the US and empirically we document that the returns of the dollar carry trade are only mildly correlated with the returns to our strategies. Furthermore, we also show that our strategy returns are virtually uncorrelated with the returns from strategies that sort on Taylor rule-implied interest rates, which are instead highly correlated with carry trade returns.
} 
shocks to the predictive components of consumption, which we take as our proxy for the cyclical components within each country. Second, we assume that the correlation of the output gap of any country with the output gap of the US is decreasing in the level of that country's output gap. This model delivers sharp predictions that allow us to speak to the novel empirical evidence that we set forward in our analysis. Indeed, we show that, in the model, sorting currencies by interest rates is not the same as sorting by output gaps. Furthermore, a currency GAP premium arises in equilibrium in this economy. While this setup abstracts away from trade in the consumption goods market, it illustrates the properties of the consumption process that are necessary in a successful fully-fledged general equilibrium model, whose analysis we leave to future research.

The remainder of the paper is as follows. Section 2 discusses related literature. Section 3 describes the data and defines the currency portfolios studied in the empirical analysis. Section 4 reports results on the predictive information content of business cycles for currency excess returns and on the performance and diversification gains from incorporating information on relative business cycles. Section 5 reports the results for asset pricing tests designed to explore whether the returns to output-gap-sorted portfolios can be understood as compensation for risk, and whether a business cycle risk factor implied by our results is priced in the cross section of currencies. Section 6 provides a theory that can explain the returns from output-gap-sorted strategies in terms of compensation for business cycle risk. Section 7 concludes. An Internet Appendix reports additional results, theoretical proofs, and some technical details on the asset pricing tests and on the construction of the output gap measures.

\section{Related Literature}

This paper contributes to several related strands of literature at the intersection of international macro-finance and empirical asset pricing. First, we contribute to the growing body of research documenting predictability in the cross-section of currency excess returns. This strand of the literature has shown that cross-sectional predictability in currencies can be exploited using various investment strategies, including carry (Lustig and Verdelhan, 2007; Lustig et al., 2011; Menkhoff et al., 2012a), momentum (Menkhoff et al., 2012b; Asness et al., 2013), value (Asness et al., 2013; 
Menkhoff et al., 2017), 'good' carry (Bekaert and Panayotov, 2018), strategies which combine carry with other signals (Jordà and Taylor, 2012; Barroso and Santa-Clara, 2015), information in the volatility risk premium (Della Corte et al., 2016a), and optimal dynamic currency strategies (Maurer et al., 2018). Our contribution to this literature is to uncover an economically distinct source of predictive information for the cross-section of currency excess returns stemming from the relative state of business cycles across countries, and to illustrate the economic mechanism through which this predictability arises as compensation for business cycle risk.

In related work, Dahlquist and Hasseltoft (2019) propose a currency strategy based on economic momentum, defined on the basis of eight economic variables that capture interest rate, price, industrial production, and unemployment information. This broad information set is combined to generate signals of countries which are growing more strongly (long position) and countries which are growing the least (short position), based on past trends that range from one to 60 months. Their results suggest that the strategy generates high risk-adjusted returns and subsumes the carry trade. Instead, we focus on a single proxy for business cycles, the output gap, which allows us to connect our empirical findings to macro-finance models and thus provide a direct economic interpretation. The simple model we propose also allows us to understand why the predictive information in output gaps is different from the predictive information in interest rates, and thereby we provide an economic mechanism to account for the difference between our strategy and the carry trade.

A second strand of the literature attempts to explain cross-sectional currency return predictability by theoretically and empirically investigating whether the returns generated by these investment strategies are compensation for risk. A series of recent papers find evidence in support of a variety of risk factors, including 'global' exchange rate risk (Lustig et al., 2011; Colacito et al., 2018), unanticipated global volatility risk (Menkhoff et al., 2012a), downside risk (Lettau et al., 2014), global imbalance risk (Della Corte et al., 2016b), and correlation risk (Mueller et al., 2017), among others. We contribute to this literature by further bridging the gap between the set of factors that explain the cross-section of currency risk premia and macroeconomic fundamentals.

Our results document that a business cycle risk factor is priced in the cross-section of currency excess returns and that the factor can be rationalized in terms of an international macro-finance 
model with long-run risk as in Colacito and Croce (2011), Bansal and Shaliastovich (2012), Lustig and Richmond (2019), and Kremens and Martin (2019). The model abstracts away from trade in the consumption goods' market and delivers closed form solutions for most equilibrium objects of interest. In the interest of space, we leave the analysis of our empirical findings in the context of a fully-fledged general equilibrium models to future research.

A third strand of related literature focuses on predicting exchange rate changes using information on macro fundamentals (Meese and Rogoff, 1983; Mark, 1995; Engel et al., 2007; Molodtsova et al., 2008; Rossi, 2013). Our empirical approach in this paper is very different in that we move away from traditional forecasting of bilateral exchange rate movements using time-series regressions and statistical metrics of forecast evaluation. Instead we focus on the role of business cycles in predicting the cross-section of currency excess returns in a multicurrency portfolio setting that is typical of the empirical asset pricing literature. ${ }^{3}$

\section{Data and Currency Portfolios}

This section describes the main data employed in the empirical analysis as well as the construction of output gaps.

\subsection{Data on Spot and Forward Exchange Rates}

We collect daily bid, mid, and ask spot and 1-month forward exchange rates vis-à-vis the US dollar from Barclays and Reuters via Datastream. The empirical analysis uses monthly data obtained by sampling end-of-month rates from October 1983 to January 2016. Our sample comprises 27 countries: Australia, Austria, Belgium, Brazil, Canada, Chile, Czech Republic, Germany, Finland, France, Iceland, Ireland, Italy, Japan, Mexico, Netherlands, New Zealand, Norway, Poland, Portugal, South Korea, Spain, Sweden, Switzerland, Turkey, United Kingdom, and the United

\footnotetext{
${ }^{3}$ While the output gap is a common measure of business cycle conditions in the macroeconomics literature, it has received comparatively little attention in financial economics. Cooper and Priestley (2009) provide a notable exception, finding that the output gap can help predict future stock returns for the US and other G7 countries both in-sample and out-of-sample. In international macroeconomics, Molodtsova et al. (2008) show that 'Taylor rule' models that incorporate output gap and inflation information display predictive power for spot exchange rate changes in time series regressions for three major exchange rates, although this result was challenged by Rogoff and Stavrakeva (2008), who argue the predictability is not robust across different subsample periods.
} 
States. The sample period for each currency differs and thus the number of countries in our sample fluctuates over time. We replace Germany with the euro area in January 1999, while countries that join the euro area drop out of the sample upon entry into the single currency. We provide full details of the source and availability of currency data in Table A1 of the Internet Appendix.

\subsection{Currency Excess Returns}

We define spot and forward exchange rates at time $t$ as $S p o t_{t}$ and $F w d_{t}$. Exchange rates are defined as units of US dollars per unit of foreign currency such that an increase in Spot $_{t}$ indicates an appreciation of the foreign currency. The excess return on buying a foreign currency in the forward market at time $t$ and selling in the spot market at time $t+1$ is computed as

$$
R X_{t+1}=\frac{\left(\text { Spot }_{t+1}-F w d_{t}\right)}{\text { Spot }_{t}},
$$

which is equivalent to the spot exchange rate return minus the forward premium

$$
R X_{t+1}=\frac{\text { Spot }_{t+1}-\text { Spot }_{t}}{\text { Spot }_{t}}-\frac{F w d_{t}-\text { Spot }_{t}}{\text { Spot }_{t}}
$$

According to the Covered Interest Parity (CIP) condition, the forward premium approximately equals the interest rate differential $\left(F w d_{t}-S p o t_{t}\right) / S p o t_{t} \simeq i_{t}-i_{t}^{*}$, where $i_{t}$ and $i_{t}^{*}$ represent the US and foreign riskless rates respectively, over the maturity of the forward contract. If CIP holds, then the currency excess return is approximately equal to the exchange rate return (i.e. $\left.\left(\operatorname{Spot}_{t+1}-\operatorname{Spot}_{t}\right) / \operatorname{Spot}_{t}\right)$ plus the interest rate differential relative to the US (i.e., $\left.i_{t}^{*}-i_{t}\right)$. As a matter of convenience, throughout this paper we refer to $f d_{t}=\left(S p o t_{t}-F w d_{t}\right) / S p o t_{t} \approx i_{t}^{*}-i_{t}$ as either the forward discount or interest rate differential relative to the US dollar. However, it is important to note that, while CIP held closely in the data prior to the global financial crisis (e.g. Akram et al., 2008), recent evidence has highlighted that post crisis deviations from CIP have become more pronounced (e.g., Du et al., 2018; Andersen et al., 2019), in which case the forward discount captures both interest rate differentials and CIP deviations. As we show below, the results in this paper are driven largely by spot exchange rate predictability, whereas the forward discount plays a negligible role in accounting for the returns of the strategies we propose. This feature is in stark contrast with carry trade returns, which are entirely driven by the forward discount. Thus, our results do not depend on whether CIP holds. 


\subsection{The Output Gap and Data on Economic Activity}

The output gap is defined as the logarithm of the difference between actual $\left(y_{t}\right)$ and 'potential' $\left(\bar{y}_{t}\right)$ output, gap $_{t}=y_{t}-\bar{y}_{t}$. A country's potential output is not directly observable and must therefore be estimated. Numerous statistical methods have been proposed to measure potential output $\bar{y}_{t}$, with the principal aim being to decompose output into its trend and cyclical components. The trend component can be viewed as the economy's natural or potential growth path, from which growth cyclically deviates. The cyclical component is thus a measure of short-term deviations and serves as our empirical proxy for the output gap.

To measure economic activity we collect industrial production data from the OECD's Original Release Data and Revisions Database. The database provides monthly 'vintages', which reflect the precise time-series available to market participants each month, and is thus free of any subsequent revisions or forward looking information.

The full sample analysis uses the April 2016 vintage of data. The full series of monthly industrial production data begin at various dates across countries. The earliest start date is January 1960, and the sample ends in January 2016 to coincide with the last industrial production data point that was available for the majority of countries in April 2016. We estimate output gaps using various statistical techniques to extract a cyclical component from macroeconomic data: (i) the linear projection method of Hamilton (2018), (ii) the Hodrick-Prescott (HP) (1980, 1997) filter, (iii) the Baxter-King (1999) filter, and the quadratic trend specification used by Clarida et al. (1998). ${ }^{4}$ Hamilton (2018) provides a quantitative analysis of the main drawbacks of the HP filter and suggests an alternative procedure for detrending output and measuring the output gap. Although the focus is to improve on the HP filter out-of-sample, Hamilton's analysis and criticisms are relevant for all other filters commonly used in this literature. Therefore, we use the Hamilton procedure in our real-time analysis, implementing the procedure recursively conditioning only on data available at the time of sorting.

For the real-time analysis, we use the full set of monthly industrial production vintages from December 1999 until January 2016. While the first 'vintage' is in December 1999, the industrial

\footnotetext{
${ }^{4}$ We provide further details of the parameters and functional forms of these statistical techniques in the Internet Appendix.
} 
production series within each vintage span back to 1960 (i.e., in December 1999, an investor could observe US industrial production data from January 1960 to October 1999). ${ }^{5}$ Each monthly vintage records the industrial production data available to an investor in that particular month. In the out-of-sample analysis, we construct output gap estimates using each monthly vintage in turn, applying the linear projection method of Hamilton (2018), and therefore the resulting estimate at time $t$ is conditioned only on information available at that time.

The linear projection methodology requires the estimation of the following time-series regression:

$$
y_{i, t}=\alpha_{i}+\sum_{s=0}^{11} \beta_{i, s} y_{i, t-24-s}+\varepsilon_{i, t}
$$

where $y_{i, t}$ is the $(\log )$ value of industrial production for country $i$ available at time $t$. We regress time- $t$ values on their corresponding value from two-years (24-months) earlier, and include 12 lags in total following the suggestion of Hamilton (2018). If industrial production is only available at quarterly intervals we use four lags beginning eight-quarters earlier. We measure the cyclical component as $c_{t}=y_{t}-\hat{y}_{t}$, where $\hat{y}_{t}$ is the fitted value from the regression in (3). Our real-time measure is therefore purely backward-looking, making no use of either revised data or forwardlooking information.

\subsection{Output Gap Portfolios}

At the end of each month $t$, we sort currencies into five portfolios based on the difference between each country's output gap and the US output gap. Portfolio 5 corresponds to countries with the highest output gap relative to the US, whereas Portfolio 1 comprises countries with the lowest output gap relative to the US. We calculate portfolio returns as the equal weighted $\left(1 / N_{k}\right)$ return across the $N_{k}$ currencies within portfolio $k$. We refer to the zero-cost dollar-neutral strategy that takes a long position in Portfolio $5\left(P_{5}\right)$ and a short position in Portfolio $1\left(P_{1}\right)$ as the $G A P_{C S}$ strategy, which is a tradeable investment portfolio that exploits the relative cross-sectional spread in business cycle conditions around the world.

\footnotetext{
${ }^{5}$ The data is available from February 1999 onwards; however the early months in the dataset have unusually short samples and missing observations. We therefore begin the analysis with the most complete dataset starting in December 1999.
} 
In addition, we also report results for trading strategies that trade all currencies with linear weights equal to

$$
w_{j, t+1}=c_{t}\left(x_{j, t}-\bar{x}_{t}\right)
$$

where $x_{j, t}$ denotes the signal for currency $j$ in month $t$ (i.e., the output gap of country $j$ minus the US output gap) and $\bar{x}_{t}=N_{t}^{-1} \sum_{j=1}^{N_{t}} x_{j, t}$ denotes the cross-sectional average of the signal (across countries, $\left.N_{t}\right) . \quad c_{t}$ is a scaling factor such that the absolute sum of all portfolio weights equals unity, that is, $c_{t}=1 / \sum_{j}\left|x_{j, t}-\bar{x}_{t}\right|$. Currencies with a signal value above the cross-sectional mean receive positive portfolio weights, whereas currencies with a signal value below the average receive negative weights. The portfolio return is then given by $r x_{t+1}^{p}=\sum_{j=1}^{N_{t}} w_{j, t+1} r x_{j, t+1}$. In the implementation of this approach we rebalance the portfolios at the end of each month.

Finally, we report returns of rank portfolios, where weights are given by

$$
w_{j, t+1}=c_{t}\left(\operatorname{rank}\left(x_{j, t}\right)-\sum_{j=1}^{N_{t}} \operatorname{rank}\left(x_{j, t}\right) / N_{t}\right) \text {. }
$$

The scaling factor $c_{t}$ is analogous to the case of linear weights above (but uses ranks of signals instead of actual signals) and ensures that we are one dollar long and one dollar short as in Asness et al. (2013). The procedures based on linear weights and rank portfolios are useful for a comparison with the $G A P_{C S}$ strategy because they trade all currencies in every period, and thereby are less reliant on currencies with extreme output gaps. This translates into a lower crosssectional standard deviation of the weights for linear and rank portfolios relative to the $G A P_{C S}$ strategy. Given the relatively small number of assets in the corner portfolios traded with the $G A P_{C S}$ strategy, these strategies provide some reassurance that results from the $G A P_{C S}$ strategy are not driven by just a few currencies.

Finally, it is important to note that all of the cross-sectional strategies are unaffected by timeseries trends in the US dollar since they take long and short positions in the US dollar of equal amount by construction.

\subsubsection{Time Series Portfolio}

At the end of each month $t$, we form a $1 / N_{t}$ (equally weighted) strategy that takes long positions in the currencies of countries with output gaps above the US output gap and short positions in the 
currencies of countries with output gaps below the US. The strategy thus invests in all currencies available at each point in time, under the expectation that countries with higher (lower) output gaps than the US should subsequently offer higher (lower) currency excess returns. In the out-ofsample analysis, we refer to this portfolio strategy as $G A P_{T S}$. Unlike the cross-sectional strategies described above, the $G A P_{T S}$ strategy is not dollar neutral because the number of currencies with output gaps above the US varies over time. The strategy is therefore exposed to any (macro) factor that impacts the evolution of the US dollar over time.

\section{Business Cycles and Currency Returns}

In this section we explore if business cycles can predict currency excess returns. Our benchmark approach is based on a cross-sectional portfolio sort, in which currencies are sorted into five bins $\left(P_{1}, P_{2}, P_{3}, P_{4}, P_{5}\right)$ based on quintiles of the cross-sectional distribution of relative output gaps from the weakest to the strongest economy currencies.

\subsection{Full Sample Performance}

In Table 1, we present the average excess returns of the five output-gap-sorted portfolios, which display an increasing pattern from $P_{1}$ to $P_{5}$ for all four of the output gap measures. Furthermore, the spread in returns between $P_{1}$ and $P_{5}$ is sizeable, ranging from $4.56 \%$ to $6.66 \%$ per annum, which are all statistically different from zero at the $1 \%$ level.

Further scrutiny of the results in Table 1 reveals that the predictability of the cross-section portfolio $(P 5-P 1)$ and the time series portfolio are mainly driven by predicting spot exchange rate returns (see row denoted $f x$ ), whereas the return from the forward premium (equal to the interest rate differential under CIP) contributes comparatively little to the return (see row denoted ir). This finding contrasts with the currency carry trade strategy, in which returns are entirely driven by exploiting forward premia across countries - the exchange rate component of the excess return is typically negative. ${ }^{6}$ The last three rows in Table 1 report the currency turnover and the spread in both forward premia and output gaps in each of the five portfolios. The turnover

\footnotetext{
${ }^{6}$ For comparison, we present the equivalent descriptive statistics for forward-premia-sorted (carry) portfolios in Table A2 of the Internet Appendix.
} 
measure is slightly higher than that reported in the literature for carry trade strategies but lower than momentum strategies (see, e.g. Menkhoff et al., 2012a,b). We note that a tendency exists for forward premia to increase as we move from $P_{1}$ to $P_{5}$, albeit non-monotonically; however, the spread is low, consistent with the returns being driven largely by the spot exchange rate component.

The results in Table 1 are qualitatively identical for all four measures of the output gap considered, indicating that they lead to comparable portfolio sorts (i.e., similar rankings of countries by the state of the business cycle). In Table A3 of the Internet Appendix, we report evidence on the correlation across portfolio sorts obtained by the different output gap measures. While the correlations are not perfect, they are sizeable, and in a range between 0.41 to 0.65 . Furthermore, we report the results from a principal component analysis applied to the four output gap estimates. The average percentage of cross-sectional variation explained by the first principal component is a hefty $86 \%$, indicating that the output gap measures have a very strong common component.

In Table 2, we present the results from a principal component decomposition of the returns of the five portfolios sorted on relative output gaps. The results indicate a strong factor structure in currency portfolio returns sorted by relative output gaps. The first principal component accounts for most of the variation in portfolio returns, but the loadings appear to be almost identical across the five portfolios, suggestive of a 'level' factor, as also documented by Lustig et al. (2011). The second principal component is instead a 'slope' factor and the loadings of the five portfolios on this principal component display a tendency to increase (monotonically for two of the output gap measures) from negative values for $P_{1}$ to positive values for $P_{5}$. Therefore, it is the second principal component that is key to understanding the cross-sectional difference in excess returns. ${ }^{7}$

We also compare the results from sorting on output gaps to a strategy that sorts on Taylor rule fundamentals. Specifically, we consider the standard Taylor rule with coefficients of 1.5 on inflation and 0.5 on the output gap respectively. We then use the differential in interest rates implied by the Taylor rule to sort currencies. The results, presented in Table 3, suggest that

\footnotetext{
${ }^{7}$ These features of the factor structure resemble the features displayed by carry portfolios sorted on interest rate differentials, where the 'slope' factor is key to understanding carry trade excess returns. However, we also find that the second principal component for portfolios sorted on output gaps is orthogonal to the analogous $H M L_{F X}$ factor documented by Lustig et al. (2011), confirming that sorting currencies on output gaps is very different from sorting currencies on interest rates.
} 
sorting on Taylor-rule implied interest rates generates large Sharpe ratios both in the cross section (Sharpe ratio of 0.90) and the time series (Sharpe ratio of 0.65). However, sorting on Taylor rules also generates excess returns that display high correlations with the $H M L_{F X}$ factor of Lustig et al. (2011) (0.84 and 0.51), whereas sorting on relative output gaps provides excess returns that are not (or only) mildly correlated with Taylor rule-sorted portfolios. The difference between the Taylor rule-sorted portfolios and the portfolios sorted on relative output gaps is also apparent by noticing that all of the predictability in the Taylor rule portfolios stems from the forward premia component, consistent with the returns from carry trade portfolios. The desirable correlation properties of portfolios sorted on output gaps are an important feature that we explore further in the paper, specifically when we investigate the diversification benefits of adding a trading strategy that sorts on output gaps to a conventional menu of currency investment strategies. ${ }^{8}$

Overall, these initial results suggest a strong link exists between the relative state of the business cycle and future currency excess returns, which is mainly driven by spot exchange rate predictability and is thus distinct from the predictability found in either carry- or Taylor-rule-based currency portfolios.

\subsection{Real-time Performance}

In Panel $\mathrm{A}$ of Table 4 we report the gross returns from implementing in real time the $G A P_{C S}$ strategy as well as the linear and rank weight cross-sectional portfolios. We also report the returns from implementing the time-series variant of this strategy, $G A P_{T S}$, and combinations of the $G A P_{T S}$ strategy with the cross-sectional strategies. We observe that each investment strategy generates a statistically significant return at conventional significance levels. The Sharpe ratio of $G A P_{C S}$ is 0.72 , the same as when using rank weights, while it is slightly higher at 0.74 when using linear weights. ${ }^{9} G_{T S}$ generates a Sharpe ratio of 0.65 out of sample, and the Sharpe

\footnotetext{
${ }^{8}$ In Table A4 of the Internet Appendix, we also present statistics for portfolios sorted on the basis of deviations in interest rates from the Taylor-rule implied rates. These deviations capture movements in short-term rates not captured by systematic monetary policy (Taylor-rule reaction functions) including, for example, liquidity fluctuations in money markets or movements in interbank risk. We find these deviations do not generate a spread in returns that is statistically different from zero, suggesting that currency excess returns are not driven by the non-systematic component of short-term rates.

${ }^{9}$ In Table A5 of the Internet Appendix we report evidence on the minimum and maximum weights for all three cross-sectional strategies. Clearly, for the high-minus-low strategy, they are $-20 \%$ and $20 \%$, given that the corner portfolios have at most 5 currencies and this strategy employs equal weights. The cross-sectional standard
} 
ratio always increases when the cross-sectional strategies are combined with the $G A P_{T S}$ strategy, reaching 0.82. This higher Sharpe ratio is due to the fact that the correlation between $G A P_{C S}$ and $G A P_{T S}$ is positive but far from perfect.

Figure 2 plots the cumulative returns to both $G A P_{C S}$ and $G A P_{T S}$ currency strategies. Specifically, the figure shows the out-of-sample cumulative returns (left-hand plot), the equivalent insample cumulative returns obtained using the Hamilton (2018) linear projection applied to revised data (middle plot), and combination strategies $C O M_{G A P}, C O M_{L I N}$, and $C O M_{R N K}$ (right-hand plot). Returns are normalized so each series has the same volatility of $6 \%$ annualized, which makes it straightforward to compare the cumulative returns. The shaded bars in Figure 2 are the NBER recession periods, which occur twice during this sample. It seems natural to examine whether the returns from our strategy are different across booms and recessions in the US, particularly in light of the recent paper by Gómez-Cram (2018) that shows expected stock returns are predictively negative in the first four-to-six months after the onset of a recession, but are high thereafter. The graphs in Figure 2 show the steady performance of the $G A P_{C S}$ strategy, in which returns do not display different behavior across booms and recessions regardless of whether the cross-sectional strategy is implemented in- or out-of-sample. This is not surprising given the $G A P_{C S}$ strategy is dollar neutral, and hence it is not obvious why or how US business cycles should be related to the $G A P_{C S}$ excess returns. However, for the $G A P_{T S}$ strategy, which is not dollar neutral, there is evidence that its returns drop during the recession associated with the global financial crisis and take a long time before returning to their previous peak, therefore displaying a very different behavior to that recorded for US stock returns by Gómez-Cram (2018). ${ }^{10}$ By construction,

deviation is $28 \%$. The largest weights remain modest for linear and rank portfolios, with a minimum of $-25 \%$ and a maximum of $25 \%$, but with considerably lower cross-sectional standard deviations (9\% and $16 \%)$ given that these strategies trade all currencies and not just those in the extreme quintiles of the cross-sectional distribution of output-gap-sorted portfolios.

${ }^{10}$ In Table A6 of the Internet Appendix, we present summary statistics on the returns to the $G A P_{C S}$ and $G A P_{T S}$ portfolios during expansions and NBER recession periods. The $G A P_{C S}$ strategy generates similar returns in both periods $\left(4.75 \%\right.$ during expansions and $5.94 \%$ during recessions), while the $G A P_{T S}$ portfolio generates a positive return of $3.90 \%$ during expansions but a $-3.99 \%$ return in recessions. This result is driven by taking cyclical positions in the US dollar, which results in a large negative return during recessions when the dollar appreciates. In the final row we present the US dollar exposure - measured as the over or under exposure to the dollar, in which a value of zero indicates a dollar-neutral portfolio, while a value of - 1 indicates a 'dollar portfolio' that is long all foreign currencies against the US dollar. During expansions the $G A P_{T S}$ portfolio has a positive dollar exposure of 0.26 , but this flips to -0.27 during recessions. 

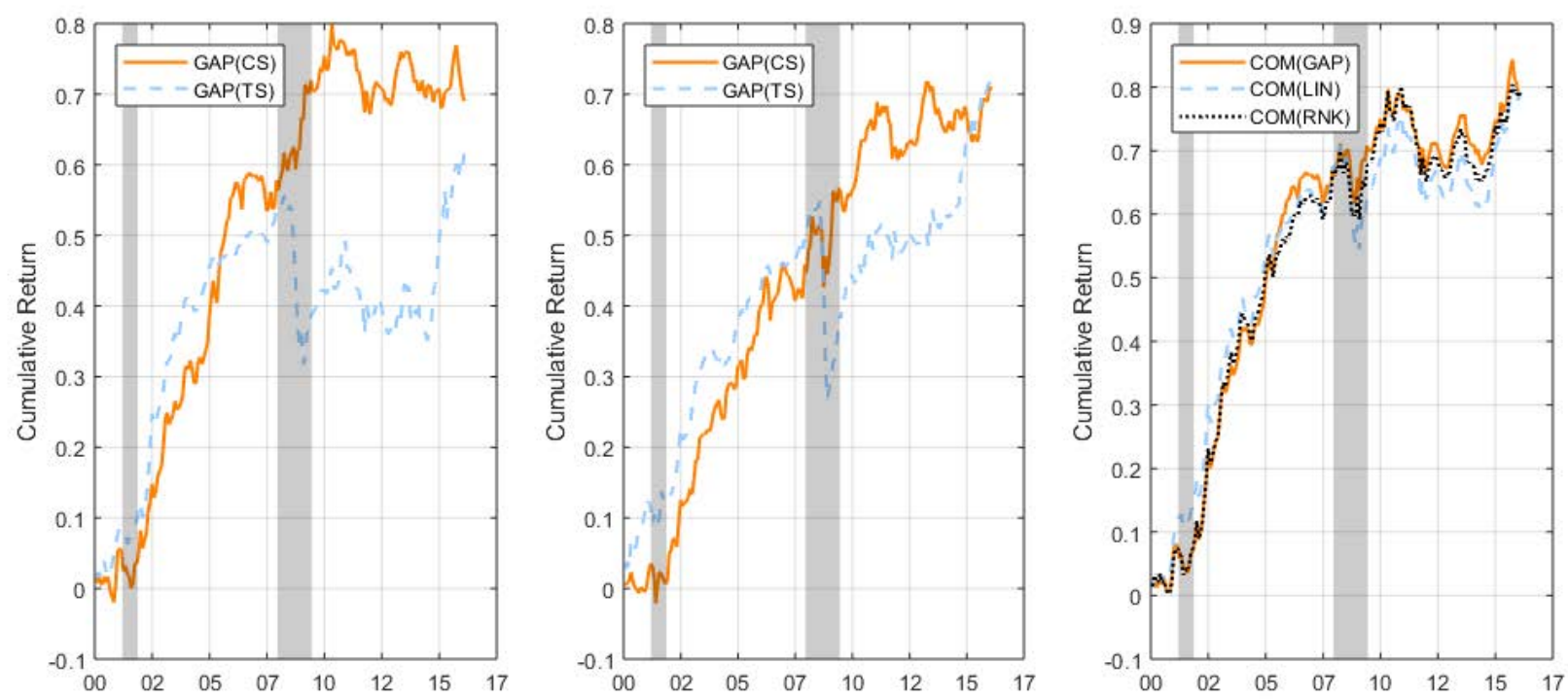

Figure 2: Cumulative Returns to GAP Strategies

The figure plots the cumulative returns to $G A P$ currency strategies. The left-hand plot shows the out-ofsample cumulative returns for the $G A P_{C S}$ and $G A P_{T S}$ strategies. The middle plot shows the equivalent in-sample cumulative returns using the Hamilton (2018) linear projection. The right-hand plot shows the three combination strategies, $C O M_{G A P}, C O M_{L I N}$, and $C O M_{R N K}$. Returns are normalized so each series has the same volatility of $6 \%$ annualized. The shaded bars reflect NBER recession periods.

the $G A P_{T S}$ strategy is more likely to be long the US dollar during US expansions and short the US dollar during US recessions. The poor performance of the $G A P_{T S}$ strategy during the recession induced by the global financial crisis likely occurs because of the sharp dollar appreciation against most currencies in the world (with the exception of other safe haven currencies such as the Japanese yen and the Swiss franc) observed during the crisis. This safety premium effect is typically explained by the special reserve currency status of the US dollar, which makes the US the recipient of large capital flows at times of major negative global shocks (e.g., Maggiori, 2017). Finally, the graphs of the combination strategies show a striking similarity, suggesting that the specific method for assigning weights to long and short positions in $G A P_{C S}$ has little bearing on the final return outcome and that, for each combination, the losses incurred by $G A P_{T S}$ during the global financial crisis are substantially mitigated by combining it with the $G A P_{C S}$ strategy.

In Panel B of Table 4 we report results in the same format as Panel A for returns net of transaction costs, i.e. accounting for bid-ask spreads. We incorporate transactions costs using 
bid-ask (b-a) spreads, such that the return on a long position is calculated as

$$
R X_{t+1}^{n e t}=\frac{\operatorname{Spot}_{t+1}^{b}-F w d_{t}^{a}}{\operatorname{Spot}_{t}^{m}}
$$

The bid-ask spread data available are for quoted spreads and not effective spreads. Since it is known that quoted spreads are much higher than effective spreads, we follow earlier work (e.g. Goyal and Saretto, 2009; Menkhoff et al., 2012a, 2017), and employ 50\% of the quoted bid-ask spread as the actual spread. ${ }^{11}$

The Sharpe ratio for $G A P_{C S}$ goes down from 0.72 to 0.50 when adjusting for bid-ask spreads, and the Sharpe ratio for $G A P_{T S}$ reduces from 0.65 to 0.50 , while the combination of $G A P_{C S}$ and $G A P_{T S}$ generates a Sharpe ratio of about 0.60. In short, transaction costs do not wipe out the performance of strategies that sort on output gaps out of sample, and the Sharpe ratios remain attractive even after accounting for bid-ask spreads. ${ }^{12}$

The results in Table 4 also confirm that the predictive power stems mainly from spot rate predictability rather than interest rate differentials: approximately $90 \%$ of the total return is delivered from the spot component across all portfolios considered. Therefore the basic features of exchange rate predictability recorded in the full sample hold in the real-time analysis. ${ }^{13}$

\subsubsection{Relationship with Other Strategies and Diversification Gains}

In addition to analyzing the real-time performance of currency strategies that sort on output gaps, we also compare the returns arising from these strategies to a number of other portfolio strategies. This analysis is useful to assess whether sorting on output gaps simply recovers returns that can be

\footnotetext{
${ }^{11}$ Even this number seems conservative: Gilmore and Hayashi (2011) find transaction costs due to bid-ask spreads are likely much lower than our 50\% rule, while Gargano et al. (2019) find a rule of $25 \%$ is more appropriate since 2011.

${ }^{12}$ In Table A7 we again consider portfolios obtained from sorting currencies on the basis of interest rates implied by Taylor rules, exactly as for Table 3 but using real-time data for the out-of-sample period. While the results confirm the strong investment performance of the Taylor rule strategy, they also confirm the in-sample result that the strategy is very highly correlated with the $H M L_{F X}$ factor, while being only modestly correlated with the $G A P_{C S}$ strategy.

${ }^{13} \mathrm{Up}$ to now we have taken the perspective of a US investor by calculating excess returns and building dollarneutral portfolios. As a robustness check, we depart from this base scenario and run calculations with four alternative base currencies. Specifically, we construct the output-gap-strategy out-of-sample from the separate perspectives of Eurozone, British, Japanese, and Swiss investors. The results, reported in Table A8 in the Internet Appendix, indicate no qualitative changes to our results based on a US perspective.
} 
obtained in other ways, or whether they constitute a novel source of exchange rate predictability which can offer diversification gains to investors.

Table 5 reports a battery of correlation coefficients between the returns from the strategies sorting on output gaps and the returns from a variety of currency strategies and equity-based strategies that we provide full details of in the Internet Appendix. The main point arising from this table is that the returns of each output gap strategy are generally uncorrelated, or only mildly correlated, with any of the alternative strategies and factors considered. For example, for the $G A P_{C S}$ strategy the correlations range from zero (for the US equity market) to 0.24 (for the dollar factor), and they are of similar magnitude for each variant of the strategy. The results suggest that strategies which sort on output gaps contain novel economic information and are not a mechanical relabelling of existing currency strategies or factors. In turn, large diversification benefits are potentially available to currency investors from adding an output gap-sorted strategy to a broader currency portfolio.

Thus, to better understand the value of the $G A P_{C S}$ strategy for a currency investor, we combine it with various canonical currency strategies and assess its value added in terms of performance. In Panel A of Table 6 we show the returns from carry, dollar carry, momentum, and value strategies from 1999 and 2016. The value strategy performs the worst during this sample, with a Sharpe ratio of essentially zero, while carry performs the best with a Sharpe ratio of 0.58 . We also consider a strategy that combines the above four canonical strategies with equal weights $(E W)$, which generates a Sharpe ratio of 0.74 - higher than each individual strategy by exploiting (albeit simplistically with equal weights) the imperfect correlation of returns across the individual strategies. In essence, the results in Panel A of Table 6 provide us with a benchmark on performance of standard currency strategies, and we ask whether combining them with the $G A P_{C S}$ strategy improves performance and to what extent. We report results in Panel B of Table 6, both when we combine each individual strategy with $G A P_{C S}$ and when we add $G A P_{C S}$ to the equally-weighted strategy alongside carry, dollar carry, momentum, and value. The results indicate that adding the $G A P_{C S}$ strategy to this menu of strategies delivers substantially higher Sharpe ratios. For example, the Sharpe ratio of the carry trade improves from 0.58 to 0.85 , and the equally-weighted strategy which includes all four benchmark strategies and $G A P_{C S}$ delivers a Sharpe ratio of 0.87 , 
in contrast to 0.74 that is obtained when $G A P_{C S}$ is excluded.

Overall, we view these findings as a confirmation of the value that the $G A P_{C S}$ strategy adds when included in a currency portfolio, driven by its desirable return and correlation properties with existing currency-based strategies.

\section{$5 \quad$ Asset Pricing and Implications}

In this section, we begin by investigating if a range of alternative pricing models can explain the returns generated by output-gap sorted portfolios. The purpose of this analysis is to evaluate whether the relationship between currency returns and business cycles can be understood from a risk-return perspective. We go on to consider the role that business cycles may also play as a novel source of risk.

Methodology. We denote the discrete excess returns on portfolio $j$ in period $t$ as $R X_{t}^{j}$. In the absence of arbitrage opportunities, risk-adjusted excess returns have a price of zero and satisfy the following Euler equation:

$$
E_{t}\left[M_{t+1} R X_{t+1}^{j}\right]=0
$$

where $M_{t+1}$ is the stochastic discount factor (SDF). A vast literature on currency asset pricing, starting from Lustig and Verdelhan (2007) and including Lustig et al. (2011), Menkhoff et al. (2012a), Della Corte et al. (2016b) and many others, considers an SDF specification that is linear in the pricing factors $f_{t+1}$, given by

$$
M_{t+1}=1-b^{\prime}\left(f_{t+1}-\mu\right)
$$

where $b$ is the vector of factor loadings, and $\mu$ denotes the factor means. When relying on equation (8), the resulting asset pricing tests are unconditional because the SDF factor loadings in $b$ are assumed to be time-invariant (i.e., $b_{t}=b$ ). However, in a more general setting the Euler equation (7) implies SDF parameters that are time-varying, which means the covariance between excess returns and the SDF is conditional (Hansen and Richard, 1987). If this is the case, the 
unconditional version of the model with constant $b$ is mispecified, potentially resulting in biased alphas (see Boguth et al., 2011). We discuss and analyze the more general case of conditional asset pricing tests later, while beginning our analysis on the basis of unconditional asset pricing tests in line with the relevant literature.

The above SDF specification implies a beta pricing model in which the expected excess return on portfolio $j$ is equal to the factor risk price $\lambda$ times the risk quantities $\beta^{j}$. The beta pricing model is defined as

$$
E\left[R X^{j}\right]=\lambda^{\prime} \beta^{j}
$$

where the market price of risk $\lambda=\Sigma_{f} b$ can be obtained via the factor loadings $b . \Sigma_{f}=$ $E\left[\left(f_{t}-\mu\right)\left(f_{t}-\mu\right)^{\prime}\right]$ is the variance-covariance matrix of the risk factors, and $\beta^{j}$ denotes the regression coefficients of each portfolio's excess return $R X_{t+1}^{j}$ on the risk factors $f_{t+1}$.

\subsection{Pricing Output-Gap Portfolios}

Risk Factors and Pricing Kernel. The recent literature on cross-sectional asset pricing in currency markets has considered a two-factor SDF. The first risk factor is the expected market excess return, approximated by the average excess return on a portfolio strategy that is long in all foreign currencies with equal weights and short in the domestic currency - the $D O L$ factor. For the second risk factor, the literature has employed several return-based factors such as the slope factor $\left(H M L_{F X}\right)$ of Lustig et al. (2011) or the global volatility risk factor of Menkhoff et al. (2012a).

Following this literature, we start from a two-factor SDF with $D O L$ as the first factor, and then consider various second factors, including: the slope factor $\left(H M L_{F X}\right)$ proposed by Lustig et al. (2011); the global imbalance factor $(I M B)$ of Della Corte et al. (2016b); the volatility factor (VOL) of Menkhoff et al. (2012a) in its factor-mimicking version (i.e., the fitted values in a regression of global FX volatility risk on currency returns); and a $G A P$ factor constructed simply as the excess return from the $G A P_{C S}$ strategy. The $G A P$ factor essentially measures the excess returns generated by sorting currencies on the output gap information and is increasing in the spread of output gaps across the world: it is therefore a measure of the return arising from 
divergences in business cycles, such that the more business cycles diverge across countries, the more the currencies of fast-growing countries appreciate. Later in the paper we provide a simple model of international financial markets with long-run risk that generates this risk factor in the pricing kernel. Our test assets are the five output-gap sorted currency portfolios obtained using real-time conditioning information as described in Section 4. We later expand the test assets to consider larger cross sections, given that asset pricing tests tend to have low power in small cross sections of assets.

Cross-Sectional Regressions. Table 7 presents the cross-sectional asset pricing results, including estimates of factor loadings $b$ and the market prices of risk $\lambda$. The factor loadings $b$ are estimated via the Generalized Method of Moments $(G M M)$ of Hansen (1982). To implement $G M M$, we use the pricing errors as a set of moments and the identity weighting matrix. Since the objective is to test whether the model can explain the cross section of expected currency excess returns, we only rely on unconditional moments and do not employ instruments. By estimating the first stage GMM using an identity-weighting matrix, we thus attempt to price all currency portfolios equally well.

We report estimates of $b$ and $\lambda$, and standard errors based on Newey and West (1987). The model's performance is evaluated using the cross-sectional $R^{2}$, the Root Mean Squared Error (RMSE), and the $H J$ distance measure of Hansen and Jagannathan (1997), which quantifies the mean-squared distance between the SDF of a proposed model and the set of admissible SDFs. ${ }^{14}$ To test whether the $H J$ distance is statistically significant, we simulate $p$-values using a weighted sum of $\chi_{1}^{2}$ distributed random variables (see, Jagannathan and Wang, 1996; Ren and Shimotsu, 2009). The $p$-values of the $H J$ distance measure are reported in brackets.

In Table 7 we report results for two-factor SDF models that include $D O L$ and, in turn, the carry factor $\left(H M L_{F X}\right)$, the volatility risk factor $(V O L)$, the global imbalance risk factor $(I M B)$, and the GAP factor. The results suggest that none of the factor loadings are statistically significant

\footnotetext{
${ }^{14}$ Note that the $H J$ calculation is essentially a $G M M$ application with the important difference that the (nonoptimal) weighting matrix is equal to the inverse of the second moment matrix of test asset returns, not the identity matrix; see the Internet Appendix for details on the technical aspects of the asset pricing methods employed in this section.
} 
at conventional significance levels with the exception of the GAP factor, which displays strong statistical significance both in terms of the factor loading and price of risk. The models involving $H M L_{F X}, V O L$, and $I M B$ also display poor explanatory power in terms of the adjusted $R^{2}$ (always negative), which is surprising considering the relative ease in achieving high $R^{2}$ statistics when test assets are characterized by a strong factor structure (Lewellen et al., 2010). In contrast, the SDF involving DOL and GAP generates an adjusted $R^{2}$ of $44 \%$ and a substantially lower RMSE relative to other SDF specifications, indicating that the pricing errors are much lower. The $p$-values from the $H J$ distance measure are always above $5 \%$ with the exception of the SDF involving $H M L_{F X}$. However, this is likely due to the low power of the $H J$ statistic in our small cross section of five test assets and, in the absence of statistical significance of factor loadings for all risk factors other than $G A P$, this result cannot be viewed as supportive of these pricing models.

Overall, the results in Table 7 suggest that the only factor that can price the currency excess returns obtained from sorting on output gaps is $G A P$, and that conventional risk factors from the currency literature are not priced. This finding highlights the novelty of the returns and the need for alternative risk factors to account for this cross section of asset returns.

\subsection{A Business Cycle Factor?}

Next, we consider in more detail the possibility that currency excess returns reflect compensation for risk linked to the relative state of business cycle conditions. The theoretical link between aggregate macroeconomic conditions and asset prices is fundamental to the study of asset pricing, and most classes of risk-based models require the SDF to be a function of the business cycle (see Cochrane, 2017, for a comprehensive review and reconciliation of the link between business cycle variables and asset pricing models). ${ }^{15}$ Specifically, we carry out asset pricing tests for two SDF specifications: a two-factor model including $D O L$ and $H M L_{F X}$, which is the most common benchmark in the literature since its introduction by Lustig et al. (2011), and a three-factor model which also includes the $G A P$ factor. This allows us to gauge the incremental pricing power of a business cycle factor beyond the two-factor benchmark.

\footnotetext{
${ }^{15}$ In complementary work, Maurer et al. (2019) use the currency market as a setting to empirically estimate country-specific SDFs and document a linear relationship with domestic output gaps.
} 
Test Portfolios. We consider two sets of test portfolios, increasing in the number of portfolios. Recall that we first considered the five output-gap-sorted portfolios (as in Table 7), which constitute a small set of test assets for the purpose of asset pricing tests. However, Lewellen et al. (2010) show that a strong factor structure in test asset returns can give rise to misleading results in empirical work, and this outcome is especially the case in small cross sections. Therefore, we now conduct asset pricing tests on the following two sets of portfolios: 10 portfolios sorted on currency value and momentum (i.e., out-of-sample test assets where the sorting variable is neither carry nor the output gap); and a larger cross-section of 20 portfolios which comprises the 5 portfolios sorted on output gap, plus 5 portfolios sorted on forward premia (carry), 5 portfolios sorted on momentum, and 5 portfolios sorted on value. We conduct the asset pricing tests excluding the pricing factors as test assets (Panel A of Table 8) and including them (Panel B of Table 8). Lewellen et al. (2010) advocate adding risk factors as test assets to ensure the factors price themselves (i.e. $\left.\lambda \approx E\left[R_{\text {factor }}\right]\right)$.

Cross-Sectional Regressions. Starting from Panel A of Table 8, we ask whether a two-factor model including $D O L$ and $H M L_{F X}$ can price the two sets of test assets described above. We focus our interest on the sign and the statistical significance of the market price of risk $\lambda$ attached to the $H M L_{F X}$ factor and of the associated factor loading $b$. We know from Table 7 that this SDF specification cannot price the returns from output gap-sorted portfolios. We find that this SDF, which is known to be powerful at pricing carry portfolios, also does not explain satisfactorily the other cross sections considered. Specifically, the factor loading on $H M L_{F X}$ is statistically insignificant from zero, and the adjusted $R^{2}$ is low. The $H J$ distance test does not indicate a rejection of the model in two cases but, with an insignificant factor loading and low $R^{2}$, the $H J$ distance result cannot be considered as supportive of the SDF.

When augmenting the SDF specification with the GAP factor, we find that both the loading and the price of risk for the GAP factor enter with positive and statistically significant coefficients. Moreover, the factor loading on $H M L_{F X}$ continues to be statistically insignificant. The adjusted $R^{2}$ for the three-factor model including the $D O L, H M L_{F X}$, and $G A P$ factors is substantially higher (in a range between $59 \%$ and $62 \%$ ) and the RMSE is substantially lower than the two- 
factor specification that excludes $G A P$.

In Panel B of Table 8 we carry out the same tests while augmenting the test assets to include $H M L_{F X}$ in the two-factor SDF, and both $H M L_{F X}$ and $G A P$ in the three-factor SDF. The results are similar to those in Panel A. Specifically, while we observe statistically significant risk prices for $H M L_{F X}$, this is due to the inclusion of $H M L_{F X}$ as a test asset. More importantly, the results from the three-factor model indicate that the addition of the GAP factor leads to strongly statistically significant factor loadings and risk prices on $G A P$, much higher cross-sectional $R^{2}$ statistics, and far lower RMSEs than in the two-factor specification. ${ }^{16}$

\subsection{Conditional Asset Pricing}

In this section we consider conditional tests based on an SDF specification that allows for timevarying loadings $b_{t}$ :

$$
M_{t+1}=1-b_{t}^{\prime}\left(f_{t+1}-\mu\right) .
$$

Other examples of conditional asset pricing tests in the currency asset pricing literature include (Lustig et al., 2011) in the context of carry portfolios, and (Menkhoff et al., 2016, Section III.C) for portfolios sorted on order flow.

Given equation (10), risk equals the conditional exposure to risk factors given the information available to investors, which implies that the covariance between excess returns and the SDF is conditional (Hansen and Richard, 1987). If this is the case, the unconditional version of the model with constant $b$ is mispecified, and alphas are biased due to underconditioning on only a subset of the investors information. This problem can be mitigated, for example, by allowing the SDF loadings to equal realized betas estimated from rolling-window regressions. The key implication of underconditioning is that, in the presence of conditional risk exposures, unconditional asset pricing tests lead to a bias in the estimated alpha. An overconditioning bias can also arise, however, when

\footnotetext{
${ }^{16}$ In Internet Appendix Tables A9 and A10 we present the equivalent results to those reported in Tables 7 and 8 when employing Fama-MacBeth estimation techniques, while in Tables A11 and A12 we present results in which we replace $H M L_{F X}$ with either the global imbalance factor (IMB) of Della Corte et al. (2016b) or the global volatility factor $(V O L)$ proposed by Menkhoff et al. (2012a). In Table A13, we present the asset pricing results for the same set of test portfolios but for which the SDF is a two-factor linear combination of $D O L$ and $G A P C S$. All of these additional tests confirm that the $G A P$ factor is priced in each of the sets of test assets considered.
} 
the econometrician uses a conditional risk proxy that is not entirely in the information set of investors (see Boguth et al., 2011), for example when using contemporaneous realized betas as proxies for conditional risk, since these betas cannot be known in real time.

In the context of our paper, it could be that, for example, the excess returns from the high output gap currency portfolio (strong economies) are more risky in bad times, in which case the unconditional version of the model with constant $b$ is mispecified because time-variation in the loadings of the portfolios on the SDF is not permitted. More generally, it is possible that time-varying differences in risk exposures can account for the inability of asset pricing models, not including the business cycle factor, to explain output-gap-portfolio returns, as documented in Section 5.1. We investigate this possibility by carrying out conditional asset pricing tests that help in addressing both the underconditioning and overconditioning biases, using as test assets the five portfolios sorted on output gap and the excess returns from the $G A P_{C S}$ strategy (i.e., $\left.P_{5}-P_{1}\right)$.

Specifically, we follow the two-step instrumental variable (IV) procedure proposed by Boguth et al. (2011). In the first step we estimate the contemporaneous exposure of the excess returns to currency portfolio $j$ to currency factors at time $t$. This step helps to overcome the underconditioning bias by allowing for a dynamic relationship between factors and returns. In the case of the two-factor pricing model, which includes $D O L$ and $H M L_{F X}$, we estimate

$$
R X_{t}^{j}=\alpha+\beta_{1, t}^{c} D O L_{t}+\beta_{2, t}^{c} H M L_{F X, t}+\varepsilon_{t}
$$

We consider different rolling windows over which to estimate the slope coefficients in the above regression, including 12, 18, 24, 30, and 36 months. The first-step potentially generates an overconditioning bias and hence we do not use the betas estimated in the first step when estimating alphas. Instead, in the second step, we forecast the betas estimated in the first step using a vector $\left(Z_{n, t-1}\right)$ of predictor variables,

$$
\beta_{k, t}^{c}=\gamma_{k}+\sum_{n=1}^{N} \gamma_{n} Z_{n, t-1}^{\prime}+\epsilon_{k, t} .
$$

We include as predictor variables the one-period lagged value of beta, as well as variables that 
have been found to predict dollar and carry factor returns including global FX volatility (Bakshi and Panayotov, 2013), the commodity return on the Commodity Research Bureau's raw industrials index (Bakshi and Panayotov, 2013), the Treasury-Eurodollar (TED) spread (Brunnermeier et al., 2009), and the average forward discount (Lustig et al., 2014). The fitted value from this regression, $\hat{\beta}_{k, t}^{c}$, is used to estimate the time-series IV alpha $\left(\alpha^{I V}\right)$ that Boguth et al. (2011) show mitigates against biases stemming from both over and underconditioning:

$$
R X_{t}^{j}=\alpha^{I V}+\left(\phi_{0}^{D O L}+\phi_{1}^{D O L} \hat{\beta}_{1, t}^{c}\right) D O L_{t}+\left(\phi_{0}^{H M L}+\phi_{1}^{H M L} \hat{\beta}_{2, t}^{c}\right) H M L_{F X, t}+u_{t} .
$$

In Panel A of Table 9 we report the IV alphas for the five output gap sorted portfolios and the $G A P_{C S}$ strategy excess returns. In addition to the two-factor model with $D O L$ and $H M L_{F X}$ (left hand side), we report results from the two factor model with $D O L$ and $G A P_{C S}$ as risk factors (middle), and the three-factor model with $D O L, H M L_{F X}$, and $G A P_{C S}$ (right hand side). We also report the $\chi^{2}$ test statistic and associated $p$-value for the test that the alphas are jointly equal to zero. A $p$-value below 0.05 indicates that the null hypothesis, that all alphas are jointly zero, can be rejected at the 5 percent level of significance. In Panel B of Table 9 we report the $\chi^{2}$ test statistic for the equivalent test on a larger set of 20 test portfolios including portfolios sorted by output gaps, forward premia, momentum, and value.

Starting from Panel A, for the two factor model including $D O L$ and $H M L_{F X}$, the $\chi^{2}$ test statistic rejects the null hypothesis that the alphas are jointly zero for every one of the 5 rolling windows considered for the beta estimation. Examining the alphas of the individual portfolios, we can see that this result is driven by statistically significant alphas in $P_{5}$ and sometimes $P_{4}$, as well as significant alphas in the $G A P_{C S}$ excess returns. However, the model specifications that include $G A P_{C S}$ (middle and right hand side of Table 9) generates alphas that are not statistically significantly different from zero, with the $\chi^{2}$ test statistic becoming considerably smaller, and its associated $p$-values comfortably above the $5 \%$ level. These results are consistent with the results from unconditional asset pricing tests reported earlier, suggesting that the most common benchmark for currency asset pricing, namely the two-factor model of Lustig et al. (2011), is unable to price the output-gap-sorted portfolios, and that a business cycle factor is needed in the SDF specification to price these portfolios. 
The results are qualitatively identical when we employ all 20 test portfolios including portfolios sorted by output gaps, forward premia, momentum, and value (Panel B of Table 9). Specifically, there is no evidence that the two-factor model with $D O L$ and $H M L_{F X}$ can price these test assets, with the exception of two cases with short rolling windows of 12 and 18 months, which generate moderately higher $p$-values between $5 \%$ and $6 \%$, whereas model specifications that include $G A P_{C S}$ all generate large $p$-values. ${ }^{17}$

Overall, the conditional asset pricing tests corroborate the earlier findings that conventional risk factors used in the currency asset pricing literature are unable to price portfolios sorted on relative output gaps, and that a business cycle factor implied by our results is priced in a broad currency cross section.

\section{A Model for the GAP Premium}

The asset pricing results suggest that standard risk factors used in the literature cannot explain the returns from currency portfolios that sort on output gaps. In this section we present a simple model that can generate a risk premium associated with relative output gaps across countries, the GAP premium. While this setup abstracts away from trade in the consumption goods market, it constitutes a useful benchmark in the international finance literature, and it has been applied to the analysis of exchange rates' volatility (Colacito and Croce, 2011), international term structure of interest rates (Bansal and Shaliastovich, 2012), gravity in exchange rates' fluctuations (Lustig and Richmond, 2019), and quanto contracts (Kremens and Martin, 2019). We follow the literature and focus on this setup due to its ability to deliver closed form solutions for all the objects of interest, and leave a fully fledged general equilibrium analysis to future research.

\footnotetext{
${ }^{17}$ We also considered other two factor models as benchmarks, where the second risk factor is $V O L$ or $I M B$ instead of $H M L_{F X}$, and find qualitatively identical results to those obtained for the two-factor model with $D O L$ and $H M L_{F X}$. These results are available upon request.
} 


\subsection{Setup of the economy}

Preferences. The economy consists of $N$ countries. Each country $i$ is populated by a representative agent with recursive preferences

$$
U_{i, t}=(1-\delta) \log \left(C_{i, t}\right)+\delta \cdot \frac{1}{1-\gamma} \log \left(E_{t}\left[\exp \left((1-\gamma) U_{i, t+1}\right)\right]\right)
$$

where $C_{i, t}, \delta$, and $\gamma$ denote the consumption in country $i$ at date $t$, the subjective discount factor, and risk aversion respectively. These preferences correspond to Epstein and Zin (1989) preferences for the case of unit intertemporal elasticity of substitution (henceforth IES).

Consumption dynamics. The logarithm of consumption growth in each country evolves according to the following law of motion:

$$
\begin{aligned}
\Delta c_{i, t+1} & =\mu_{c}+z_{i, t}+\sqrt{\sigma_{i, t}} \varepsilon_{i, t+1}^{c} \\
z_{i, t} & =\rho_{z} z_{i, t-1}+\varphi_{z} \sqrt{\sigma} \varepsilon_{i, t}^{z} \\
\sigma_{i, t} & =\left(1-\rho_{\sigma}\right) \bar{\sigma}+\rho_{\sigma} \sigma_{i, t-1}+\sqrt{\sigma_{\sigma}} \varepsilon_{i, t}^{\sigma}, \quad \forall i \in\{1,2, \ldots, N\}
\end{aligned}
$$

where $z_{i, t}$ is a consumption factor that proxies for the output gap, and $\sigma_{i, t}$ is the conditional variance of consumption growth. We document in the Internet Appendix that the output gap estimated using the same methodology that we adopt in our empirical analysis is highly correlated with $z_{i, t}$. In what follows, we will proxy the output gap with the $z_{i, t}$ factor. ${ }^{18}$

All shocks within a country are orthogonal to each other with the exception of

$$
\rho_{i, t}^{z \sigma}=\operatorname{corr}\left(\varepsilon_{i, t}^{\sigma}, \varepsilon_{i, t}^{z}\right)=\operatorname{corr}\left(\varepsilon_{i, t}^{z}+\alpha \varepsilon_{i, t}^{\nu}, \varepsilon_{i, t}^{z}\right)=\frac{1}{\sqrt{1+\alpha^{2}}} \geq 0
$$

where $\varepsilon_{i, t}^{z}$ and $\varepsilon_{i, t}^{\nu}$ are two i.i.d. normally distributed orthogonal shocks. To better highlight the key mechanism of the model, we set to zero all the correlations of international shocks with the

\footnotetext{
${ }^{18}$ The explanation for why the correlation between output gap and the predictive component $z_{i, t}$ is positive is straightforward. Consider the case in which the output gap is measured as the residual from the regression $c_{i, t}=\alpha+\beta c_{i, t-1}+\xi_{i, t}$. Since the estimated output gap, $\hat{\xi}_{i, t}$, is equal to $z_{i, t-1}+\sqrt{\sigma_{i, t-1}} \varepsilon_{i, t}^{c}$, the positive correlation with the predictive component $z_{i, t}$ follows immediately. In the Internet Appendix, we extend this analysis to the case of a general number of regressors and document that this correlation is generally large. We focus on the correlation with the cyclical component extracted using the methodology proposed by Hamilton (2018), because it coincides with the empirical measure that we adopt for our core set of results. We cannot claim that any trend-cycle decomposition would give rise to a large and/or positive correlation and thank an anonymous referee for pushing us to illustrate this point.
} 
exception of the international correlation of the shock $\varepsilon_{i, t}^{z}$ in each country with the shock $\varepsilon_{k, t}^{z}$ in the base country $k$. Specifically, we assume that this correlation is time-varying according to the process:

$$
\operatorname{corr}\left(\varepsilon_{i, t}^{z}, \varepsilon_{k, t}^{z}\right)=\rho_{i k, t}^{z}=(2 \bar{\rho}-1)+2(1-\bar{\rho}) \frac{1}{1+\exp \left\{z_{i, t}\right\}}
$$

from which it is easy to show that: (i) the unconditional mean of the correlation is $\bar{\rho}$ (i.e. $E\left[\rho_{i k, t}^{z}\right]=$ $\bar{\rho})$; (ii) the correlation of each country $i$ with the base country $k$ declines with the level of the output gap in country $k$ (i.e. $\frac{\partial \rho_{i k, t}^{z}}{\partial z_{i, t}}<0$ ). In the Internet Appendix we provide some empirical support for this hypothesized comovement between correlations and output gap.

Financial Markets. We assume that there is a complete set of state and date contingent bonds that each investor has access to in frictionless financial markets at each point in time.

\subsection{Equilibrium outcomes}

Risk-free rates. We document in Lemma 3 of the Internet Appendix that the risk-free rates are equal to

$$
r_{i, t}^{f}=\mu_{c}-\log (\delta)+z_{i, t}-\left(\gamma-\frac{1}{2}\right) \sigma_{i, t}, \quad \forall i \in\{1,2, \ldots, N\}
$$

Equation (17) provides an important connection between our model and the empirical evidence provided in the previous sections: given the imperfect degree of correlation between $z_{i, t}$ and $\sigma_{i, t}$, sorting on the level of the risk-free rate is not the same as sorting on the output gap.

Currency risk premia. The following Proposition establishes the connection between sorting the cross-section of currencies according to the output gap and the existence of an excess return.

Proposition 1 (GAP premium). Let $i$ and $j$ be two countries for which the following condition holds: $z_{i, t} \geq z_{j, t}$. Then the excess return of a strategy that is long the currency of country $i$ and short the currency of country $j$ is

$$
\begin{aligned}
E_{t}\left[G A P_{t+1}^{i j}\right] & =E_{t}\left[R X_{t+1}^{i}-R X_{t+1}^{j}\right] \\
& =2(1-\bar{\rho}) \kappa\left(\frac{1}{1+\exp \left\{z_{j, t}\right\}}-\frac{1}{1+\exp \left\{z_{i, t}\right\}}\right)>0
\end{aligned}
$$


where the coefficient of proportionality $\kappa$ is equal to

$$
\kappa=\delta\left[\frac{\rho_{z} \sqrt{\bar{\sigma}}}{1-\delta \rho_{z}}+\frac{1}{2} \frac{(1-\gamma) \sqrt{\sigma_{\sigma}}}{1-\delta \rho_{\sigma}}\right]^{2}>0 .
$$

Proof. See Internet Appendix.

The interpretation of Proposition 1 is intuitive. The representative investor of the base country $k$ dislikes (likes) periods of low (high) output gap shocks. Given the assumption of complete markets, the log-growth rate of exchange rates is equal to the difference of logarithms of the SDFs of any two countries. The more correlated is the output gap of a country with the output gap of country $k$, the better hedge it provides against negative output gap shocks in country $k$. Indeed, in the extreme case in which two countries have perfectly correlated output gap shocks, the exchange rate of their currencies would have no exposure to output gap risk. Given our postulated negative relationship between the output gap of country $i$ and its correlation with the output gap of the base country $k$, it follows that low output gap countries (high $\rho_{i k, t}^{z}$ ) have safe currencies, while high output gap countries (low $\rho_{i k, t}^{z}$ ) have risky currencies.

We note that in the absence of time-varying volatility, the GAP premium would be entirely driven by differentials in risk-free rates (this follows immediately from shutting down $\sigma_{i, t}$ in Equation (17)). However, in the general case discussed here, the presence of time-varying macroeconomic uncertainty breaks this tight relationship. In fact, a country $i$ could have a very strong economy (very positive $z_{i, t}$ ) and low risk-free rates, as long as the level of uncertainty in country $i$ is large and investors are risk-averse enough. In this case, the currency of country $i$ would still command a large GAP premium, despite the possibly low risk-free rate. Equivalently, the GAP premium depends crucially on expected currency appreciations, which are going to result in a positive premium notwithstanding a low or sometimes negative interest rate differential.

\section{Conclusions}

Understanding and measuring the sources of macroeconomic risk that drive asset prices is a fundamental challenge in asset pricing. In this paper, we provide robust empirical evidence that business cycles, proxied by output gaps, are an important determinant of the cross-section of 
expected currency returns. Our primary result is that the currencies of strong economies (high output gaps) command higher expected returns. The excess returns from a trading strategy that sorts currencies on relative output gaps generates high risk-adjusted returns that are uncorrelated with the excess returns from popular currency investment strategies, thereby providing tangible diversification gains to global investors.

Moreover, we find that a business cycle risk factor that captures the spread in output gaps across countries is priced in the cross section of currency excess returns that includes portfolios sorted by carry, value, and momentum. In general, these findings are important for the broad theoretical literature seeking to explain the macroeconomic drivers of currency risk premia. We document that a currency GAP premium arises in equilibrium in an international macro-finance model with long-run risk, in which the correlations of the shocks vary over time with the predictive components of consumption. Extending this framework to a fully fledged general equilibrium analysis represents an important direction for future research.

In future work, researchers could explore alternative theoretical mechanisms that can explain the link between business cycles and the cross section of currency excess returns reported in the paper. The model presented here is only one of potentially several frameworks that can predict these facts. Empirical researchers may also wish to explore alternative ways to measure business cycles, using richer financial and economic datasets, as a fruitful avenue to break new ground in the empirical asset pricing of currency markets. 


\section{References}

Akram, Q. F., Rime, D., Sarno, L., 2008. Arbitrage in the foreign exchange market: Turning on the microscope. Journal of International Economics 76, 237-253.

Andersen, L., Duffie, D., Song, Y., 2019. Funding value adjustments. Journal of Finance 74, $145-192$.

Andrews, D. W. K., 1991. Hetroskedasticity and autocorrelation consistent covariance matrix estimation. Econometrica 59, 817-858.

Asness, C. S., Moskowitz, T. J., Pedersen, L. H., 2013. Value and momentum everywhere. Journal of Finance 68, 929-985.

Bakshi, G., Panayotov, G., 2013. Predictability of currency carry trades and asset pricing implications. Journal of Financial Economics 110, 139-163.

Bansal, R., Shaliastovich, I., 2012. A long-run risks explanation of predictability puzzles in bond and currency markets. Review of Financial Studies 26, 1-33.

Barroso, P., Santa-Clara, P., 2015. Beyond the carry trade: Optimal currency portfolios. Journal of Financial and Quantitative Analysis 50, 1037-1056.

Baxter, M., King, R. G., 1999. Measuring business cycles: Approximate band-pass filters for economic time series. Review of Economics and Statistics 81, 575-593.

Baz, J., Granger, N. M., Harvey, C. R., Le Roux, N., Rattray, S., 2015. Dissecting investment strategies in the cross section and time series. Working paper: Man Group.

Bekaert, G., Panayotov, G., 2018. Good carry, bad carry. Journal of Financial and Quantitative Analysis forthcoming.

Berg, K. A., Mark, N. C., 2018. Global macro risks in currency excess returns. Journal of Empirical Finance 45, 300-315.

Boguth, O., Carlson, M., Fisher, A., Simutin, M., 2011. Conditional risk and performance evaluation: Volatility timing, overconditioning, and new estimates of momentum alphas. Journal of Financial Economics 102, 363-389.

Brunnermeier, Markus, K., Nagel, S., Pedersen, L. H., 2009. Carry Trades and Currency Crashes. In: Acemoglu, D., Rogoff, K., Woodford, M. (eds.), NBER Macroeconomics Annual 2008, University of Chicago Press.

Burnside, C., 2011. The cross section of foreign currency risk premia and consumption growth risk: Comment. American Economic Review 101, 3456-3476.

Clarida, R., Gali, J., Gertler, M., 1998. Monetary policy rules in practice: Some international evidence. European Economic Review 42, 1033-1067. 
Cochrane, J. H., 2005. Asset Pricing: Revised Edition. Princeton University, Princeton NJ.

Cochrane, J. H., 2017. Macro-finance. Review of Finance 21, 945-985.

Colacito, R., Croce, M., 2011. Risks for the long-run and the real exchange rate. Journal of Political Economy 119, 153-181.

Colacito, R., Croce, M. M., Gavazzoni, F., Ready, R. C., 2018. Currency risk factors in a recursive multi-country economy. Journal of Finance 73, 2719-2756.

Cooper, I., Priestley, R., 2009. Time-varying risk premiums and the output gap. Review of Financial Studies 22, 2801-2833.

Dahlquist, M., Hasseltoft, H., 2019. Economic momentum and currency returns. Journal of Financial Economics forthcoming.

Della Corte, P., Ramadorai, T., Sarno, L., 2016a. Volatility risk premia and exchange rate predictability. Journal of Financial Economics 120, 21-40.

Della Corte, P., Riddiough, S. J., Sarno, L., 2016b. Currency premia and global imbalances. Review of Financial Studies 29, 2161-2193.

Du, W., Tepper, A., Verdelhan, A., 2018. Deviations from covered interest rate parity. Journal of Finance 73, 915-957.

Engel, C., Mark, N. C., West, K. D., 2007. Exchange rate models are not as bad as you think. NBER Macroeconomics Annual 22, 381-441.

Epstein, L. G., Zin, S. E., 1989. Substitution, risk aversion, and the temporal behavior of consumption and asset returns: A theoretical framework. Econometrica 57, 937-69.

Fung, W., Hsieh, D. A., 2001. The risk in hedge fund strategies: Theory and evidence from trend followers. Review of Financial Studies 14, 313-341.

Gabaix, X., Maggiori, M., 2015. International liquidity and exchange rate dynamics. Quarterly Journal of Economics 130, 1369-1420.

Gargano, A., Riddiough, S. J., Sarno, L., 2019. Foreign exchange volume. Working paper: The University of Melbourne and Cass Business School.

Gilmore, S., Hayashi, F., 2011. Emerging market currency excess returns. American Economic Journal: Macroeconomics 3, 85-111.

Gómez-Cram, R., 2018. Late to recessions: Stocks and the business cycle. Working paper: The Wharton School, University of Pennsylvania.

Goyal, A., Jegadeesh, N., 2018. Cross-sectional and time-series tests of return predictability: What is the difference? Review of Financial Studies 31, 1784-1824. 
Goyal, A., Saretto, A., 2009. Cross-section of option returns and volatility. Journal of Financial Economics 94, 310-326.

Hamilton, J. D., 2018. Why you should never use the Hodrick-Prescott filter. Review of Economics and Statistics 100, 831-843.

Hansen, L. P., 1982. Large sample properties of generalized method of moments. Econometrica $50,1029-1054$.

Hansen, L. P., Jagannathan, R., 1997. Assessing specification errors in stochastic discount factor models. Journal of Finance 52, 557-590.

Hansen, P., Richard, S. F., 1987. The role of conditioning information in deducing testable restrictions implied by dynamic asset pricing models. Econometrica 55, 587-613.

Hassan, T. A., 2013. Country size, currency unions, and international asset returns. Journal of Finance 68, 2269-2308.

Hodrick, R. J., Prescott, E. C., 1980. Postwar U.S. business cycles: An empirical investigation. Working Paper: Carnegie-Mellon University.

Hodrick, R. J., Prescott, E. C., 1997. Postwar U.S. business cycles: An empirical investigation. Journal of Money, Credit and Banking 29, 1-16.

Jagannathan, R., Wang, Z., 1996. The conditional CAPM and the cross-section of expected returns. Journal of Finance 51, 3-53.

Jordà, Ò., Taylor, A. M., 2012. The carry trade and fundamentals: Nothing to fear but FEER itself. Journal of International Economics 88, 74-90.

Kremens, L., Martin, I., 2019. The quanto theory of exchange rates. American Economic Review 109, 810-843.

Kydland, F. E., Prescott, E. C., 1990. Business cycles: Real facts and a monetary myth. Federal Reserve Bank of Minneapolis Quarterly Review 14, 3-18.

Lettau, M., Maggiori, M., Weber, M., 2014. Conditional risk premia in currency markets and other asset classes. Journal of Financial Economics 114, 197-225.

Lewellen, J., Nagel, S., Shanken, J., 2010. A skeptical appraisal of asset pricing tests. Journal of Financial Economics 96, 175-194.

Ludvigson, S. C., 2013. Advances in consumption-based asset pricing: Empirical tests. Handbook of the Economics of Finance 2, 799-906.

Lustig, H., Richmond, R. J., 2019. Gravity in FX $R^{2}$ : Understanding the factor structure in exchange rates. Review of Financial Studies forthcoming. 
Lustig, H., Roussanov, N., Verdelhan, A., 2011. Common risk factors in currency markets. Review of Financial Studies 24, 3731-3777.

Lustig, H., Roussanov, N., Verdelhan, A., 2014. Countercyclical currency risk premia. Journal of Financial Economics 111, 527-553.

Lustig, H., Verdelhan, A., 2007. The cross-section of foreign currency risk premia and consumption growth risk. American Economic Review 97, 89-117.

Maggiori, M., 2017. Financial intermediation, international risk sharing, and reserve currencies. American Economic Review 107, 3038-3071.

Mark, N. C., 1995. Exchange rates and fundamentals: Evidence on long horizon predictability. American Economic Review 85, 201-218.

Maurer, T., Tô, T.-D., Tran, N.-K., 2018. Optimal factor strategy in FX markets. Working paper: Washington University in St. Louis and the University of New South Wales.

Maurer, T., To, T.-D., Tran, N.-K., 2019. Pricing risks across currency denominations. Management Science forthcoming.

Meese, R. A., Rogoff, K., 1983. Empirical exchange rate models of the seventies: Do they fit out of sample? Journal of International Economics 14, 3-24.

Menkhoff, L., Sarno, L., Schmeling, M., Schrimpf, A., 2012a. Carry trades and global foreign exchange volatility. Journal of Finance $67,681-718$.

Menkhoff, L., Sarno, L., Schmeling, M., Schrimpf, A., 2012b. Currency momentum strategies. Journal of Financial Economics 106, 660-684.

Menkhoff, L., Sarno, L., Schmeling, M., Schrimpf, A., 2016. Information flows in foreign exchange markets: Dissecting customer currency trades. Journal of Finance 71, 601-634.

Menkhoff, L., Sarno, L., Schmeling, M., Schrimpf, A., 2017. Currency value. Review of Financial Studies 30, 416-441.

Molodtsova, T., Nikolsko-Rzhevskyy, A., Papell, D. H., 2008. Taylor rules with real-time data: A tale of two countries and one exchange rate. Journal of Monetary Economics 55, 167-180.

Moskowitz, T. J., Ooi, Y. H., Pedersen, L. H., 2012. Time-series momentum. Journal of Financial Economics 104, 228-250.

Mueller, P., Stathopoulos, A., Vedolin, A., 2017. International correlation risk. Journal of Financial Economics 126, 270-299.

Newey, W. K., West, K. D., 1987. A simple, positive semi-definite, heteroskedasticity and autocorrelation consistent covariance matrix. Econometrica 55, 703-708. 
Pástor, L., Stambaugh, R. F., 2003. Liquidity risk and expected stock returns. Journal of Political Economy 111, 642-685.

Priestly, M. B., 1981. Spectral Analysis and Time Series. Academic Press, London.

Ready, R., Roussanov, N., Ward, C., 2017. Commodity trade and the carry trade: A tale of two countries. Journal of Finance 72, 2629-2684.

Ren, Y., Shimotsu, K., 2009. Improvement in finite sample properties of the Hansen-Jagannathan distance test. Journal of Empirical Finance 16, 483-506.

Rogoff, K. S., Stavrakeva, V., 2008. The continuing puzzle of short horizon exchange rate forecasting. Working paper: Harvard University and London Business School.

Rossi, B., 2013. Exchange rate predictability. Journal of Economic Literature 51, 1063-1119.

Verdelhan, A., 2018. The share of systematic variation in bilateral exchange rates. Journal of Finance 73, 375-418. 
Table 1: Full Sample Business Cycle Currency Portfolios

The table presents descriptive statistics for five currency portfolios sorted by output gaps. The output gap is estimated as (log) industrial production minus the $(\log )$ trend in industrial production. The trend is estimated in four ways using a (i) HodrickPrescott filter; (ii) Baxter-King filter, (iii) linear projection, and (iv) quadratic time trend. Portfolios are rebalanced monthly with strong (weak) economy currencies entering $P_{5}\left(P_{1}\right)$. We report summary statistics for the annualized excess mean return and its decomposition between the exchange rate $(f x)$ and interest rate $(i r)$ components. We also report the Sharpe ratio (Sharpe), standard deviation $(s t d)$, skewness (skew), kurtosis (kurt), maximum drawdown $(m d d)$, average turnover $(t / o)$, average forward premium $(f p)$, and average output gap (gap) for each portfolio. The Cross Section portfolio is long $P_{5}$ and short $P_{1}$. The Time Series portfolio takes a $1 / \mathrm{N}$ position in currencies, going long (short) currencies issued by countries with an output gap above (below) the US output gap. The superscripts *, **, *** represent significance of the Cross Section and Time Series portfolios at the 10\%, 5\%, and 1\% level using Newey and West (1987) standard errors. The sample is from October 1983 to January 2016.

\begin{tabular}{|c|c|c|c|c|c|c|c|c|c|c|c|c|c|c|}
\hline \multirow{5}{*}{$\begin{array}{c}\text { mean }(\%) \\
\quad f x(\%) \\
\text { ir }(\%)\end{array}$} & \multicolumn{5}{|c|}{ Hodrick-Prescott Filter } & \multirow{2}{*}{$\begin{array}{c}\text { Cross } \\
\text { Section } \\
\end{array}$} & \multirow{2}{*}{$\begin{array}{l}\text { Time } \\
\text { Series }\end{array}$} & \multicolumn{5}{|c|}{ Baxter-King Filter } & \multirow{2}{*}{$\begin{array}{c}\text { Cross } \\
\text { Section }\end{array}$} & \multirow{2}{*}{$\begin{array}{l}\text { Time } \\
\text { Series }\end{array}$} \\
\hline & $\mathbf{P}_{1}$ & $\mathbf{P}_{2}$ & $\mathbf{P}_{3}$ & $\mathbf{P}_{4}$ & $\mathbf{P}_{5}$ & & & $\mathbf{P}_{1}$ & $\mathbf{P}_{2}$ & $\mathbf{P}_{3}$ & $\mathbf{P}_{4}$ & $\mathbf{P}_{5}$ & & \\
\hline & -0.25 & 0.96 & 2.77 & 4.00 & 6.41 & $6.66^{* * *}$ & $2.45^{* * *}$ & -0.44 & 2.45 & 2.39 & 3.72 & 5.97 & $6.41^{* * *}$ & $3.83^{* * *}$ \\
\hline & -2.34 & -1.03 & 0.88 & 1.58 & 2.72 & 5.06 & 2.03 & -2.34 & 0.65 & 0.49 & 1.23 & 1.92 & 4.26 & 3.38 \\
\hline & 2.09 & 1.99 & 1.89 & 2.41 & 3.69 & 1.60 & 0.41 & 1.90 & 1.80 & 1.90 & 2.49 & 4.06 & 2.15 & 0.44 \\
\hline Sharpe & -0.02 & 0.11 & 0.27 & 0.43 & 0.71 & 0.82 & 0.54 & -0.04 & 0.26 & 0.26 & 0.39 & 0.68 & 0.77 & 0.74 \\
\hline$s t d$ & 10.18 & 9.09 & 10.12 & 9.32 & 9.05 & 8.14 & 4.57 & 10.15 & 9.50 & 9.33 & 9.51 & 8.82 & 8.31 & 5.21 \\
\hline skew & -0.06 & -0.47 & -0.28 & -0.27 & -0.28 & 0.01 & -0.92 & -0.08 & 0.06 & -0.21 & -0.29 & -0.61 & 0.07 & -0.39 \\
\hline kurt & 4.49 & 4.72 & 4.75 & 4.39 & 3.97 & 4.32 & 10.89 & 3.94 & 3.83 & 4.32 & 4.22 & 5.00 & 4.25 & 5.70 \\
\hline$m d d(\%)$ & 42.5 & 34.2 & 23.9 & 23.6 & 24.4 & 9.0 & 8.6 & 49.0 & 28.8 & 26.1 & 24.6 & 21.8 & 23.0 & 9.2 \\
\hline$t / o(\%)$ & 44.8 & 58.2 & 67.2 & 60.6 & 44.8 & & & 10.0 & 21.8 & 29.8 & 23.1 & 11.6 & & \\
\hline$f p(t, \%)$ & 2.23 & 2.03 & 1.80 & 2.45 & 4.15 & & & 1.91 & 1.87 & 1.75 & 2.38 & 4.81 & & \\
\hline \multirow[t]{3}{*}{ gap $(t, \%)$} & -3.08 & -0.96 & 0.11 & 1.17 & 3.01 & & & -2.75 & -0.84 & 0.18 & 1.30 & 3.01 & & \\
\hline & \multicolumn{5}{|c|}{ Linear Projection } & Cross & Time & \multicolumn{5}{|c|}{ Quadratic Time Trend } & Cross & Time \\
\hline & $\mathbf{P}_{1}$ & $\mathbf{P}_{2}$ & $\mathbf{P}_{3}$ & $\mathbf{P}_{4}$ & $\mathbf{P}_{5}$ & Section & Series & $\mathbf{P}_{1}$ & $\mathbf{P}_{2}$ & $\mathbf{P}_{3}$ & $\mathbf{P}_{4}$ & $\mathbf{P}_{5}$ & Section & Series \\
\hline mean (\%) & 0.46 & 2.85 & 2.23 & 3.18 & 5.41 & $4.95^{* * *}$ & $3.72^{* * *}$ & 0.27 & 1.99 & 3.08 & 4.21 & 4.83 & $4.56^{* * *}$ & $2.14^{* *}$ \\
\hline$f x(\%)$ & -2.25 & 0.93 & 0.27 & 1.13 & 1.95 & 4.20 & 3.36 & -1.04 & -0.16 & 0.02 & 1.54 & 1.75 & 2.80 & 1.95 \\
\hline ir (\%) & 2.71 & 1.92 & 1.96 & 2.05 & 3.46 & 0.74 & 0.37 & 1.31 & 2.15 & 3.06 & 2.67 & 3.08 & 1.76 & 0.19 \\
\hline Sharpe & 0.05 & 0.32 & 0.23 & 0.33 & 0.56 & 0.66 & 0.72 & 0.03 & 0.21 & 0.32 & 0.49 & 0.51 & 0.60 & 0.41 \\
\hline$s t d$ & 9.80 & 8.91 & 9.59 & 9.65 & 9.63 & 7.47 & 5.18 & 10.05 & 9.58 & 9.76 & 8.66 & 9.53 & 7.56 & 5.27 \\
\hline skew & -0.24 & -0.24 & -0.50 & -0.07 & -0.54 & -0.34 & -1.23 & -0.23 & -0.21 & -0.07 & -0.51 & -0.15 & -0.68 & -1.24 \\
\hline kurt & 4.66 & 5.21 & 4.79 & 3.58 & 5.44 & 5.13 & 10.94 & 4.23 & 4.58 & 4.29 & 4.50 & 5.02 & 6.29 & 10.93 \\
\hline$m d d(\%)$ & 40.4 & 28.4 & 31.8 & 29.4 & 19.1 & 35.3 & 11.6 & 38.9 & 28.5 & 31.1 & 24.8 & 21.5 & 18.3 & 16.5 \\
\hline$t / o(\%)$ & 26.0 & 43.8 & 52.7 & 44.5 & 26.4 & & & 20.0 & 32.9 & 44.3 & 33.8 & 19.7 & & \\
\hline$f p(t, \%)$ & 2.68 & 2.01 & 1.90 & 2.17 & 3.97 & & & 1.17 & 2.04 & 3.15 & 2.87 & 3.35 & & \\
\hline $\operatorname{gap}(t, \%)$ & -1.33 & -0.30 & 0.31 & 0.90 & 1.98 & & & -8.41 & -3.35 & -0.22 & 2.59 & 7.78 & & \\
\hline
\end{tabular}


Table 2: Principal Component Decomposition of Business Cycle Portfolios

The table presents results from a principal component decomposition of the returns to five currency portfolios sorted by output gaps. The output gap is estimated as $(\log )$ industrial production minus the $(\log )$ trend in industrial production. The trend is estimated in four ways using a (i) Hodrick-Prescott filter; (ii) Baxter-King filter, (iii) linear projection, and (iv) quadratic time trend. Portfolios are rebalanced monthly with strong (weak) economy currencies entering $P_{5}\left(P_{1}\right)$. We report the loading of each portfolio on all five principal components $(P C s)$ and the percentage of total return variation explained by each $P C$. The sample is from October 1983 to January 2016.

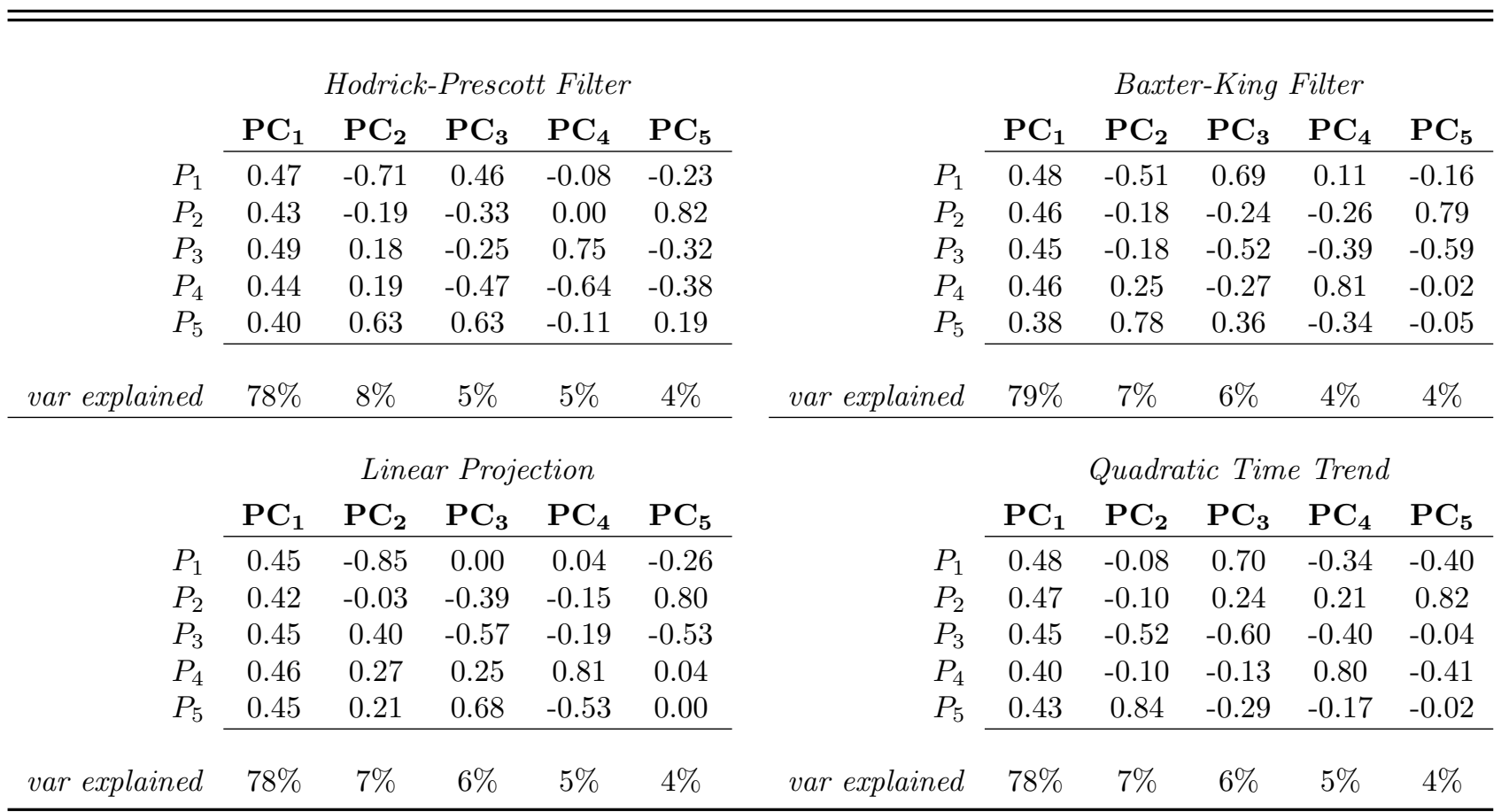




\section{Table 3: Taylor-rule Currency Portfolios}

The table presents descriptive statistics for five currency portfolios sorted by their Taylor-rule implied interest rate. The Taylor rule is calibrated to equal $1.5 \pi_{t}+0.5 y_{t}$, where $\pi_{t}$ is inflation and $y_{t}$ is the in-sample output gap calculated using a Hodrick-Prescott filter. Portfolios are rebalanced monthly with high (low) implied interest rate currencies entering $P_{5}\left(P_{1}\right)$. We report summary statistics for the annualized excess mean return and its decomposition between the exchange rate $(f x)$ and interest rate $(i r)$ components. We also report the Sharpe ratio (Sharpe), standard deviation (std), skewness (skew), kurtosis (kurt), maximum drawdown ( $m d d$ ), average turnover $(t / o)$, average forward premium $(f p)$, and average output gap ( $g a p)$ for each portfolio. The Cross Section portfolio is long $P_{5}$ and short $P_{1}$. The Time Series portfolio takes a $1 / \mathrm{N}$ position in currencies, going long (short) currencies issued by countries with a Taylor-rule implied interest rate above (below) the US Taylor-rule implied interest rate. The superscripts *, **, *** represent significance of the Cross Section and Time Series portfolios at the 10\%, 5\%, and 1\% level using Newey and West (1987) standard errors. We also report the correlation of the Cross Section and Time Series portfolios with the equivalent portfolios sorted on Hodrick-Prescott filtered output gaps $\left(\rho_{G A P}\right)$, and interest rates $\left(\rho_{H M L_{F X}}\right)$. The sample is from October 1983 to January 2016.

\begin{tabular}{lccccccc}
\hline \hline & \multicolumn{9}{c}{ Taylor Rule } & \multicolumn{3}{c}{ Cross } & Time \\
& $\mathbf{P}_{\mathbf{1}}$ & $\mathbf{P}_{\mathbf{2}}$ & $\mathbf{P}_{\mathbf{3}}$ & $\mathbf{P}_{\mathbf{4}}$ & $\mathbf{P}_{\mathbf{5}}$ & Section & Series \\
\cline { 2 - 8 } mean (\%) & -1.52 & 1.19 & 4.25 & 2.68 & 7.45 & $8.97^{* * *}$ & $2.75^{* * *}$ \\
$\quad$ fx (\%) & -0.56 & 1.07 & 2.74 & 0.16 & -1.67 & -1.11 & 0.32 \\
$\quad$ ir (\%) & -0.96 & 0.12 & 1.51 & 2.52 & 9.12 & 10.08 & 2.43 \\
Sharpe & -0.16 & 0.12 & 0.45 & 0.28 & 0.75 & 0.90 & 0.65 \\
std & 9.59 & 9.79 & 9.36 & 9.45 & 9.92 & 9.92 & 4.25 \\
skew & 0.16 & -0.10 & -0.33 & -0.42 & -0.55 & -0.42 & -1.04 \\
kurt & 4.05 & 3.88 & 4.79 & 4.35 & 4.57 & 4.85 & 9.99 \\
mdd (\%) & 61.3 & 34.7 & 25.2 & 28.8 & 20.6 & 13.8 & 11.2 \\
t/o (\%) & 24.9 & 40.9 & 43.5 & 33.2 & 12.9 & & \\
fp $(t, \%)$ & -0.85 & 0.19 & 1.37 & 2.50 & 9.87 & & \\
gap $(t, \%)$ & -1.59 & -0.18 & 0.36 & 0.50 & 1.11 & & \\
$\rho_{\text {GAP }}$ & & & & & & 0.25 & 0.36 \\
$\rho_{H M L_{F X}}$ & & & & & & 0.84 & 0.51 \\
\hline \hline
\end{tabular}


Table 4: Real-Time Business Cycle Currency Portfolios

The table presents investment performance for output-gap-based currency trading strategies. The output gap is estimated using monthly 'vintages' of real-time industrial production data from the OECD's Real-Time Data and Revisions Database. To estimate the output-gap we follow the linear projection procedure in Hamilton (2018) by running the regression, $y_{i, t}=\alpha_{i}+\sum_{s=0}^{11} \beta_{i, s} y_{i, t-24-s}+\varepsilon_{i, t}$ each month, in which $y$ is $(\log )$ industrial production. The output gap is constructed as the difference between the most recently available data point at time $t\left(y_{t}\right)$ and the fitted value from the regression. $G A P_{C S}$ is a high-minus-low portfolio formed as $P_{5}-P_{1}$, after sorting currencies into five portfolios ranging from the lowest $\left(P_{1}\right)$ to the highest $\left(P_{5}\right)$ output gap. LIN and $R N K$ take a position in all currencies with the weight determined by either the magnitude or relative size of the output gap. $G A P_{T S}$ is a $1 / \mathrm{N}$ time-series strategy long (short) currencies issued by countries with an output gap above (below) the US output gap. The three $C O M$ portfolios take 50-50 weights in $G A P_{T S}$ and the $G A P_{C S}, L I N$, and $R N K$ strategies. We report summary statistics for the annualized mean, which is then further split between the exchange rate $(f x)$ and interest rate (ir) components, we also report the Sharpe ratio (Sharpe), skewness (skew), kurtosis (kurt), and maximum drawdown ( $m d d)$. The superscripts *, **, *** represent significance of the strategies' mean excess returns at the $10 \%, 5 \%$, and $1 \%$ significance levels using Newey and West (1987) corrected standard errors. The sample runs from December 1999 to January 2016.

Panel A: Investment Performance Excluding Bid-Ask Spreads

\begin{tabular}{|c|c|c|c|c|c|c|c|}
\hline \multicolumn{8}{|c|}{ Panel A: Investment Performance Excluding Bid-Ask Spreads } \\
\hline & GAP $_{\mathrm{CS}}$ & LIN & RNK & $\mathbf{G A P}_{\mathrm{TS}}$ & $\mathrm{COM}_{\mathrm{GAP}}$ & $\mathrm{COM}_{\text {LIN }}$ & $\mathrm{COM}_{\mathrm{RNK}}$ \\
\hline mean (\%) & $4.92^{* * *}$ & $2.16^{* * *}$ & $3.88^{* * * *}$ & $2.76^{* *}$ & $3.82^{* * *}$ & $2.45^{* * *}$ & $3.30^{* * *}$ \\
\hline$f x(\%)$ & 4.21 & 1.74 & 3.38 & 2.83 & 3.50 & 2.26 & 3.08 \\
\hline ir $(\%)$ & 0.71 & 0.42 & 0.49 & -0.07 & 0.33 & 0.19 & 0.22 \\
\hline Sharpe & 0.72 & 0.74 & 0.72 & 0.65 & 0.82 & 0.82 & 0.82 \\
\hline skew & 0.31 & 0.34 & 0.25 & -0.70 & -0.01 & -0.46 & -0.23 \\
\hline kurt & 2.83 & 3.23 & 3.24 & 5.17 & 3.02 & 3.49 & 3.25 \\
\hline$m d d(\%)$ & 6.88 & 2.91 & 5.40 & 4.27 & 4.66 & 2.97 & 4.03 \\
\hline \multicolumn{8}{|c|}{ Panel B: Investment Performance Including Bid-Ask Spreads } \\
\hline & $\mathbf{G A P}_{\mathrm{CS}}$ & LIN & RNK & $\mathbf{G A P}_{\mathrm{TS}}$ & $\mathrm{COM}_{\mathrm{GAP}}$ & $\mathrm{COM}_{\text {LIN }}$ & $\mathrm{COM}_{\mathrm{RNK}}$ \\
\hline mean (\%) & $3.46^{* *}$ & $1.45^{* *}$ & $2.50^{* *}$ & $2.14^{*}$ & $2.79^{* *}$ & $1.78^{* *}$ & $2.31^{* *}$ \\
\hline$f x(\%)$ & 3.10 & 1.19 & 2.34 & 2.37 & 2.71 & 1.76 & 2.33 \\
\hline ir $(\%)$ & 0.36 & 0.25 & 0.15 & -0.22 & 0.08 & 0.03 & -0.02 \\
\hline Sharpe & 0.50 & 0.50 & 0.46 & 0.50 & 0.60 & 0.60 & 0.57 \\
\hline skew & 0.31 & 0.33 & 0.24 & -0.70 & -0.01 & -0.46 & -0.24 \\
\hline kurt & 2.81 & 3.20 & 3.22 & 5.19 & 3.01 & 3.50 & 3.26 \\
\hline$m d d(\%)$ & 6.86 & 2.91 & 5.39 & 4.27 & 4.66 & 2.97 & 4.03 \\
\hline
\end{tabular}


Table 5: Correlations Between Trading Strategies

The table presents linear correlation coefficients between trading strategies. In Panel A, we report correlations between output gap currency trading strategies. The output gap is estimated using monthly 'vintages' of real-time industrial production data from the OECD's Real-Time Data and Revisions Database. To estimate the output-gap we follow the linear projection procedure in Hamilton (2018) by running the regression, $y_{i, t}=\alpha_{i}+\sum_{s=0}^{11} \beta_{i, s} y_{i, t-24-s}+\varepsilon_{i, t}$ each month, in which $y$ is (log) industrial production. The output gap is constructed as the difference between the most recently available data point at time $t\left(y_{t}\right)$ and the fitted value from the regression. $G A P_{C S}$ is a high-minus-low portfolio formed as $P_{5}-P_{1}$, after sorting currencies into five portfolios ranging from the lowest $\left(P_{1}\right)$ to the highest $\left(P_{5}\right)$ output gap. $L I N$ and $R N K$ take a position in all currencies with the weight determined by either the magnitude or relative size of the output gap. $G A P_{T S}$ is a $1 / \mathrm{N}$ time-series strategy long (short) currencies issued by countries with an output gap above (below) the US output gap. The three COM portfolios take 50-50 weights in the GAPSS and the GAPCS, LIN, and $R N K$ strategies. In Panel $\mathrm{B}$, we present correlations between the output gap currency trading strategies and various currency and equity-based strategies. The sample runs from December 1999 to January 2016.

\begin{tabular}{|c|c|c|c|c|c|c|c|}
\hline Panel & A: Output & Gap & Jurrency & Trading & Strategies & & \\
\hline & $\mathbf{G A P}_{\mathrm{CS}}$ & LIN & RNK & $\mathbf{G A P}_{\mathrm{TS}}$ & $\mathrm{COM}_{\mathrm{GAP}}$ & COM $_{\text {LIN }}$ & $\mathrm{COM}_{\mathrm{RNK}}$ \\
\hline \multicolumn{8}{|l|}{ High-Minus-Low GAP ${ }_{C S}$} \\
\hline Linear Weights (LIN) & 0.86 & & & & & & \\
\hline Rank Weights (RNK) & 0.88 & 0.93 & & & & & \\
\hline$G A P_{T S}$ & 0.36 & 0.34 & 0.38 & & & & \\
\hline GAP Model Combo (COM $\left.M_{G A P}\right)$ & 0.90 & 0.79 & 0.83 & 0.73 & & & \\
\hline LIN Model Combo (COM $\left.M_{L I N}\right)$ & 0.68 & 0.74 & 0.73 & 0.89 & 0.91 & & \\
\hline RNK Model Combo $\left(C O M_{R N K}\right)$ & 0.78 & 0.81 & 0.87 & 0.79 & 0.94 & 0.96 & \\
\hline
\end{tabular}

Panel B: Alternative Trading Strategies in Currency, Equity, and Interest Rate Markets

\begin{tabular}{lccccccc}
\hline & $\mathbf{G A P}_{\mathbf{C S}}$ & $\mathbf{L I N}$ & $\mathbf{R N K}$ & $\mathbf{G A P}_{\mathbf{T S}}$ & $\mathbf{C O M}_{\mathbf{G A P}}$ & $\mathbf{C O M}_{\mathbf{L I N}}$ & $\mathbf{C O M}_{\mathrm{RNK}}$ \\
\cline { 2 - 8 } HML & 0.06 & 0.07 & 0.02 & 0.02 & 0.06 & 0.05 & 0.03 \\
Dollar & 0.24 & 0.21 & 0.22 & 0.23 & 0.28 & 0.27 & 0.27 \\
Dollar Carry & 0.23 & 0.21 & 0.22 & 0.23 & 0.28 & 0.27 & 0.27 \\
Value & 0.15 & 0.03 & 0.13 & 0.04 & 0.13 & 0.05 & 0.11 \\
Momentum & 0.07 & 0.15 & 0.08 & -0.06 & 0.02 & 0.03 & 0.02 \\
Global Imbalance & 0.13 & 0.12 & 0.10 & 0.23 & 0.20 & 0.22 & 0.18 \\
Foreign Exchange Trend Strategy & 0.08 & 0.08 & 0.08 & 0.07 & 0.09 & 0.09 & 0.09 \\
Interest Rate Trend Strategy & 0.07 & 0.12 & 0.13 & -0.22 & -0.05 & -0.10 & -0.03 \\
Illiquidity & 0.08 & 0.12 & 0.04 & 0.21 & 0.15 & 0.21 & 0.14 \\
US Equity & 0.00 & -0.04 & -0.01 & 0.10 & 0.05 & 0.06 & 0.05 \\
\hline \hline
\end{tabular}




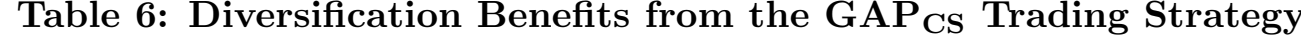

The table presents the investment performance of common currency trading strategies and the impact on performance from adding the $G A P_{C S}$ strategy. The output gap is estimated using monthly 'vintages' of real-time industrial production data from the OECD's Real-Time Data and Revisions Database. To estimate the output gap we follow the linear projection procedure in Hamilton (2018) by running the regression, $y_{i, t}=\alpha_{i}+\sum_{s=0}^{11} \beta_{i, s} y_{i, t-24-s}+\varepsilon_{i, t}$ each month, in which $y$ is (log) industrial production. The output gap is constructed as the difference between the most recently available data point at time $t\left(y_{t}\right)$ and the fitted value from the regression. $G A P_{C S}$ is a high-minus-low portfolio formed as $P_{5}-P_{1}$, after sorting currencies into five portfolios ranging from the lowest $\left(P_{1}\right)$ to the highest $\left(P_{5}\right)$ output gap. In Panel $\mathrm{A}$, we report the investment performance of popular currency investment strategies, in which $H M L_{F X}$ is the currency carry trade; DCAR is the "dollar carry" trade; $M O M$ is a momentum trade; VAL is a value trade and $E W$ is a $1 / \mathrm{N}$ portfolio that takes an equal position in each currency strategy. In Panel B, we add the $G A P_{C S}$ strategy. We report summary statistics for the annualized excess mean return, the Sharpe ratio (Sharpe), standard deviation (std), skewness (skew), kurtosis (kurt), maximum drawdown, percentage increase in Sharpe ratio $\left(\% \Delta\right.$ Sharpe), and weight in the $G A P_{C S}$ portfolio $\left(w_{G A P}\right)$. The superscripts *,**,*** represent significance of the strategies' mean excess returns at the $10 \%, 5 \%$, and $1 \%$ confidence levels using Newey and West (1987) corrected standard errors. The sample runs from December 1999 to January 2016.

\begin{tabular}{|c|c|c|c|c|c|}
\hline \multicolumn{6}{|c|}{ Panel A: Excluding the GAP $_{\mathrm{CS}}$ Strategy } \\
\hline & HML $_{F X}$ & DCAR & MOM & VAL & EW \\
\hline mean (\%) & $6.34^{* *}$ & 2.60 & 1.41 & 0.05 & $2.60^{* * *}$ \\
\hline Sharpe & 0.58 & 0.31 & 0.16 & 0.01 & 0.74 \\
\hline$s t d$ & 10.91 & 8.51 & 9.01 & 8.65 & 3.53 \\
\hline skew & -0.72 & -0.49 & 0.28 & 0.47 & -0.24 \\
\hline kurt & 5.23 & 4.78 & 3.31 & 4.42 & 4.13 \\
\hline$m d d(\%)$ & 0.16 & 0.17 & 0.23 & 0.39 & 0.07 \\
\hline \multicolumn{6}{|c|}{ Panel B: Including the GAP CS $_{\text {Strategy }}$} \\
\hline & $\begin{array}{c}\text { GAP }_{\text {CS }}+ \\
\text { HML }_{\text {FX }}\end{array}$ & $\begin{array}{c}\text { GAP }_{\text {CS }}+ \\
\text { DCAR }\end{array}$ & $\begin{array}{c}\text { GAP }_{\text {CS }}+ \\
\text { MOM }\end{array}$ & $\begin{array}{c}\text { GAP }_{\text {CS }}+ \\
\text { VAL }\end{array}$ & EW \\
\hline mean (\%) & $5.61^{* * *}$ & $3.74^{* * *}$ & $3.15^{* *}$ & $2.47^{*}$ & $3.06^{* * *}$ \\
\hline Sharpe & 0.85 & 0.62 & 0.54 & 0.42 & 0.87 \\
\hline$s t d$ & 6.64 & 6.07 & 5.87 & 5.93 & 3.53 \\
\hline skew & -0.11 & -0.30 & 0.34 & 0.54 & 0.12 \\
\hline kurt & 4.38 & 3.91 & 3.57 & 5.10 & 4.20 \\
\hline$m d d(\%)$ & 0.07 & 0.09 & 0.08 & 0.19 & 0.06 \\
\hline$\% \Delta$ Sharpe & 45.6 & 102 & 243 & 7625 & 17.7 \\
\hline$w_{G A P}(\%)$ & 50.0 & 50.0 & 50.0 & 50.0 & 20.0 \\
\hline
\end{tabular}




\section{Table 7: Pricing Business Cycle Portfolios}

The table presents cross-sectional asset pricing results. We construct various two-factor linear SDF's that include the $D O L$ factor plus a second pricing factor, including 'slope' risk $\left(H M L_{F X}\right)$, global imbalance risk $(I M B)$, volatility risk $(V O L)$, and the $G A P_{C S}$ factor. In each model, we price five currency portfolios sorted on output gaps using real-time information. We report Generalized Method of Moments (GMM) one-step estimates of factor loadings on the pricing kernel ( $b$ 's) and prices of factor risk $(\lambda$ 's). The superscripts *, **, ${ }^{* * *}$ represent significance of the coefficients at the $10 \%, 5 \%$, and $1 \%$ significance levels using Newey and West (1987) corrected standard errors (reported in parentheses). We also report goodness-of-fit statistics for each model including the adjusted $R^{2}$ statistic, Root Mean Squared Pricing Error $(R M S E)$, and the Hansen-Jagannathan distance statistic $\left(H J_{d i s t}\right)$ with simulated $p$-values in brackets. The $H J_{\text {dist }}$ statistic measures the distance between the estimated pricing kernel and the efficient set of permissible pricing kernels. A $p$-value less than $5 \%$ indicates the null hypothesis that the pricing kernel is efficient can be rejected at the $95 \%$ confidence level. We provide full details of the pricing factors in Section 5. The sample runs from December 1999 to January 2016.

\begin{tabular}{|c|c|c|c|c|c|c|c|}
\hline & \multicolumn{2}{|c|}{$\begin{array}{c}\text { SDF } \\
\text { Loadings }(b)\end{array}$} & \multicolumn{2}{|c|}{$\begin{array}{c}\text { Risk } \\
\text { Prices }(\lambda)\end{array}$} & \multicolumn{3}{|c|}{ Model Fit } \\
\hline & DOL & FAC & DOL & FAC & $\operatorname{Adj} . R^{2}$ & RMSE & $\mathrm{HJ}_{\text {dist }}$ \\
\hline $\mathrm{DOL}+\mathrm{HML}_{\mathrm{FX}}$ & $\begin{array}{c}0.22 \\
(0.26)\end{array}$ & $\begin{array}{c}0.19 \\
(0.72)\end{array}$ & $\begin{array}{c}0.02 \\
(0.02)\end{array}$ & $\begin{array}{c}0.03 \\
(0.10)\end{array}$ & -0.78 & 1.69 & $\begin{array}{c}0.22 \\
{[0.03]}\end{array}$ \\
\hline $\mathrm{DOL}+\mathrm{IMB}$ & $\begin{array}{l}-1.39 \\
(1.43)\end{array}$ & $\begin{array}{l}7.52 \\
(5.78)\end{array}$ & $\begin{array}{l}0.04^{*} \\
(0.02)\end{array}$ & $\begin{array}{c}0.26^{* *} \\
(0.12)\end{array}$ & -0.15 & 1.59 & $\begin{array}{c}0.19 \\
{[0.61]}\end{array}$ \\
\hline $\mathrm{DOL}+\mathrm{VOL}$ & $\begin{array}{l}-3.21 \\
(2.86)\end{array}$ & $\begin{array}{l}-40.5 \\
(31.6)\end{array}$ & $\begin{array}{c}0.03 \\
(0.02)\end{array}$ & $\begin{array}{c}-0.03^{* *} \\
(0.02)\end{array}$ & -0.19 & 1.51 & $\begin{array}{c}0.21 \\
{[0.46]}\end{array}$ \\
\hline $\mathrm{DOL}+\mathrm{GAP}_{\mathrm{CS}}$ & $\begin{array}{c}0.08 \\
(0.26)\end{array}$ & $\begin{array}{c}0.83^{* * *} \\
(0.29)\end{array}$ & $\begin{array}{c}0.02 \\
(0.02)\end{array}$ & $\begin{array}{c}0.05^{* * *} \\
(0.02)\end{array}$ & 0.44 & 0.95 & $\begin{array}{c}0.13 \\
{[0.34]}\end{array}$ \\
\hline
\end{tabular}


Table 8: Asset Pricing using DOL, $\mathrm{HML}_{\mathrm{Fx}}$, and $\mathrm{GAP}_{\mathrm{CS}}$ as Pricing Factors

The table presents cross-sectional asset pricing results for two sets of test portfolios. The SDF is constructed as a linear combination of $D O L$ and $H M L_{F X}$ (2 pricing factors, left-side) and $D O L, H M L_{F X}$, and $G A P_{C S}$ (3 pricing factors, right-side). In Panel B, we also include $H M L_{F X}$ and $G A P_{C S}$ as test assets. We report Generalized Method of Moments (GMM) one-step estimates of factor loadings on the pricing kernel $\left(b\right.$ 's) and prices of factor risk $(\lambda ' s)$. The superscripts $*{ }^{* *},{ }^{* * *}$ represent significance of the coefficients at the 10\%, 5\%, and 1\% significance levels using Newey and West (1987) corrected standard errors (reported in parentheses). In addition, we report goodness-of-fit statistics for each model including the adjusted $R^{2}$ statistic, Root Mean Squared Pricing Error $(R M S E)$, and the Hansen-Jagannathan distance statistic $\left(H J_{\text {dist }}\right)$ with simulated $p$-values in brackets. The $H J_{\text {dist }}$ statistic measures the distance between the estimated pricing kernel and the efficient set of permissible pricing kernels. A $p$-value less than $5 \%$ indicates the null hypothesis that the pricing kernel is efficient can be rejected at the $95 \%$ confidence level. The sample runs from December 1999 to January 2016.

\begin{tabular}{|c|c|c|c|c|c|c|c|c|c|c|c|c|c|c|c|c|}
\hline \multirow{5}{*}{$\begin{array}{c}10 \mathrm{TPs} \\
\text { (val, mom) } \\
20 \mathrm{TPs} \\
\text { (gap, car, } \\
\text { val, mom) }\end{array}$} & \multicolumn{7}{|c|}{2 Pricing Factors $\left(\mathrm{DOL}+\mathrm{HML}_{\mathrm{FX}}\right)$} & \multicolumn{9}{|c|}{3 Pricing Factors $\left(\mathrm{DOL}+\mathrm{HML}_{\mathrm{FX}}+\mathrm{GAP}_{\mathrm{CS}}\right)$} \\
\hline & \multicolumn{2}{|c|}{ Loadings $(b)$} & \multicolumn{2}{|c|}{ Risk Prices $(\lambda)$} & \multicolumn{3}{|c|}{ Model Fit } & \multicolumn{3}{|c|}{ Loadings $(b)$} & \multicolumn{3}{|c|}{ Risk Prices $(\lambda)$} & \multicolumn{3}{|c|}{ Model Fit } \\
\hline & DOL & $\mathrm{HML}_{\mathrm{FX}}$ & DOL & $\mathrm{HML}_{\mathrm{FX}}$ & Adj. $R^{2}$ & RMSE & $\mathrm{HJ}_{\text {dist }}$ & DOL & $\mathrm{HML}_{\mathrm{FX}}$ & $\mathrm{GAP}_{\mathrm{CS}}$ & DOL & $\mathrm{HML}_{\mathrm{FX}}$ & $\mathrm{GAP}_{\mathrm{CS}}$ & Adj. $R^{2}$ & RMSE & $\mathrm{HJ}_{\text {dist }}$ \\
\hline & $\begin{array}{c}0.19 \\
(0.26)\end{array}$ & $\begin{array}{c}0.08 \\
(0.32)\end{array}$ & $\begin{array}{c}0.02 \\
(0.02)\end{array}$ & $\begin{array}{c}0.01 \\
(0.04)\end{array}$ & -0.35 & 1.32 & $\begin{array}{c}0.22 \\
{[0.81]}\end{array}$ & $\begin{array}{l}-0.31 \\
(0.36)\end{array}$ & $\begin{array}{c}0.43 \\
(0.41)\end{array}$ & $\begin{array}{c}2.57^{* *} \\
(1.01)\end{array}$ & $\begin{array}{c}0.02 \\
(0.02)\end{array}$ & $\begin{array}{c}0.07 \\
(0.05)\end{array}$ & $\begin{array}{c}0.14^{* * *} \\
(0.05)\end{array}$ & 0.59 & 0.67 & $\begin{array}{c}0.16 \\
{[0.96]}\end{array}$ \\
\hline & $\begin{array}{c}0.18 \\
(0.27)\end{array}$ & $\begin{array}{c}0.36 \\
(0.22)\end{array}$ & $\begin{array}{c}0.02 \\
(0.02)\end{array}$ & $\begin{array}{l}0.05^{*} \\
(0.03)\end{array}$ & 0.26 & 1.36 & $\begin{array}{c}0.33 \\
{[0.99]}\end{array}$ & $\begin{array}{l}-0.02 \\
(0.28)\end{array}$ & $\begin{array}{c}0.35 \\
(0.22)\end{array}$ & $\begin{array}{c}1.05^{* * *} \\
(0.32)\end{array}$ & $\begin{array}{c}0.02 \\
(0.02)\end{array}$ & $\begin{array}{l}0.06^{*} \\
(0.03)\end{array}$ & $\begin{array}{c}0.06^{* * *} \\
(0.02)\end{array}$ & 0.62 & 0.94 & $\begin{array}{c}0.30 \\
{[0.99]}\end{array}$ \\
\hline \multicolumn{17}{|c|}{ Panel B: Including Pricing Factors as Test Portfolios } \\
\hline & \multicolumn{7}{|c|}{2 Pricing Factors $\left(\mathrm{DOL}+\mathrm{HML}_{\mathrm{FX}}\right)$} & \multicolumn{9}{|c|}{3 Pricing Factors $\left(\mathrm{DOL}+\mathrm{HML}_{\mathrm{FX}}+\mathrm{GAP}_{\mathrm{CS}}\right)$} \\
\hline & \multicolumn{2}{|c|}{ Loadings $(b)$} & \multicolumn{2}{|c|}{ Risk Prices $(\lambda)$} & \multicolumn{3}{|c|}{ Model Fit } & \multicolumn{3}{|c|}{ Loadings $(b)$} & \multicolumn{3}{|c|}{ Risk Prices $(\lambda)$} & \multicolumn{3}{|c|}{ Model Fit } \\
\hline & DOL & $\mathrm{HML}_{\mathrm{FX}}$ & DOL & $\mathrm{HML}_{\mathrm{FX}}$ & Adj. $R^{2}$ & RMSE & $\mathrm{HJ}_{\text {dist }}$ & DOL & $\mathrm{HML}_{\mathrm{FX}}$ & $\mathrm{GAP}_{\mathrm{CS}}$ & DOL & $\mathrm{HML}_{\mathrm{FX}}$ & $\mathrm{GAP}_{\mathrm{CS}}$ & Adj. $R^{2}$ & RMSE & $\mathrm{HJ}_{\text {dist }}$ \\
\hline $\begin{array}{c}10 \text { TPs } \\
\text { (val, mom) }\end{array}$ & $\begin{array}{c}0.16 \\
(0.28)\end{array}$ & $\begin{array}{l}0.41^{*} \\
(0.22)\end{array}$ & $\begin{array}{c}0.02 \\
(0.02)\end{array}$ & $\begin{array}{c}0.06^{* *} \\
(0.03)\end{array}$ & 0.31 & 1.37 & $\begin{array}{c}0.23 \\
{[0.80]}\end{array}$ & $\begin{array}{l}-0.02 \\
(0.28)\end{array}$ & $\begin{array}{l}0.40^{*} \\
(0.21)\end{array}$ & $\begin{array}{c}0.97^{* * *} \\
(0.30)\end{array}$ & $\begin{array}{c}0.02 \\
(0.02)\end{array}$ & $\begin{array}{c}0.06^{* *} \\
(0.03)\end{array}$ & $\begin{array}{c}0.06^{* * *} \\
(0.02)\end{array}$ & 0.65 & 0.96 & $\begin{array}{c}0.19 \\
{[0.91]}\end{array}$ \\
\hline $\begin{array}{c}20 \text { TPs } \\
\text { (gap, car, } \\
\text { val, mom) }\end{array}$ & $\begin{array}{c}0.17 \\
(0.28)\end{array}$ & $\begin{array}{l}0.41^{*} \\
(0.22)\end{array}$ & $\begin{array}{c}0.02 \\
(0.02)\end{array}$ & $\begin{array}{c}0.06^{* *} \\
(0.03)\end{array}$ & 0.46 & 1.34 & $\begin{array}{c}0.69 \\
{[0.91]}\end{array}$ & $\begin{array}{c}0.00 \\
(0.28)\end{array}$ & $\begin{array}{l}0.40^{*} \\
(0.21)\end{array}$ & $\begin{array}{c}0.91^{* * *} \\
(0.30)\end{array}$ & $\begin{array}{c}0.02 \\
(0.02)\end{array}$ & $\begin{array}{c}0.06^{* *} \\
(0.03)\end{array}$ & $\begin{array}{c}0.05^{* * *} \\
(0.02)\end{array}$ & 0.74 & 0.92 & $\begin{array}{c}0.69 \\
{[0.98]}\end{array}$ \\
\hline
\end{tabular}


Table 9: Conditional Asset Pricing

The table presents results from conditional asset pricing tests. In Panel A, we present annualized two-step instrumental variable (IV) alphas following the procedure of Boguth et al. (2011) on five output gap sorted portfolios and the GAPCS factor. The contemporaneous exposure of the portfolios to the pricing factors (i.e. betas) are initially estimated over either 12, 18, 24, 30, or 36 months. The instruments used to predict betas include the lagged beta, global foreign exchange volatility, the Commodity Research Bureau's industrial metals index, the Treasury-Eurodollar (TED) spread, and the average forward discount. The superscripts *, **, *** represent significance of the alphas at the $10 \%, 5 \%$, and $1 \%$ significance levels using Newey and West (1987) corrected standard errors. We also report the $\chi^{2}$ test statistic and associated $p$-value in square brackets, for the test that alphas are jointly equal to zero. A $p$-value less than $5 \%$ indicates the null hypothesis that the alphas are jointly equal to zero can be rejected at the $95 \%$ confidence level. In Panel B, we report the $\chi^{2}$ test statistic and associated $p$-value in square brackets for the equivalent test when pricing 20 currency portfolios, which include portfolios sorted according to output gaps (x5), forward premia (x5), currency momentum (x5), and currency value (x5). The sample runs from December 1999 to January 2016.

Panel A: GAP Portfolios

\begin{tabular}{|c|c|c|c|c|c|c|c|c|c|c|c|c|c|c|c|}
\hline \multirow{3}{*}{ Months } & \multicolumn{5}{|c|}{$\begin{array}{l}2 \text { Pricing Factors } \\
\left(\mathrm{DOL}+\mathrm{HML}_{\mathrm{FX}}\right)\end{array}$} & \multicolumn{5}{|c|}{$\begin{array}{c}2 \text { Pricing Factors } \\
\left(\mathrm{DOL}+\mathrm{GAP}_{\mathrm{CS}}\right)\end{array}$} & \multicolumn{5}{|c|}{$\begin{array}{c}3 \text { Pricing Factors } \\
\left(\mathrm{DOL}+\mathrm{HML}_{\mathrm{FX}}+\mathrm{GAP}_{\mathrm{CS}}\right)\end{array}$} \\
\hline & 12 & 18 & 24 & 30 & 36 & 12 & 18 & 24 & 30 & 36 & 12 & 18 & 24 & 30 & 36 \\
\hline & -0.89 & -1.27 & -1.13 & -1.16 & -0.95 & 0.58 & 0.33 & 0.42 & 0.59 & 0.71 & 0.62 & 0.25 & 0.03 & 0.13 & 0.34 \\
\hline$P_{2}$ & -0.85 & -0.58 & -0.40 & -0.49 & -0.87 & -0.78 & -0.40 & -0.29 & -0.41 & -0.66 & -1.14 & -0.69 & -0.50 & -0.46 & -0.69 \\
\hline$P_{3}$ & -0.91 & -0.76 & -0.38 & -0.83 & -0.76 & -0.83 & -0.84 & -0.77 & -1.03 & -0.89 & -0.82 & -0.94 & -0.54 & -0.89 & -0.67 \\
\hline$P_{4}$ & 1.54 & $1.78^{*}$ & $1.87^{*}$ & $1.88^{*}$ & 1.53 & 0.37 & 0.93 & 0.85 & 0.98 & 0.66 & 1.11 & 1.19 & 1.31 & 1.57 & 1.19 \\
\hline$P_{5}$ & $2.18^{* *}$ & $2.05^{* *}$ & $1.62^{* *}$ & $1.85^{* *}$ & $1.97^{* *}$ & 0.58 & 0.33 & 0.42 & 0.59 & 0.71 & 0.62 & 0.25 & 0.03 & 0.13 & 0.34 \\
\hline$G A P_{C S}$ & $2.96^{* *}$ & $3.18^{* *}$ & $2.74^{*}$ & $3.00^{* *}$ & $3.12^{* *}$ & 0.00 & 0.00 & 0.00 & 0.00 & 0.00 & 0.00 & 0.00 & 0.00 & 0.00 & 0.00 \\
\hline$\chi^{2}$ & $\begin{array}{c}14.46 \\
{[0.025]}\end{array}$ & $\begin{array}{c}14.50 \\
{[0.025]}\end{array}$ & $\begin{array}{c}15.79 \\
{[0.015]}\end{array}$ & $\begin{array}{c}13.62 \\
{[0.034]}\end{array}$ & $\begin{array}{c}12.65 \\
{[0.049]}\end{array}$ & $\begin{array}{c}1.45 \\
{[0.963]}\end{array}$ & $\begin{array}{c}2.02 \\
{[0.918]}\end{array}$ & $\begin{array}{c}6.25 \\
{[0.396]}\end{array}$ & $\begin{array}{c}9.29 \\
{[0.158]}\end{array}$ & $\begin{array}{c}5.55 \\
{[0.475]}\end{array}$ & $\begin{array}{c}3.25 \\
{[0.776]}\end{array}$ & $\begin{array}{c}1.64 \\
{[0.950]}\end{array}$ & $\begin{array}{c}2.35 \\
{[0.885]}\end{array}$ & $\begin{array}{c}3.70 \\
{[0.717]}\end{array}$ & $\begin{array}{c}3.26 \\
{[0.775]}\end{array}$ \\
\hline
\end{tabular}

Panel B: All Portfolios

\begin{tabular}{|c|c|c|c|c|c|c|c|c|c|c|c|c|c|c|c|}
\hline \multirow{4}{*}{$\begin{array}{l}\text { Months } \\
\chi^{2}\end{array}$} & \multicolumn{5}{|c|}{$\begin{array}{l}2 \text { Pricing Factors } \\
\left(\mathrm{DOL}+\mathrm{HML}_{\mathrm{FX}}\right)\end{array}$} & \multicolumn{5}{|c|}{$\begin{array}{c}2 \text { Pricing Factors } \\
\left(\mathrm{DOL}+\mathrm{GAP}_{\mathrm{CS}}\right)\end{array}$} & \multicolumn{5}{|c|}{$\begin{array}{c}3 \text { Pricing Factors } \\
\left(\mathrm{DOL}+\mathrm{HML}_{\mathrm{FX}}+\mathrm{GAP}_{\mathrm{CS}}\right)\end{array}$} \\
\hline & 12 & 18 & 24 & 30 & 36 & 12 & 18 & 24 & 30 & 36 & 12 & 18 & 24 & 30 & 36 \\
\hline & 31.29 & 30.70 & 44.86 & 36.95 & 33.53 & 23.35 & 17.91 & 24.49 & 27.96 & 19.37 & 25.06 & 16.49 & 17.85 & 17.09 & 17.20 \\
\hline & {$[0.051]$} & {$[0.059]$} & {$[0.001]$} & {$[0.012]$} & {$[0.029]$} & {$[0.272]$} & [0.593] & {$[0.222]$} & {$[0.110]$} & {$[0.498]$} & [0.199] & {$[0.686]$} & {$[0.597]$} & {$[0.647]$} & {$[0.640]$} \\
\hline
\end{tabular}




\section{INTERNET APPENDIX \\ Business Cycles and Currency Returns}

NOT FOR PUBLICATION 


\section{Estimating the Output Gap In-Sample}

\section{Hodrick-Prescott Filter}

The Hodrick-Prescott filter minimizes the following expression to produce a new time series of trend output, $y_{i, t}^{t r}$

$$
\sum_{t=1}^{T}\left(y_{i, t}-y_{i, t}^{t r}\right)^{2}+\lambda \sum_{t=2}^{T-1}\left[\left(y_{i, t+1}^{g r}-y_{i, t}^{g r}\right)-\left(y_{i, t}^{t r}-y_{i, t-1}^{t r}\right)\right]^{2}
$$

where $y_{i, t}$ is the logarithm of industrial production at time $t$ for country $i, \lambda$ is a weighing factor to control the smoothness of the trend line. The lower the value of $\lambda$, the more the resulting trend will resemble the raw data series. We follow the suggestion of Hodrick and Prescott (1980) and Kydland and Prescott (1990) and set $\lambda=1600$ to smooth quarterly data and $\lambda=14400$ to smooth monthly data. The output gap (cyclical component) is then constructed as the difference between $y_{i, t}$ and the trend series extracted from the filter $c_{i, t}=y_{i, t}-y_{i, t}^{t r}$.

\section{Baxter-King Filter}

The Baxter-King filter removes both low and high frequency components from a time series. Specifically it involves the estimation of the moving average model

$$
\hat{y}_{i, t}=\sum_{n=-K}^{K} B_{n} x_{t-n}
$$

The values $B_{n}$ can be estimated using an inverse Fourier transform such that they minimize the mean squared error between $y_{t}$ and $\hat{y}_{t}$ (see Priestly, 1981). We follow the suggestion of Baxter and King (1999) and set $\mathrm{K}=12$ for quarterly data and $\mathrm{K}=36$ for monthly data. We also set standard upper and lower limits for the cutoff frequency of 6 and 32 quarters for quarterly data and 8 and 96 months for monthly data.

\section{Linear Projection}

We follow the linear projection method proposed by Hamilton (2018) and project (log) industrial production at time $t$ on 12-lags of industrial production beginning 24-months earlier ${ }^{1}$

$$
y_{i, t}=\alpha_{i}+\sum_{s=0}^{11} \beta_{i, s} y_{i, t-24-s}+\varepsilon_{i, t}
$$

The output gap (cyclical component) is then constructed as the difference between $y_{i, t}$ and the fitted value from the above regression $c_{i, t}=y_{i, t}-\hat{y}_{i, t}$.

\footnotetext{
${ }^{1}$ For quarterly industrial production time series we project onto four lags beginning eight-quarters earlier.
} 


\section{Quadratic Time Trend}

The quadratic time trend projects the logarithm of industrial production on a time trend $t$ and quadratic time trend $t^{2}$

$$
y_{i, t}=\alpha_{i}+\beta_{i, 1} t+\beta_{i, 2} t^{2}+\varepsilon_{i, t}
$$

The output gap (cyclical component) is then constructed as the difference between $y_{i, t}$ and the fitted value from the above regression $c_{i, t}=y_{i, t}-\hat{y}_{i, t}$.

\section{Alternative Currency Portfolios, Factors, and Strategies}

Carry Trade Portfolios. At the end of each month $t$, we allocate currencies to five portfolios on the basis of their forward discounts (or interest rate differential relative to the US). This exercise implies that currencies with the lowest forward discounts (or lowest interest rate differential relative to the US) are assigned to Portfolio 1, whereas currencies with the highest forward discounts (or highest interest rate differential relative to the US) are assigned to Portfolio 5. We compute the excess return for each portfolio as an equally weighted average of the currency excess returns within that portfolio. The strategy that is long Portfolio 5 and short Portfolio 1 is referred to as $H M L_{F X}$.

Currency Momentum Portfolios. At the end of each month $t$, we form five portfolios based on exchange rate returns over the previous month. We assign the $20 \%$ of all currencies with the lowest lagged exchange rate returns to Portfolio 1 and the $20 \%$ of all currencies with the highest lagged exchange rate returns to Portfolio 5. We then compute the excess return for each portfolio as an equally weighted average of the currency excess returns within that portfolio. A strategy long in Portfolio 5 (winner currencies) and short in Portfolio 1 (loser currencies) is denoted as MOM.

Value Portfolios. At the end of each month $t$, we form five portfolios based on the lagged five-year real exchange rate return as in Asness et al. (2013). This measure of currency value is based on calculating the deviation from relative purchasing power parity. Specifically, relative inflation over a 5-year window vis-à-vis the US is compared with the foreign exchange (FX) rate appreciation over the same period versus the US dollar. To provide a more stable measure of the FX rate appreciation, Asness et al. (2013) calculate the appreciation as today's FX rate minus the average FX rate observed 4.5 to 5.5 years earlier. If inflation growth in the foreign economy outpaced that in the US but the US dollar did not appreciate against the foreign currency by an offsetting amount, then the foreign currency is considered 'overvalued'.

To construct currency value portfolios, we collect monthly data on consumer price indices from the IMF's International Financial Statistics database beginning in October 1978 and also collect additional FX spot rate data from Global Financial Data beginning in April 1978, such that the first currency value signals are obtained in October 1983 . We assign the $20 \%$ of all currencies with the highest lagged real exchange rate return to Portfolio 1 and the $20 \%$ of all currencies with the lowest lagged real exchange rate return to Portfolio 5. We compute the excess 
return for each portfolio as an equally weighted average of the currency excess returns within that portfolio. A strategy long in Portfolio 5 (undervalued currencies) and short in Portfolio 1 (overvalued currencies) is denoted as $V A L$.

Other Factors and Portfolios. In addition to the portfolios described above, we also compare the properties of the output-gap portfolios against other popular strategies and factors in the literature. These include: (i) the Dollar factor, proposed by Lustig et al. (2011), which is essentially a market factor in currency space, equal to the average return of a large basket of foreign currencies against the US dollar; (ii) the Dollar Carry strategy as proposed by Lustig et al. (2014), which conditions the Dollar factor on the average forward premia of currencies against the US and thus goes long (short) the US dollar whenever interest rates are relatively high (low) in the US; (iii) the Global Imbalance factor of Della Corte et al. (2016b), which is a factor that compensates investors for financing risky economies with large stocks of liabilities that issue the majority of those in foreign currency; (iv) the Trend-Following risk factors proposed by Fung and Hsieh (2001), which reflect the option-like returns typically generated by hedge funds (we use the FX and interest-rate trend-following returns); (v) the Pástor and Stambaugh (2003) measure of Aggregate Market Liquidity, and (vi) the Market Risk Premium collected from Kenneth French's website. ${ }^{2}$

\section{Asset Pricing Tests}

We provide further details on the asset pricing methods used in Sections 5.1 and 5.2 of the paper to evaluate whether the relationship between currency returns and business cycles can be understood from a risk-return perspective.

We denote the discrete excess returns on portfolio $j$ in period $t$ as $R X_{t}^{j}$, for $j=1, \ldots, N$ and $t=1, \ldots, T$; and let $R X_{t}$ be a $N$-dimensional vector of test asset excess returns. In the absence of arbitrage opportunities, risk-adjusted excess returns have a price of zero and satisfy the following Euler equation:

$$
E_{t}\left[M_{t+1} R X_{t+1}^{j}\right]=0
$$

with an SDF linear in $k$ pricing factors $f_{t+1}$, given by

$$
M_{t+1}=1-b^{\prime}\left(f_{t+1}-\mu\right)
$$

where $b$ is the vector of factor loadings, and $\mu$ denotes the factor means. Equation (21) is referred to as an unconditional asset pricing model because the SDF factor loadings in $b$ are assumed to be time-invariant. The vast majority of papers in the currency asset pricing literature, starting from Lustig and Verdelhan (2007), focus on Equation (21). However, in a more general setting the Euler

\footnotetext{
${ }^{2}$ The hedge fund risk factors returns are available on David A. Hsieh's website at http://faculty .fuqua .duke . edu/ dah7/DataLibrary/TF-FAC.xls. We collect liquidity data from Lubos Pastor's website at http://faculty . chicagobooth.edu/lubos.pastor/research/ and market data from Kenneth French's website at http://mba. tuck.dartmouth.edu/pages/faculty/ken.french/data_library.html. We thank each author for making their data publicly available.
} 
equation (20) implies SDF parameters that are time-varying, which means the covariance between excess returns and the SDF is conditional (Hansen and Richard, 1987; Boguth et al., 2011). If this is the case, for example, it could be that excess returns from high output gap currencies (strong economies) are more risky in bad times, in which case the unconditional version of the model with constant $b$ is mispecified. We analyze this more general case of conditional asset pricing tests in Section 5.3 of the paper.

The SDF specification (21) implies a beta pricing model in which the expected excess return on portfolio $j$ is equal to the factor risk price $\lambda$ times the risk quantities $\beta^{j}$. The beta pricing model is defined as

$$
E\left[R X^{j}\right]=\lambda^{\prime} \beta^{j}
$$

where the market price of risk $\lambda=\Sigma_{f} b$ can be obtained via the factor loadings $b . \Sigma_{f}=$ $E\left[\left(f_{t}-\mu\right)\left(f_{t}-\mu\right)^{\prime}\right]$ is the variance-covariance matrix of the risk factors, and $\beta^{j}$ are the regression coefficients of each portfolio's excess return $R X_{t+1}^{j}$ on the risk factors $f_{t+1}$.

We estimate the SDF parameters, including estimates of factor loadings $b$ and the market prices of risk $\lambda$, via the Generalized Method of Moments (GMM) of Hansen (1982). To implement $G M M$, we use the pricing errors as a set of moments and the identity weighting matrix. Since the objective is to test whether the model can explain the cross section of expected currency excess returns, we only rely on unconditional moments and do not employ instruments. With an identity matrix, GMM attempts to price all currency portfolios equally well. Factor means and the individual elements of the covariance matrix of risk factors $\Sigma_{f}$ are estimated simultaneously with the SDF parameters by adding the corresponding moment conditions to the asset pricing moment conditions implied by the Euler condition (20). This one-step approach ensures that we adequately incorporate estimation uncertainty associated with the fact that factor means and the factor covariance matrix need to be estimated (see, for example, Burnside, 2011).

Formally, the Euler equation (20) implies the following moment conditions for the $N$-dimensional vector of test asset excess returns $R X_{t+1}$

$$
E\left\{\left[1-b^{\prime}\left(f_{t+1}-\mu\right)\right] R X_{t+1}\right\}=0 .
$$

In addition to these $N$ moment restrictions, our set of $G M M$ moment conditions also includes $k$ moment conditions $E\left[f_{t}-\mu\right]=0$ accounting for the fact that factor means $\mu$ have to be estimated. ${ }^{3}$ Factor risk prices $\lambda$ can be easily obtained from our GMM estimates via the relation $\lambda=\Sigma_{f} b$, where $\Sigma_{f}=E\left[\left(f_{t}-\mu\right)\left(f_{t}-\mu\right)^{\prime}\right]$ is the factor covariance matrix. Following Burnside (2011), the covariance matrix $\Sigma_{f}$ is estimated along with the other model parameters by including an additional set of corresponding moment conditions. Hence, the estimating function takes the following form

$$
g\left(z_{t}, \theta\right)=\left[\begin{array}{c}
{\left[1-b^{\prime}\left(f_{t}-\mu\right)\right] R X_{t}} \\
f_{t}-\mu \\
\operatorname{vec}\left(\left(f_{t}-\mu\right)\left(f_{t}-\mu\right)^{\prime}\right)-\operatorname{vec}\left(\Sigma_{f}\right)
\end{array}\right]
$$

\footnotetext{
${ }^{3}$ This applies because the risk factors considered here are not mean zero by construction.
} 
where $\theta$ contains the parameters $\left.\left(b^{\prime}, \mu^{\prime}, \operatorname{vec}\left(\Sigma_{f}\right)^{\prime}\right)^{\prime}\right)$ and $z_{t}$ represents the data $\left(R X_{t}, f_{t}\right)$. By exploiting the moment conditions $E\left[g\left(z_{t}, \theta\right)\right]=0$ defined by $(24)$, estimation uncertainty - due to the fact that factor means and the covariance matrix of factors have to be estimated - is incorporated in the standard errors of factor risk prices. The one-step GMM estimation uses a pre-specified weighting matrix $W_{T}$ based on the identity matrix $I_{N}$ for the first $N$ asset pricing moment conditions and a large weight assigned to the additional moment conditions (for precise estimation of factor means and the factor covariance matrix). Standard errors are computed based on a HAC estimate of the long-run covariance matrix $S=\sum_{j=-\infty}^{\infty} E\left[g\left(z_{t}, \theta\right) g\left(z_{t-j}, \theta\right)^{\prime}\right]$ by the Newey and West (1987) procedure with the number of lags in the Bartlett kernel determined optimally by the data-driven approach of Andrews (1991).

The model's performance is evaluated using the cross-sectional $R^{2}$, the Root Mean Squared Error (RMSE), and the $H J$ distance measure of Hansen and Jagannathan (1997), which quantifies the mean-squared distance between the SDF of a proposed model and the set of admissible SDFs. Put simply, this measure gives the least squares distance between the model's SDF and the nearest point to such SDF in the space of all SDFs that price the test assets correctly. The $H J$ distance measure for a given model's SDF applied to the data $z_{t}$ and with parameters $\theta, M_{t}\left(z_{t}, \theta\right)$ is defined as

$$
H J=\sqrt{\min _{\theta} g_{T}\left(z_{t}, \theta\right)^{\prime} G_{T}^{-1} g_{T}\left(z_{t}, \theta\right)}
$$

where $G_{T} \equiv T^{-1} \sum_{t=1}^{T} R X_{t} R X_{t}^{\prime}$, and $g_{T}\left(z_{t}, \theta\right) \equiv T^{-1} \sum_{t=1}^{T}\left[M_{t}\left(z_{t}, \theta\right) R X_{t}-I_{N}\right]$. The $H J$ calculation is essentially a GMM application with the (non-optimal) weighting matrix equal to the inverse of the second moment matrix of asset returns; setting $W_{T}=G_{T}^{-1}$ is important because this weighting matrix does not depend on the model parameters $\theta$, and hence the $H J$ distance metric is comparable across different candidate SDF specifications (see Hansen and Jagannathan, 1997; Ludvigson, 2013). To test whether the $H J$ distance is statistically significant, we simulate $p$-values using a weighted sum of $\chi_{1}^{2}$ distributed random variables (see, Jagannathan and Wang, 1996; Ren and Shimotsu, 2009).

\section{Details of a model for the GAP premium}

In what follows, we provide the derivations for the model presented in the main text. For compactness, we will denote $\theta=\frac{1}{1-\gamma}$.

Lemma 1 (Equilibrium Utility). The equilibrium utility takes the form:

$$
U_{i, t}=\log C_{i, t}+A_{i}+B \cdot z_{i, t}+D_{i} \cdot \sigma_{i, t},
$$

where

$$
\begin{aligned}
A_{i} & =\frac{\delta}{1-\delta}\left[\mu_{c}+\left(1-\rho_{\sigma}\right) D_{i} \bar{\sigma}+\frac{1}{2 \theta}\left(B \varphi_{z} \sqrt{\bar{\sigma}}+D_{i} \sqrt{\sigma_{\sigma}}\right)^{2}+\frac{\alpha^{2}}{2 \theta} D_{i}^{2} \sigma_{\sigma}\right] \\
B & =\frac{\delta}{1-\delta \rho_{z}}, \quad D_{i}=\frac{\delta}{2 \theta\left(1-\delta \rho_{\sigma}\right)} .
\end{aligned}
$$


Proof. We shall solve for $V_{i, t}=U_{i, t}-\log C_{i, t}$ :

$$
\begin{aligned}
V_{i, t} & =\delta \theta \log E_{t} \exp \left\{\frac{U_{i, t+1}-\log C_{i, t+1}+\Delta c_{i, t+1}}{\theta}\right\} \\
& =\delta \theta \log E_{t} \exp \left\{\frac{V_{i, t+1}+\mu_{c}+z_{i, t}+\sqrt{\sigma_{i, t}} \varepsilon_{i, t+1}^{c}}{\theta}\right\} .
\end{aligned}
$$

Guess that the solution is of the type:

$$
V_{i, t}=A_{i}+B_{i} z_{i, t}+D_{i} \sigma_{i, t}
$$

For compactness, we are going to suppress all the subscript $i$ in the remainder of these derivations. Then:

$$
\begin{aligned}
V_{t}= & \delta \theta \log E_{t} \exp \left\{\frac{A+B z_{t}+D \sigma_{t+1}+\mu_{c}+z_{t}+\sqrt{\sigma_{t}} \varepsilon_{t+1}^{c}}{\theta}\right\} \\
= & \delta A+\delta \mu_{c}+\delta z_{t}+\frac{\delta}{2 \theta} \sigma_{t}+\delta \theta \log E_{t} \exp \left\{\frac{B}{\theta}\left(\rho_{z} z_{t}+\phi_{z} \sqrt{\sigma} \varepsilon_{t+1}^{z}\right)+\right. \\
& +\frac{D}{\theta}\left[\left(1-\rho_{\sigma} \bar{\sigma}+\rho_{\sigma} \sigma_{t}+\sqrt{\sigma_{\sigma}}\left(\varepsilon_{t+1}^{z}+\alpha \varepsilon_{t+1}^{\nu}\right)\right]\right\} \\
= & \delta\left[A+\mu_{c}+\left(1-\rho_{\sigma}(D \bar{\sigma})\right]+\delta\left(1+B \rho_{z}\right) z_{t}+\delta\left[\frac{1}{2 \theta}+\rho_{\sigma} D\right] \sigma_{t}+\right. \\
& +\delta \theta \log E_{t} \exp \left\{\frac{1}{\theta}\left[B \phi_{z} \sqrt{\bar{\sigma}}+D \sqrt{\sigma_{\sigma}}\right] \varepsilon_{t+1}^{z}+\frac{\alpha}{\theta}\left(D \sqrt{\sigma_{\sigma}}\right) \varepsilon_{t+1}^{\nu}\right\} \\
= & \delta\left[A+\mu_{c}+\left(1-\rho_{\sigma}(D \bar{\sigma})+\frac{1}{2 \theta}\left(B \phi_{z} \sqrt{\bar{\sigma}}+D \sqrt{\sigma_{\sigma}}\right)^{2}+\frac{\alpha^{2}}{2 \theta} D^{2} \sigma_{\sigma}\right]+\right. \\
& +\delta\left(1+B \rho_{z}\right) z_{t}+\delta\left(\frac{1}{2 \theta}+\rho_{\sigma} D\right) \sigma_{t} .
\end{aligned}
$$

Matching coefficients concludes the proof.

Lemma 2 (Equilibrium SDFs). The equilibrium of the logarithm of the SDF in each country is

$$
m_{i, t+1}=\log \delta-\Delta c_{i, t+1}+\frac{\tilde{V}_{i, t+1}}{\theta}-\frac{1}{\theta} E_{t} \tilde{V}_{i, t+1}-\frac{1}{2 \theta^{2}} \operatorname{Var}_{t} \tilde{V}_{i, t+1}
$$

where $\tilde{V}_{i, t}=V_{t}+\Delta c_{i, t}$.

Proof. The log-SDF in each country is

$$
\begin{aligned}
m_{t+1} & =\log \delta-\Delta c_{t+1}+\frac{1}{\theta} U_{t+1}-\log E_{t} \exp \left\{\frac{U_{t+1}}{\theta}\right\} \\
& =\log \delta-\Delta c_{t+1}+\frac{U_{t+1}-\log C_{t}}{\theta}-\log E_{t} \exp \left\{\frac{U_{t+1-\log C_{t+1}+\log C_{t+1}-\log C_{t}}}{\theta}\right\} \\
& =\log \delta-\Delta c_{t+1}+\frac{V_{t+1+\Delta c_{t+1}}}{\theta}-\log E_{t} \exp \left\{\frac{V_{t+1}+\Delta c_{t+1}}{\theta}\right\}
\end{aligned}
$$


Using the definition of $\tilde{V}_{i, t}$ and noting that $\tilde{V}_{i, t}$ is conditionally normally distributed conclude the proof.

Lemma 3 (Risk-free rates). In each country, the logarithm of the risk-free rate is equal to

$$
r_{i, t}=\mu_{c}-\log \delta-\left(\gamma-\frac{1}{2}\right)\left(\bar{\sigma}+\tilde{\sigma}_{i, t}\right)
$$

where $\tilde{\sigma}_{i, t}=\rho_{\sigma} \tilde{\sigma}_{i, t-1}+\alpha \rho_{\sigma} \sqrt{\sigma_{\sigma}} \varepsilon_{t}^{\nu}$.

Proof. By definition, the log-risk-free rate in each country is equal to

$$
r_{i, t}=-\log E_{t} \exp \left\{m_{i, t+1}\right\} .
$$

Using the equilibrium SDF and dropping the subscripts $i$ to simplify notation, we get

$$
\begin{aligned}
r_{t} & =-\log E_{t} \exp \left\{\log \delta-\Delta c_{t+1}+\frac{\tilde{V}_{i, t+1}}{\theta}-\frac{1}{\theta} E_{t} \tilde{V}_{i, t+1}-\frac{1}{2 \theta^{2}} \operatorname{Var}_{t} \tilde{V}_{i, t+1}\right\} \\
& =-\log \delta+E_{t} \Delta c_{t+1}-\frac{1}{2} \operatorname{Var}_{t} \Delta c_{t+1}+\frac{1}{\theta} \operatorname{cov}_{t}\left[\Delta c_{t+1}, \tilde{V}_{i, t+1}\right] \\
& =-\log \delta+\mu_{c}+z_{t}-\frac{1}{2} \sigma_{t}+\frac{1}{\theta} \sigma_{t} \\
& =-\left(\log \delta-\mu_{c}\right)+z_{t}-\left(\frac{1}{2}-\frac{1}{\theta}\right) \sigma_{t} .
\end{aligned}
$$

Lemma 4 (Currency excess return). Let $\gamma>1$ and take currency of country $k$ as the base currency. The excess return of currency $i \in\{1,2, \ldots, N\}$ over the base currency is

$$
\begin{aligned}
\log E_{t}\left[R X_{t+1}^{i}\right] & =\operatorname{Var}_{t}\left[m_{t+1}^{k}\right]-\operatorname{cov}_{t}\left[m_{t+1}^{k}, m_{t+1}^{i}\right] \\
& =\frac{\delta^{2} \alpha^{2}(1-\gamma)^{4}}{4\left(1-\delta \rho_{\sigma}\right)^{2}} \sigma_{\sigma}+\gamma^{2} \sigma_{t}^{k}+\kappa\left(1-\rho_{i k, t}^{z}\right),
\end{aligned}
$$

where the coefficient of proportionality $\kappa$ is equal to

$$
\kappa=\delta\left[\frac{\rho_{z} \sqrt{\bar{\sigma}}}{1-\delta \rho_{z}}+\frac{1}{2} \frac{(1-\gamma) \sqrt{\sigma_{\sigma}}}{1-\delta \rho_{\sigma}}\right]^{2}>0 .
$$

Proof. We shall start by computing the conditional variance and covariance needed for the conditional currency risk premium. Based on the equilibrium SDF, it is easy to show that

$$
m_{t+1}-E_{t}\left[m_{t+1}\right]=-\left(1-\frac{1}{\theta}\right) \sqrt{\sigma_{t}} \varepsilon_{t+1}^{c}+\frac{1}{\theta}\left[B \varphi_{z} \sqrt{\bar{\sigma}}+D \sqrt{\sigma_{\sigma}}\right] \varepsilon_{t+1}^{z}+\frac{D}{\theta} \sqrt{\sigma_{\sigma}}\left(\alpha \varepsilon_{t+1}^{\nu}\right),
$$


where we dropped the country subscript $i$ to simplify notation. It follows that the conditional variance of the $\mathrm{SDF}$ is equal to:

$$
V_{t}\left[m_{t+1}\right]=\left(1-\frac{1}{\theta}\right)^{2} \sigma_{t}+\frac{1}{\theta^{2}}\left[B \varphi_{z} \sqrt{\bar{\sigma}}+D \sqrt{\sigma_{\sigma}}\right]^{2}+\frac{D^{2} \alpha^{2}}{\theta^{2}} \sigma_{\sigma}
$$

while the conditional covariance is:

$$
\operatorname{cov}_{t}\left[m_{i, t+1}, m_{j, t+1}\right]=\left(1-\frac{1}{\theta}\right)^{2} \sqrt{\sigma_{i, t}} \sqrt{\sigma_{j, t}} \rho_{c}+\frac{1}{\theta^{2}}\left[B \varphi_{z} \sqrt{\bar{\sigma}}+D \sqrt{\sigma_{\sigma}}\right]^{2} \rho_{i j, t}^{z} .
$$

Combining (27) and (28) into the formula for the currency excess return in (26) and using the expressions for $B, D$, and $\theta$ concludes the proof.

Proof of Proposition 1 in main text. The proof follows directly by taking the difference of the currency risk premiums in Lemma 4 for countries $i$ and $j$ and by using the assumed process for the conditional correlation of shocks in Equation (16) of the main text.

\section{Relationship between predictive component and output gap in the model}

Consider the following data generating process:

$$
\begin{aligned}
y_{t} & =\rho_{y} y_{t-1}+x_{t-1}+\sigma_{y} \varepsilon_{y, t}, \\
x_{t} & =\rho_{x} x_{t-1}+\sigma_{x} \varepsilon_{x, t}
\end{aligned}
$$

where all shocks are i.i.d. distributed as standard normals and $\varepsilon_{y, t} \perp \varepsilon_{x, t}$. In what follows, we will consider the limit for $\rho_{y} \rightarrow 1$, in which case the long-run risk $x_{t-1}$ is the conditional expectation of $\Delta y_{t}$. Additionally, we will assume stationarity of the $x_{t}$ process, i.e. the assumption of $\rho_{x}<1$ is retained throughout the derivations. This data generating process maps directly into the one used in the model when $y_{t}=\log C_{i, t}$ and $x_{t}=z_{i, t}$ and where, for simplicity, we set the unconditional growth rate of consumption to zero and abstract away from time-varying volatility.

Consider the following regression:

$$
y_{t}=\sum_{j=0}^{l} \beta_{j} \cdot y_{t-k-l}+\xi_{t} .
$$

which we use in the empirical analysis to estimate the output gap. We want to sign and quantify the magnitude of the correlation between:

1. the fitted residual, $\widehat{\xi}_{t}$ (our measure of the output gap)

2. the conditional expectation of $\Delta y_{t}$, i.e. $x_{t-1}$ (the long-run risk). 
In what follows, we shall consider both the univariate case $(l=0$ in equation $(30))$ and the multivariate case $(l>0$ in equation (30)).

Univariate case. In the univariate case of regression (30), i.e. $l=0$, we can characterize the correlation in closed form. The following lemma contains the analytical expression for several moments that are useful to characterize the regression coefficients in equation (30).

Lemma 5. The following unconditional moments can be obtained from the system of equations (29):

$$
\begin{aligned}
E\left[x_{t}^{2}\right] & =\frac{\sigma_{x}^{2}}{1-\rho_{x}^{2}}, \\
E\left[x_{t} y_{t}\right] & =\frac{\rho_{x} \sigma_{x}^{2}}{\left(1-\rho_{x} \rho_{y}\right)\left(1-\rho_{x}^{2}\right)}, \\
E\left[y_{t}^{2}\right] & =\frac{\sigma_{y}^{2}}{1-\rho_{y}^{2}}+\frac{\left(1+\rho_{x} \rho_{y}\right) \sigma_{x}^{2}}{\left(1-\rho_{x} \rho_{y}\right)\left(1-\rho_{x}^{2}\right)\left(1-\rho_{y}^{2}\right)} \\
E\left[y_{t} y_{t-k}\right] & =\rho_{y}^{k} E\left[y_{t}^{2}\right]+\left(\sum_{i=0}^{k-1} \rho_{x}^{i} \rho_{y}^{(k-1)-i}\right) E\left[x_{t} y_{t}\right] .
\end{aligned}
$$

Proof. The proof of equation (31) is trivial and will be omitted in the interest of space. For equation (32), we note that:

$$
\begin{aligned}
E\left[x_{t} y_{t}\right]= & E\left[\left(\rho_{x} x_{t-1}+\sigma_{x} \varepsilon_{x, t}\right)\left(\rho_{y} y_{t-1}+x_{t-1}+\sigma_{y} \varepsilon_{y, t}\right)\right] \\
= & \rho_{y} \sigma_{x} E\left[y_{t-1} \varepsilon_{x, t}\right]+\rho_{x} \rho_{y} E\left[x_{t-1} y_{t-1}\right]+\rho_{x} E\left[x_{t-1}^{2}\right] \\
& +\sigma_{x} E\left[x_{t-1} \varepsilon_{x, t}\right]+\rho_{x} \sigma_{y} E\left[x_{t-1} \varepsilon_{y, t}\right]+\sigma_{x} \sigma_{y} E\left[\varepsilon_{x, t} \varepsilon_{y, t}\right] .
\end{aligned}
$$

Equation (32) follows immediately by noticing that $E\left[y_{t-1} \varepsilon_{x, t}\right]=0, E\left[x_{t-1} \varepsilon_{x, t}\right]=0, E\left[x_{t-1} \varepsilon_{y, t}\right]=$ $0, E\left[\varepsilon_{x, t} \varepsilon_{y, t}\right]=0$, and $E\left[x_{t} y_{t}\right]=E\left[x_{t-1} y_{t-1}\right]$. Equation (33) is obtained from

$$
\begin{aligned}
E\left[y_{t}^{2}\right] & =E\left[\left(\rho_{y} y_{t-1}+x_{t-1}+\sigma_{y} \varepsilon_{y, t}\right)^{2}\right] \\
& =\rho_{y}^{2} \underbrace{E\left[y_{t-1}^{2}\right]}_{E\left[y_{t}^{2}\right]}+\underbrace{E\left[x_{t-1}^{2}\right]}_{E\left[x_{t}^{2}\right]}+\sigma_{y}^{2} \underbrace{E\left[\varepsilon_{y, t}^{2}\right]}_{1}+2 \rho_{y} \underbrace{E\left[x_{t-1} y_{t-1}\right]}_{E\left[x_{t} y_{t}\right]}+2 \sigma_{y} \underbrace{E\left[x_{t-1} \varepsilon_{y, t}\right]}_{0}+2 \rho_{y} \sigma_{y} \underbrace{E\left[y_{t-1} \varepsilon_{y, t}\right]}_{0},
\end{aligned}
$$

after using equations (31)-(32). In order to obtain equation (34), we first note that the autocovariance of $y_{t}$ can be written recursively:

$$
\begin{aligned}
E\left[y_{t} y_{t-1}\right] & =E\left[\left(\rho_{y} y_{t-1}+x_{t-1}+\sigma_{y} \varepsilon_{y, t}\right) y_{t-1}\right] \\
& =\rho_{y} \underbrace{E\left[y_{t-1}^{2}\right]}_{\text {eq. (33) }}+\underbrace{E\left[x_{t-1} y_{t-1}\right]}_{\text {eq. }(32)}+\sigma_{y} \underbrace{E\left[y_{t-1} \varepsilon_{y, t}\right]}_{0}=\rho_{y} E\left[y_{t}^{2}\right]+E\left[x_{t} y_{t}\right], \\
E\left[y_{t} y_{t-2}\right] & =E\left[\left(\rho_{y} y_{t-1}+x_{t-1}+\sigma_{y} \varepsilon_{y, t}\right) y_{t-2}\right] \\
& =\rho_{y} \underbrace{E\left[y_{t-1} y_{t-2}\right]}_{E\left[y_{t} y_{t-1}\right]}+E\left[x_{t-1} y_{t-2}\right]=\rho_{y} E\left[y_{t} y_{t-1}\right]+E\left[\left(\rho_{x} x_{t-2}+\sigma_{x} \varepsilon_{x, t-1}\right) y_{t-2}\right] \\
& =\rho_{y} E\left[y_{t} y_{t-1}\right]+\rho_{x} E\left[x_{t-2} y_{t-2}\right]=\rho_{y} E\left[y_{t} y_{t-1}\right]+\rho_{x} E\left[x_{t} y_{t}\right],
\end{aligned}
$$




$$
\begin{aligned}
E\left[y_{t} y_{t-3}\right] & =\rho_{y} E\left[y_{t} y_{t-2}\right]+\rho_{x}^{2} E\left[x_{t} y_{t}\right] \\
\cdots & \\
E\left[y_{t} y_{t-k}\right] & =\rho_{y} E\left[y_{t} y_{t-k+1}\right]+\rho_{x}^{(k-1)} E\left[x_{t} y_{t}\right] .
\end{aligned}
$$

Equation (34) obtains by recursive substitution of each lag $k-1$ autocovariance into each lag $k$ autocovariance.

The following proposition summarizes the main finding.

Proposition 2. Let $l=0$ in equation (30). When $\rho_{y} \rightarrow 1$ :

1. the estimated regression coefficient is $\widehat{\beta}_{0}=1$,

2. the covariance between $\widehat{\xi}_{t}$ and $x_{t-1}$ is positive and equal to

$$
\operatorname{cov}\left(\widehat{\xi}_{t}, x_{t-1}\right)=\frac{\left(1-\rho_{x}^{k}\right)}{\left(1-\rho_{x}\right)} \frac{\sigma_{x}^{2}}{1-\rho_{x}^{2}}>0
$$

3. the correlation between $\widehat{\xi}_{t}$ and $x_{t-1}$ is

$$
\operatorname{corr}\left(\widehat{\xi}_{t}, x_{t-1}\right)=\frac{\left(1-\rho_{x}^{k}\right) /\left(1-\rho_{x}\right)}{\sqrt{\left(1-\rho_{x}^{2}\right)\left[\frac{\sigma_{y}^{2}}{\sigma_{y}^{2}} k+\frac{k}{\left(1-\rho_{x}\right)^{2}}-2 \rho_{x} \frac{1-\rho_{x}^{k}}{1-\rho_{x}^{2}}\right]}} .
$$

Proof. The proof consists of three parts.

1. We show that $\lim _{\rho_{y} \rightarrow 1} \widehat{\beta}_{0}=1$. Note that:

$$
\lim _{\rho_{y} \rightarrow 1} \widehat{\beta}_{0}=\lim _{\rho_{y} \rightarrow 1} \frac{E\left[y_{t} y_{t-k}\right]}{E\left[y_{t}^{2}\right]} .
$$

Using the moments obtained in equations (33) and (34) of lemma 5, we can rewrite this as

$$
\lim _{\rho_{y} \rightarrow 1} \frac{E\left[y_{t} y_{t-k}\right]}{E\left[y_{t}^{2}\right]}=\lim _{\rho_{y} \rightarrow 1} \frac{\rho_{y}^{k} E\left[y_{t}^{2}\right]+\left(\sum_{i=0}^{k-1} \rho_{x}^{i} \rho_{y}^{(k-1)-i}\right) E\left[x_{t} y_{t}\right]}{E\left[y_{t}^{2}\right]}=1
$$

where the last equality follows from the fact that $E\left[x_{t} y_{t}\right]$ in equation (32) of lemma 2 converges to a finite number. 
2. We show that $\operatorname{cov}\left(\widehat{\xi}_{t}, x_{t-1}\right)=\frac{\left(1-\rho_{x}^{k}\right)}{\left(1-\rho_{x}\right)} \frac{\sigma_{x}^{2}}{1-\rho_{x}^{2}}>0$. Since $\widehat{\beta}_{0}=1$, the residual of regression $(30)$ is equal to

$$
\begin{aligned}
\widehat{\xi}_{t} & =y_{t}-y_{t-k}=\sum_{j=0}^{k-1} x_{t-1-j}+\sigma_{y} \sum_{j=0}^{k-1} \varepsilon_{y, t-j} \\
& =\left(\sum_{j=0}^{k-1} \rho_{x}^{j}\right) x_{t-k}+\sigma_{x}\left[\sum_{j=0}^{k-2}\left(\sum_{i=0}^{k} \rho_{x}^{i}\right) \varepsilon_{x, t-1-j}\right]+\sigma_{y} \sum_{j=0}^{k-1} \varepsilon_{y, t-j} \\
& =\left(\frac{1-\rho_{x}^{k}}{1-\rho_{x}}\right) x_{t-k}+\sigma_{x}\left[\sum_{j=0}^{k-2}\left(\frac{1-\rho_{x}^{j+1}}{1-\rho_{x}}\right) \varepsilon_{x, t-1-j}\right]+\sigma_{y} \sum_{j=0}^{k-1} \varepsilon_{y, t-j} .
\end{aligned}
$$

Using the autoregressive structure of $x_{t}$, it is possible to show that

$$
x_{t-1}=\rho_{x}^{k-1} x_{t-k}+\sigma_{x} \sum_{j=0}^{k-2} \rho_{x}^{j} \varepsilon_{x, t-1-j} .
$$

We can now compute the covariance between the estimated output gap and the conditional expectation of $y_{t}$ :

$$
\begin{aligned}
\operatorname{cov}\left(\widehat{\xi}_{t}, x_{t-1}\right) & =\rho_{x}^{k-1}\left(\frac{1-\rho_{x}^{k}}{1-\rho_{x}}\right) \frac{\sigma_{x}^{2}}{1-\rho_{x}^{2}}+\sigma_{x}^{2} \sum_{j=0}^{k-2} \frac{\rho_{x}^{j}-\rho_{x}^{2 j+1}}{1-\rho_{x}} \\
& =\rho_{x}^{k-1}\left(\frac{1-\rho_{x}^{k}}{1-\rho_{x}}\right) \frac{\sigma_{x}^{2}}{1-\rho_{x}^{2}}+\frac{\sigma_{x}^{2}}{1-\rho_{x}} \sum_{j=0}^{k-2} \rho_{x}^{j}-\frac{\sigma_{x}^{2}}{1-\rho_{x}} \sum_{j=0}^{k-2} \rho_{x}^{2 j+1} \\
& =\rho_{x}^{k-1}\left(\frac{1-\rho_{x}^{k}}{1-\rho_{x}}\right) \frac{\sigma_{x}^{2}}{1-\rho_{x}^{2}}+\frac{\sigma_{x}^{2}}{1-\rho_{x}} \frac{1-\rho_{x}^{k-1}}{1-\rho_{x}}-\sigma_{x}^{2} \frac{\rho_{x}}{1-\rho_{x}} \frac{1-\rho_{x}^{2 k-2}}{1-\rho_{x}^{2}} \\
& =\frac{\sigma_{x}^{2}}{1-\rho_{x}^{2}}\left[\rho_{x}^{k-1}\left(\frac{1-\rho_{x}^{k}}{1-\rho_{x}}\right)+\frac{\left(1-\rho_{x}^{k-1}\right)\left(1-\rho_{x}^{2}\right)}{\left(1-\rho_{x}\right)^{2}}-\frac{\rho_{x}\left(1-\rho_{x}^{2 k-2}\right)}{1-\rho_{x}}\right] \\
& =\frac{\sigma_{x}^{2}}{1-\rho_{x}^{2}}\left[\frac{\left.\rho_{x}^{k-1}-\rho_{x}^{2 k-1}-\rho_{x}+\rho_{x}^{2 k-1}+\frac{1-\rho_{x}^{k-1}+\rho_{x}-\rho_{x}^{k}}{1-\rho_{x}}\right]}{1-\rho_{x}}\right. \\
& =\frac{\sigma_{x}^{2}}{1-\rho_{x}^{2}}\left[\frac{1-\rho_{x}^{k}}{1-\rho_{x}}\right] .
\end{aligned}
$$

As long as $\rho_{x}<1$, this covariance is positive.

3. We show that $\operatorname{corr}\left(\widehat{\xi}_{t}, x_{t-1}\right)=\frac{\left(1-\rho_{x}^{k}\right) /\left(1-\rho_{x}\right)}{\sqrt{\left(1-\rho_{x}^{2}\right)\left[\frac{\sigma_{y}^{2}}{\sigma_{y}^{2}} k+\frac{k}{\left(1-\rho_{x}\right)^{2}}-2 \rho_{x} \frac{1-\rho_{x}^{k}}{1-\rho_{x}^{2}}\right.}}$. Since we have already computed the covariance between output gap and long-run risk in the previous step of this proof and the variance of $x_{t}$ in lemma 5 , we shall focus on the variance of $\widehat{\xi}_{t}$ to obtain the expression for the correlation:

$$
V\left(\widehat{\xi}_{t}\right)=\left(\frac{1-\rho_{x}^{k}}{1-\rho_{x}}\right)^{2} V\left(x_{t}\right)+\sigma_{x}^{2} \sum_{j}^{k-2}\left(\frac{1-\rho_{x}^{j+1}}{1-\rho_{x}}\right)^{2}+k \sigma_{y}^{2}
$$


Focus on the middle term of the above equation:

$$
\begin{aligned}
\sigma_{x}^{2} \sum_{j}^{k-2}\left(\frac{1-\rho_{x}^{j+1}}{1-\rho_{x}}\right)^{2} & =\frac{\sigma_{x}^{2}}{\left(1-\rho_{x}\right)^{2}} \sum_{j=0}^{k-2}\left(1+\rho_{x}^{2 j+2}-2 \rho_{x}^{j+1}\right) \\
& =\frac{\sigma_{x}^{2}}{\left(1-\rho_{x}\right)^{2}}\left[(k-1)+\rho_{x}^{2} \sum_{j=0}^{k-2}\left(\rho_{x}^{2}\right)^{j}-2 \rho_{x} \sum_{j=0}^{k-2} \rho_{x}^{j}\right] \\
& =\frac{\sigma_{x}^{2}}{\left(1-\rho_{x}\right)^{2}}\left[(k-1)+\rho_{x}^{2} \frac{1-\left(\rho_{x}^{2}\right)^{k-1}}{1-\rho_{x}^{2}}-2 \rho_{x} \frac{1-\rho_{x}^{k-1}}{1-\rho_{x}}\right] \\
& =\frac{\sigma_{x}^{2}\left[(k-1)\left(1-\rho_{x}^{2}\right)+\rho_{x}^{2}-\rho_{x}^{2 k}-\left(2 \rho_{x}-2 \rho_{x}^{k}\right)\left(1+\rho_{x}\right)\right]}{\left(1-\rho_{x}\right)^{2}\left(1-\rho_{x}^{2}\right)} \\
& =\frac{\sigma_{x}^{2}\left[k\left(1-\rho_{x}^{2}\right)-1-\rho_{x}^{2 k}-2 \rho_{x}+2 \rho_{x}^{k}+2 \rho_{x}^{k+1}\right]}{\left(1-\rho_{x}\right)^{2}\left(1-\rho_{x}^{2}\right)} .
\end{aligned}
$$

By plugging (36) inside (35), we get:

$$
\begin{aligned}
V\left(\widehat{\xi}_{t}\right) & =\frac{\left(1+\rho_{x}^{2 k}-2 \rho_{x}^{k}\right) \sigma_{x}^{2}}{\left(1-\rho_{x}\right)^{2}\left(1-\rho_{x}^{2}\right)}+\frac{\sigma_{x}^{2}\left[k\left(1-\rho_{x}^{2}\right)-1-\rho_{x}^{2 k}-2 \rho_{x}+2 \rho_{x}^{k}+2 \rho_{x}^{k+1}\right]}{\left(1-\rho_{x}\right)^{2}\left(1-\rho_{x}^{2}\right)}+k \sigma_{y}^{2} \\
& =\frac{\sigma_{x}^{2}}{\left(1-\rho_{x}\right)^{2}\left(1-\rho_{x}^{2}\right)}\left[k\left(1-\rho_{x}^{2}\right)-2 \rho_{x}\left(1-\rho_{x}^{k}\right)\right]+k \sigma_{y}^{2} .
\end{aligned}
$$

Using the definition of correlation concludes the proof.

The explanation for why the covariance (and thus correlation) is positive is straightforward. Consider the case in which $k=1$. If this is the case, then $\widehat{\xi}_{t}=x_{t-1}+\sigma_{y} \varepsilon_{t}^{y}$, which is clearly positively correlated with $x_{t-1}$.

To get an assessment of how large this positive correlation is, we set the model's parameters to $\rho_{x}=0.98, \sigma_{y}=0.02 / \sqrt{12}$, and $\sigma_{x}=0.1 \sigma_{y}$. This choice of parameters results in an annual volatility of $\Delta y_{t}$ of about $2 \%$ and in a moderate autocorrelation of $\Delta y_{t}$. The figure below shows that the correlation can be as high as $0.7-0.8$, for values of $k$ in the range of $24-36$, which correspond to the lags that we use in the empirical investigation.

Multivariate case. In the multivariate case $(l>0$ in regression (30)) we lose analytical tractability. To quantify the correlation between the estimated output gap and the long-run risk, we conduct a simulation exercise. We set the parameters of the model in the system of equations (29) to $\rho_{y}=1, \rho_{x}=0.98, \sigma_{y}=0.02 / \sqrt{12}$, and $\sigma_{x}=0.1 \sigma_{y}$ and simulate $T=25000$ observations. We then estimate regression (30) for various combinations of $k$ and $l$, obtain the fitted residual $\hat{\xi}_{t}$, and compute its correlation with $x_{t-1}$.

The results are reported in Panel A of the table below. The correlation between estimated output gap and long-run risk is positive in all cases and it can be as high as 0.77. For the 


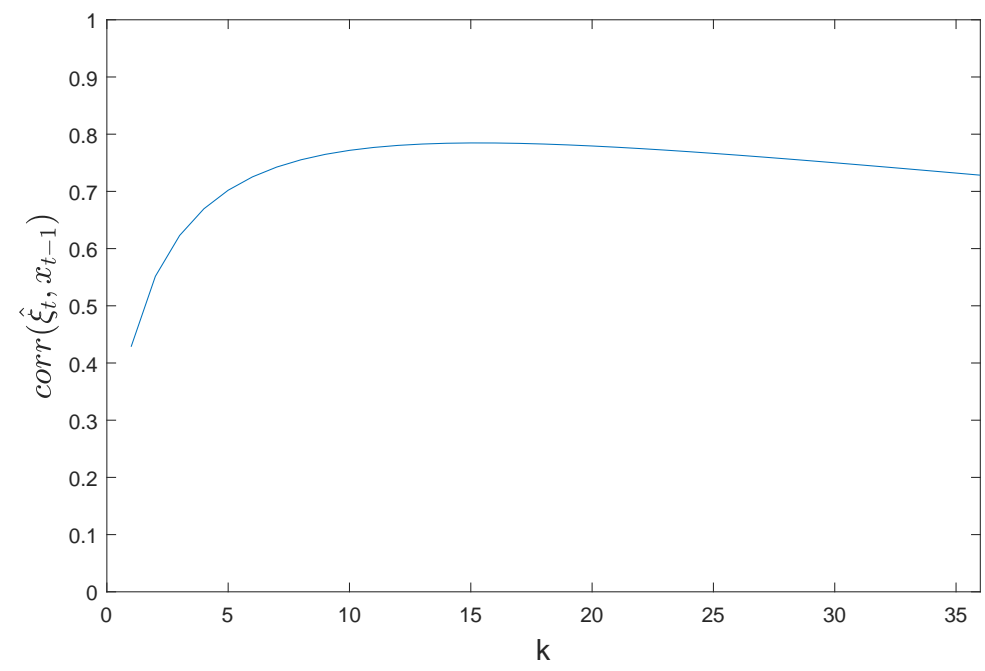

Correlation between output gap and long-run risk (univariate case). The correlation is displayed for values of $k$ ranging from 1 to 36 and $l=0$. The parameters of the data generating process are set to $\rho_{y}=1, \rho_{x}=0.98, \sigma_{y}=0.02 / \sqrt{12}$, and $\sigma_{x}=0.1 \sigma_{y}$.

specification that we consider in the main empirical exercise in the paper, $k=24$ and $l=11$, the correlation is 0.62 .

Non-integrated case. We also consider the case in which the autocorrelation of $y_{t}$ does not converge to 1 . We replicate the same simulation exercises described for the multivariate setup and vary the autocorrelation coefficient $\rho_{y}$ between 0.9 and 1 . When we run the regressions to estimate the output gap, we set the parameter $k$ to 24 and vary the parameter $l$ that governs the number of lags in the regression between 0 and 11 . The results are tabulated in Panel $\mathrm{B}$ of the table below and show that the correlation between output gap and long-run risk is still positive and large.

\begin{tabular}{lcccccccccccc}
\hline \hline & \multicolumn{10}{c}{ Panel A: Output gap and long-run risk correlation } & (multivariate case) \\
\cline { 2 - 13 } & 0 & 1 & 2 & 3 & 4 & 5 & 6 & 7 & 8 & 9 & 10 & 11 \\
\hline $\mathrm{k}=1$ & 0.42 & 0.35 & 0.31 & 0.27 & 0.25 & 0.23 & 0.22 & 0.21 & 0.20 & 0.19 & 0.19 & 0.18 \\
$\mathrm{k}=12$ & 0.77 & 0.71 & 0.66 & 0.62 & 0.60 & 0.58 & 0.56 & 0.55 & 0.54 & 0.53 & 0.53 & 0.52 \\
$\mathrm{k}=24$ & 0.77 & 0.72 & 0.70 & 0.68 & 0.66 & 0.65 & 0.64 & 0.63 & 0.63 & 0.62 & 0.62 & 0.62 \\
$\mathrm{k}=36$ & 0.72 & 0.70 & 0.68 & 0.67 & 0.67 & 0.66 & 0.66 & 0.65 & 0.65 & 0.65 & 0.65 & 0.65 \\
\multicolumn{10}{c}{ Panel B: Output gap and long-run risk correlation (non-integrated case) } \\
\hline$\rho_{y}=1.00$ & 0.77 & 0.72 & 0.70 & 0.68 & 0.66 & 0.65 & 0.64 & 0.63 & 0.63 & 0.62 & 0.62 & 0.62 \\
$\rho_{y}=0.95$ & 0.67 & 0.66 & 0.66 & 0.66 & 0.66 & 0.66 & 0.66 & 0.66 & 0.65 & 0.65 & 0.65 & 0.65 \\
$\rho_{y}=0.90$ & 0.66 & 0.66 & 0.66 & 0.66 & 0.66 & 0.66 & 0.66 & 0.66 & 0.66 & 0.66 & 0.66 & 0.66 \\
\hline \hline
\end{tabular}

Notes: The parameters of the data generating process are set to $\rho_{x}=0.98, \sigma_{y}=0.02 / \sqrt{12}$, and $\sigma_{x}=$ $0.1 \sigma_{y}$. In Panel $\mathrm{A}$, we set $\rho_{y}=1$, and in Panel $\mathrm{B}$, the regression parameter $k$ is set to 24 . 


\section{Further Empirical Evidence}

In this section we provide further empirical evidence on the validity of the model's assumptions. An assumption of the model is that shocks to country $i$ 's conditional variance are positively correlated with shocks to country $i$ 's output gap $\left(\rho_{i, t}^{z, \sigma}>0\right)$. Related to this assumption, if the correlation is positive but imperfect (i.e. $\alpha \neq 0$ ), then sorting currencies by interest rates is different to sorting currencies by output gaps. We explore this assumption empirically. To do so, we extract the conditional variance of industrial production growth using a $\operatorname{GARCH}(1,1)$ model and proxy for the shocks to conditional variances and output gaps using the residuals from $\operatorname{AR}(1)$ models fitted to the series. We test the sign and magnitude of the relationship by estimating a pooled OLS regression of conditional variance shocks on output gap shocks (including country-level dummy variables). We find the estimated coefficient is positive and highly statistically significant $(\beta=0.25, p$-value $=0.00)$ but we can strongly reject the hypothesis that the coefficient equals unity $(p$-value $=0.00)$.

A necessary condition for the output gap premia to be positive is linked to the behaviour of the time-varying correlation between output gap shocks in countries $i$ and $j$. The condition requires that the correlation falls as the output gap in country $i$ rises (here country $j$ refers to the base currency, i.e. the US in our empirical setup). We test the condition empirically by forming output gap shocks as the residuals from $\mathrm{AR}(1)$ models and construct dynamic conditional correlations using a DCC $(1,1)$ model. We estimate the relationship between these conditional correlations and the model implied transformation of output gaps $\left(1+\exp \left\{z_{i, t}\right\}\right)^{-1}$, via a pooled OLS regression (with country-level dummy variables). The condition is supported if the slope coefficient is positive. We estimate the coefficient to equal 0.32 , with associated $p$-value $=0.01$, and thus we find clear empirical support for the condition. 
Table A1: Foreign Exchange Rate Data

\begin{tabular}{|c|c|c|c|c|c|c|c|}
\hline \multicolumn{8}{|c|}{ DataStream Codes } \\
\hline Country & Code & Currency & Spot & 1M Forward & Source & Start Date & End Date \\
\hline Austria & ATS & schilling & AUSTSC\$ & USATS1F & Reuters & $31 / 12 / 1996$ & $31 / 12 / 1998$ \\
\hline Australia & AUD & dollar & BBAUDSP & BBAUD1F & Barclays & $31 / 12 / 1984$ & $31 / 01 / 2016$ \\
\hline Belgium & $\mathrm{BEF}$ & franc & BELGLU\$ & USBEF1F & Reuters & $31 / 12 / 1996$ & $31 / 12 / 1998$ \\
\hline Brazil & BRL & real & BRACRU\$ & USBRL1F & Reuters & $31 / 03 / 2004$ & $31 / 01 / 2016$ \\
\hline Canada & $\mathrm{CAD}$ & dollar & BBCADSP & BBCAD1F & Barclays & $31 / 12 / 1984$ & $31 / 01 / 2016$ \\
\hline Switzerland & $\mathrm{CHF}$ & franc & BBCHFSP & BBCHF1F & Barclays & $31 / 10 / 1983$ & $31 / 01 / 2016$ \\
\hline Chile & CLP & peso & CHILPE $\$$ & USCLP1F & Reuters & $31 / 03 / 2004$ & $31 / 01 / 2016$ \\
\hline Czech Republic & $\mathrm{CZK}$ & koruna & TDCZKSP & TDCZK1M & Reuters & $31 / 12 / 1996$ & $31 / 01 / 2016$ \\
\hline Germany* & DEM & deutschemark & BBDEMSP & BBDEM1F & Barclays & $31 / 10 / 1983$ & $31 / 01 / 2016$ \\
\hline Spain & $\mathrm{ESP}$ & peseta & SPANPE\$ & USESP1F & Reuters & $31 / 12 / 1996$ & $31 / 12 / 1998$ \\
\hline Finland & FIM & markka & FINMAR $\$$ & USFIM1F & Reuters & $31 / 12 / 1996$ & $31 / 12 / 1998$ \\
\hline France & FRF & franc & BBFRFSP & BBFRF1F & Barclays & $31 / 10 / 1983$ & $31 / 12 / 1998$ \\
\hline UK & GBP & pound & BBGBPSP & BBGBP1F & Barclays & $31 / 10 / 1983$ & $31 / 01 / 2016$ \\
\hline Ireland & IEP & punt & BBIEPSP & BBIEP1F & Barclays & $31 / 10 / 1993$ & $31 / 12 / 1998$ \\
\hline Iceland & ISK & krona & ICEKRO\$ & USISK1F & Reuters & $31 / 03 / 2004$ & $31 / 01 / 2016$ \\
\hline Italy & ITL & lira & BBITLSP & BBITL1F & Barclays & $31 / 03 / 1984$ & $31 / 12 / 1998$ \\
\hline Japan & JPY & yen & BBJPYSP & BBJPY1F & Barclays & $31 / 10 / 1983$ & $31 / 01 / 2016$ \\
\hline South Korea & KRW & won & KORSWO\$ & USKRW1F & Reuters & $28 / 02 / 2002$ & $31 / 01 / 2016$ \\
\hline Mexico & MXN & peso & MEXPES\$ & USMXN1F & Reuters & $31 / 12 / 1996$ & $31 / 01 / 2016$ \\
\hline Netherlands & NLG & guilder & BBNLGSP & BBNLG1F & Barclays & $31 / 10 / 1983$ & $31 / 12 / 1998$ \\
\hline Norway & NOK & krone & BBNOKSP & BBNOK1F & Barclays & $31 / 12 / 1984$ & $31 / 01 / 2016$ \\
\hline New Zealand & NZD & dollar & BBNZDSP & BBNZD1F & Barclays & $31 / 12 / 1984$ & $31 / 01 / 2016$ \\
\hline Poland & PLN & zloty & TDPLNSP & TDPLN1M & Reuters & $31 / 08 / 1996$ & $31 / 01 / 2016$ \\
\hline Portugal & PTE & escudo & PORTES\$ & USPTE1F & Reuters & $31 / 12 / 1996$ & $31 / 12 / 1998$ \\
\hline Sweden & SEK & krona & BBSEKSP & BBSEK1F & Barclays & $31 / 12 / 1984$ & $31 / 01 / 2016$ \\
\hline Turkey** (first lira) & TRY & lira & TURKLI\$ & USTRY1F & Reuters & $31 / 12 / 1996$ & $31 / 10 / 2000$ \\
\hline Turkey (second lira) & TRY & lira & TURKLI\$ & USTRY1F & Reuters & $31 / 03 / 2004$ & $31 / 01 / 2016$ \\
\hline
\end{tabular}

* We replace the German deutschemark with the euro after 1998.

** We remove the period of hyperinflation in Turkey due to large deviations from CIP. 


\section{Table A2: Carry-Trade Currency Portfolios}

The table presents descriptive statistics for five currency portfolios sorted by forward premia. Portfolios are rebalanced monthly with high (low) interest rate currencies entering $P_{5}\left(P_{1}\right)$. We report summary statistics for the annualized excess mean return and its decomposition between the exchange rate $(f x)$ and interest rate $(i r)$ components. We also report the Sharpe ratio (Sharpe), standard deviation $(s t d)$, skewness (skew), kurtosis (kurt), maximum drawdown $(m d d)$, average turnover $(t / o)$, average forward premium $(f p)$, and average output gap (gap) for each portfolio. The Cross Section portfolio is long $P_{5}$ and short $P_{1}$. The Time Series portfolio takes a $1 / \mathrm{N}$ position in currencies, going long (short) currencies issued by countries with an interest rate above (below) the US interest rate. The superscripts *, **, *** represent significance of the Cross Section and Time Series portfolios at the 10\%, 5\%, and 1\% level using Newey and West (1987) standard errors. The sample is from October 1983 to January 2016.

\begin{tabular}{|c|c|c|c|c|c|c|c|}
\hline \multirow{5}{*}{$\begin{array}{r}\text { mean }(\%) \\
f x(\%) \\
\text { ir }(\%)\end{array}$} & \multicolumn{5}{|c|}{ Forward Premia } & \multirow{2}{*}{$\begin{array}{c}\text { Cross } \\
\text { Section }\end{array}$} & \multirow{2}{*}{$\begin{array}{c}\text { Time } \\
\text { Series }\end{array}$} \\
\hline & $\mathbf{P}_{1}$ & $\mathbf{P}_{2}$ & $\mathbf{P}_{3}$ & $\mathbf{P}_{4}$ & $\mathbf{P}_{5}$ & & \\
\hline & -0.63 & 1.02 & 3.88 & 2.83 & 7.17 & $7.80^{* * *}$ & $4.43 * * *$ \\
\hline & 1.58 & 1.35 & 2.54 & -0.40 & -3.05 & -4.63 & 0.85 \\
\hline & -2.20 & -0.33 & 1.34 & 3.22 & 10.22 & 12.43 & 3.59 \\
\hline Sharpe & -0.06 & 0.11 & 0.42 & 0.29 & 0.68 & 0.72 & 0.79 \\
\hline std & 9.80 & 9.30 & 9.23 & 9.72 & 10.49 & 10.87 & 5.60 \\
\hline skew & 0.26 & -0.09 & -0.29 & -0.48 & -0.63 & -0.93 & -1.14 \\
\hline kurt & 3.80 & 3.73 & 5.12 & 4.85 & 5.56 & 5.30 & 9.32 \\
\hline$m d d(\%)$ & 54.0 & 32.6 & 23.2 & 27.8 & 19.9 & 19.8 & 8.2 \\
\hline$t / o(\%)$ & 18.5 & 25.6 & 29.6 & 24.1 & 13.5 & & \\
\hline$f p(t, \%)$ & -2.15 & -0.32 & 1.25 & 3.25 & 10.94 & & \\
\hline $\operatorname{gap}(t, \%)$ & -0.04 & 0.02 & 0.08 & -0.05 & 0.30 & & \\
\hline
\end{tabular}




\section{Table A3: Correlation and Factor Structure of Output Gap Measures}

The table presents the average cross-sectional correlation and factor structure across measures of countries' output gap. The output gap is estimated as $(\log )$ industrial production minus the $(\log )$ trend in industrial production. The trend is estimated in four ways using a (i) Hodrick-Prescott filter; (ii) Baxter-King filter, (iii) linear projection, and (iv) quadratic time trend. In Panel A, entries below the diagonal are linear Pearson correlations, calculated by taking the time-series average of monthly cross-sectional correlations for all available currencies. The entries above the diagonal are Spearman rank correlations, also calculated as the time-series average of monthly cross-sectional correlations. In Panel B, we report the average proportion of cross-sectional variation accounted for by each principal component $(P C)$. To calculate, we estimate the variation explained by each $P C$ every month and report the average across the sample. The sample is from October 1983 to January 2016.

\begin{tabular}{lcccc}
\hline \hline \multicolumn{5}{c}{ Panel A: Output-Gap Correlations } \\
\hline & HP & BK & LP & QT \\
\hline Hodrick-Prescott Filter (HP) & & 0.63 & 0.51 & 0.41 \\
Baxter-King Filter (BK) & 0.65 & & 0.55 & 0.53 \\
Linear Projection (LP) & 0.54 & 0.56 & & 0.47 \\
Quadratic Time-trend (QT) & 0.45 & 0.58 & 0.48 & \\
\hline
\end{tabular}

Panel B: Output-Gap Factor Structure

\begin{tabular}{lcccc}
\hline & $\mathbf{P C}_{\mathbf{1}}$ & $\mathbf{P C}_{\mathbf{2}}$ & $\mathbf{P C}_{\mathbf{3}}$ & $\mathbf{P C}_{\mathbf{4}}$ \\
\cline { 2 - 5 } var explained & $86 \%$ & $10 \%$ & $3 \%$ & $1 \%$ \\
\hline \hline
\end{tabular}


Table A4: Currency Portfolios Sorted on Deviations from Taylor-Rule-Implied Interest Rates

The table presents descriptive statistics for five currency portfolios sorted by their deviation from a Taylor-rule implied interest rate. The Taylor rule is calibrated to equal $1.5 \pi_{t}+0.5 y_{t}$, where $\pi_{t}$ is inflation and $y_{t}$ is the in-sample output gap calculated using a Hodrick-Prescott filter. Portfolios are rebalanced monthly with the highest (lowest) interest-rate deviation currencies entering $P_{5}$ $\left(P_{1}\right)$. We report summary statistics for the annualized excess mean return and its decomposition between the exchange rate $(f x)$ and interest rate (ir) components. We also report the Sharpe ratio (Sharpe), standard deviation (std), skewness (skew), kurtosis (kurt), maximum drawdown $(m d d)$, average turnover $(t / o)$, average forward premium $(f p)$, and average output gap ( $g a p)$ for each portfolio. The Cross Section portfolio is long $P_{5}$ and short $P_{1}$. The Time Series portfolio takes a $1 / \mathrm{N}$ position in currencies, going long (short) currencies issued by countries with a positive (negative) deviation from the Taylor-rule interest rate. The superscripts $*,{ }^{*},{ }^{* * *}$ represent significance of the Cross Section and Time Series portfolios at the 10\%, 5\%, and 1\% level using Newey and West (1987) standard errors. We also report the correlation of the Cross Section and Time Series portfolios with the equivalent portfolios sorted on Hodrick-Prescott filtered output gaps $\left(\rho_{G A P}\right)$, and interest rates $\left(\rho_{H M L_{F X}}\right)$. The sample is from October 1983 to January 2016.

\begin{tabular}{|c|c|c|c|c|c|c|c|}
\hline \multirow{5}{*}{$\begin{array}{r}\text { mean }(\%) \\
f x(\%) \\
i r(\%)\end{array}$} & \multicolumn{5}{|c|}{ Deviations from Taylor Rule } & \multirow{2}{*}{$\begin{array}{c}\text { Cross } \\
\text { Section }\end{array}$} & \multirow{2}{*}{$\begin{array}{c}\text { Time } \\
\text { Series }\end{array}$} \\
\hline & $\mathbf{P}_{1}$ & $\mathbf{P}_{2}$ & $\mathbf{P}_{3}$ & $\mathbf{P}_{4}$ & $\mathbf{P}_{5}$ & & \\
\hline & 3.95 & 2.76 & 0.74 & 3.17 & 3.06 & -0.89 & $1.82^{* *}$ \\
\hline & 0.12 & 1.92 & -0.53 & 1.03 & -1.17 & -1.29 & 0.98 \\
\hline & 3.83 & 0.84 & 1.28 & 2.14 & 4.23 & 0.40 & 0.84 \\
\hline Sharpe & 0.40 & 0.30 & 0.08 & 0.33 & 0.30 & -0.11 & 0.34 \\
\hline std & 9.83 & 9.29 & 9.27 & 9.64 & 10.27 & 8.44 & 5.30 \\
\hline skew & 0.06 & -0.10 & -0.27 & -0.49 & -0.29 & -0.26 & -0.39 \\
\hline kurt & 5.98 & 4.17 & 4.40 & 5.21 & 4.45 & 8.09 & 5.93 \\
\hline$m d d(\%)$ & 25.2 & 26.8 & 24.1 & 25.0 & 34.0 & 63.3 & 15.0 \\
\hline$t / o(\%)$ & 29.8 & 49.2 & 59.1 & 54.4 & 34.9 & & \\
\hline$f p(t, \%)$ & 4.41 & 0.89 & 1.27 & 2.20 & 4.25 & & \\
\hline $\operatorname{gap}(t, \%)$ & 1.42 & 0.63 & 0.10 & -0.35 & -1.58 & & \\
\hline$\rho_{G A P}$ & & & & & & -0.33 & -0.05 \\
\hline$\rho_{H M L_{F X}}$ & & & & & & 0.20 & 0.61 \\
\hline
\end{tabular}




\section{Table A5: Portfolio Weights}

The table presents summary statistics on the portfolio weights in the $G A P_{C S}, L I N$, and $R N K$ output-gap-sorted portfolios. We report the average maximum $(\overline{\max })$, minimum $(\overline{\min })$, and standard deviation $(\overline{s t d})$, calculated as the time-series mean of the maximum, minium, and standard deviation of weights each month. The sample is from December 1999 to January 2016.

\begin{tabular}{lccc}
\hline \hline & & & \\
& GAP $_{\mathbf{C S}}$ & LIN & RNK \\
\cline { 2 - 4 }$\overline{\max }$ & 0.20 & 0.18 & 0.25 \\
$\overline{\text { min }}$ & -0.20 & -0.16 & -0.25 \\
$\overline{s t d}$ & 0.28 & 0.09 & 0.16 \\
\hline \hline
\end{tabular}




\section{Table A6: Real-Time Business Cycle Currency Portfolios During US Booms and Recessions}

The table presents investment performance for output-gap-based currency trading strategies during booms and recessions in the US. The output gap is estimated using monthly 'vintages' of real-time industrial production data from the OECD's Real-Time Data and Revisions Database. To estimate the output-gap we follow the linear projection procedure in Hamilton (2018) by running the regression, $y_{i, t}=\alpha_{i}+\sum_{s=0}^{11} \beta_{i, s} y_{i, t-24-s}+\varepsilon_{i, t}$ each month, in which $y$ is $(\log )$ industrial production. Periods of recession are consistent with those defined by the NBER's Business Cycle Dataing Committee. The output gap is constructed as the difference between the most recently available data point at time $t\left(y_{t}\right)$ and the fitted value from the regression. $G A P_{C S}$ is a high-minus-low portfolio formed as $P_{5}-P_{1}$, after sorting currencies into five portfolios ranging from the lowest $\left(P_{1}\right)$ to the highest $\left(P_{5}\right)$ output gap. GAPSS is a $1 / \mathrm{N}$ time-series strategy long (short) currencies issued by countries with an output gap above (below) the US output gap. We report summary statistics for the annualized mean, which is then further split between the exchange rate $(f x)$ and interest rate $(i r)$ components, we also report the Sharpe ratio (Sharpe), skewness (skew), kurtosis (kurt), maximum drawdown ( mdd), and the exposure of the strategy to the US dollar (\$ exposure). The superscripts *, **, *** represent significance of the strategies' mean excess returns at the $10 \%, 5 \%$, and $1 \%$ significance levels using Newey and West (1987) corrected standard errors. The sample runs from December 1999 to January 2016.

\begin{tabular}{lcccc}
\hline \hline & & & & \\
& \multicolumn{2}{c}{ Expansions } & \multicolumn{2}{c}{ Recessions } \\
\hline \multirow{2}{*}{ mean (\%) } & $\mathrm{GAP}_{\mathrm{CS}}$ & $\mathrm{GAP}_{\mathrm{TS}}$ & $\mathrm{GAP}_{\mathrm{CS}}$ & $\mathrm{GAP}_{\mathrm{TS}}$ \\
\cline { 2 - 5 }$\quad$ fx (\%) & $3.75^{* *}$ & $3.90^{* * *}$ & $5.94^{*}$ & -3.99 \\
$\quad$ ir (\%) & 0.78 & -0.09 & 5.65 & -4.61 \\
Sharpe & 0.71 & 1.00 & 0.29 & 0.62 \\
skew & 0.27 & -0.20 & 0.43 & -0.69 \\
kurt & 2.78 & 4.23 & 2.71 & -1.08 \\
mdd (\%) & 8.18 & 6.92 & 5.99 & 16.68 \\
\$ exposure & 0.00 & 0.26 & 0.00 & -0.27 \\
\hline \hline
\end{tabular}




\section{Table A7: Real-Time Taylor-rule Currency Portfolios}

The table presents investment performance for Taylor-rule-based trading strategies. The Taylor rule is calibrated to equal $1.5 \pi_{t}+$ $0.5 y_{t}$, where $\pi_{t}$ is inflation and $y_{t}$ is the out-of-sample output gap calculated using monthly 'vintages' of real-time industrial production data from the OECD's Real-Time Data and Revisions Database. To estimate the output-gap we follow the linear projection procedure in Hamilton (2018) by running the regression, $y_{i, t}=\alpha_{i}+\sum_{s=0}^{11} \beta_{i, s} y_{i, t-24-s}+\varepsilon_{i, t}$ each month, in which $y$ is $(\log )$ industrial production. The output gap is constructed as the difference between the most recently available data point at time $t\left(y_{t}\right)$ and the fitted value from the regression. $C S$ is a high-minus-low portfolio formed as $P_{5}-P_{1}$, after sorting currencies into five portfolios ranging from the lowest $\left(P_{1}\right)$ to the highest $\left(P_{5}\right)$ implied interest rate. $L I N$ and $R N K$ take a position in all currencies with the weight determined by either the magnitude or relative size of the implied interest rate. $T S$ is a $1 / \mathrm{N}$ time-series strategy long (short) currencies issued by countries with an implied rate above (below) the US implied rate. The three $C O M$ portfolios take 50-50 weights in $T S$ and the $C S$, $L I N$, and $R N K$ strategies. We report summary statistics for the annualized mean, which is then further split between the exchange rate $(f x)$ and interest rate (ir) components, we also report the Sharpe ratio (Sharpe), skewness (skew), kurtosis (kurt), and maximum drawdown $(m d d)$. The superscripts $*, * *, * * *$ represent significance of the strategy mean excess returns at the $10 \%, 5 \%$, and $1 \%$ significance levels using Newey and West (1987) corrected standard errors. We also report the correlation of the portfolios with the equivalent strategies sorted on output gaps as in Table $4\left(\rho_{G A P}\right)$ and forward premia $\left(\rho_{H M L_{F X}}\right)$. The sample runs from December 1999 to January 2016.

\begin{tabular}{|c|c|c|c|c|c|c|c|}
\hline \multicolumn{3}{|c|}{ Panel A: Investmen } & \multicolumn{5}{|c|}{ Performance Excluding Bid-Ask Spreads } \\
\hline & CS & LIN & RNK & $\mathrm{GAP}_{\mathrm{TS}}$ & $\mathrm{COM}_{\mathrm{GAP}}$ & $\mathrm{COM}_{\text {LIN }}$ & $\mathrm{COM}_{\mathrm{RNK}}$ \\
\hline mean (\%) & $6.05^{* *}$ & $3.24^{* * *}$ & $4.68^{* *}$ & $3.40^{* *}$ & $4.73^{* * *}$ & $3.33^{* * *}$ & $4.04^{* * *}$ \\
\hline$f x(\%)$ & -2.34 & -1.23 & -1.49 & 1.48 & -0.41 & 0.15 & 0.02 \\
\hline ir (\%) & 8.39 & 4.47 & 6.17 & 1.92 & 5.13 & 3.18 & 4.02 \\
\hline Sharpe & 0.63 & 0.73 & 0.64 & 0.79 & 0.77 & 0.87 & 0.78 \\
\hline skew & -0.25 & -0.70 & -0.25 & -0.19 & -0.22 & -0.52 & -0.34 \\
\hline kurt & 3.35 & 6.06 & 3.34 & 5.70 & 3.27 & 4.51 & 3.61 \\
\hline$m d d(\%)$ & 9.57 & 4.47 & 7.34 & 4.31 & 6.17 & 3.84 & 5.21 \\
\hline$\rho_{G A P}$ & 0.24 & 0.18 & 0.17 & 0.21 & 0.26 & 0.23 & 0.23 \\
\hline$\rho_{H M L_{F X}}$ & 0.79 & 0.87 & 0.83 & 0.44 & 0.77 & 0.69 & 0.74 \\
\hline \multicolumn{8}{|c|}{ Panel B: Investment $\mathrm{P}$} \\
\hline & CS & LIN & RNK & $\mathrm{GAP}_{\mathrm{TS}}$ & $\mathrm{COM}_{\mathrm{GAP}}$ & $\mathrm{COM}_{\text {LIN }}$ & $\mathrm{COM}_{\mathrm{RNK}}$ \\
\hline mean (\%) & $4.75^{*}$ & $2.52^{* *}$ & $3.37^{*}$ & $2.78^{* * *}$ & $3.77^{* *}$ & $2.65^{* * *}$ & $3.08^{* *}$ \\
\hline$f x(\%)$ & -3.34 & -1.78 & -2.49 & 1.02 & -1.14 & -0.36 & -0.71 \\
\hline ir (\%) & 8.09 & 4.30 & 5.85 & 1.77 & 4.91 & 3.01 & 3.79 \\
\hline Sharpe & 0.50 & 0.57 & 0.46 & 0.65 & 0.61 & 0.69 & 0.59 \\
\hline skew & -0.26 & -0.73 & -0.27 & -0.21 & -0.23 & -0.54 & -0.35 \\
\hline kurt & 3.37 & 6.15 & 3.36 & 5.74 & 3.28 & 4.55 & 3.64 \\
\hline$m d d(\%)$ & 9.55 & 4.45 & 7.32 & 4.30 & 6.16 & 3.83 & 5.20 \\
\hline$\rho_{G A P}$ & 0.24 & 0.18 & 0.17 & 0.21 & 0.26 & 0.23 & 0.23 \\
\hline$\rho_{H M L_{F X}}$ & 0.79 & 0.87 & 0.83 & 0.44 & 0.77 & 0.69 & 0.74 \\
\hline
\end{tabular}


Table A8: Real-Time Business Cycle Portfolios across Different Home Investors

The table presents investment performance for output-gap-based currency trading strategies from the perspective of German, Japanese, British, and Swiss investors. The output gap is estimated using monthly 'vintages' of real-time industrial production data from the OECD's Real-Time Data and Revisions Database. To estimate the output-gap we follow the linear projection procedure in Hamilton (2018) by running the regression, $y_{i, t}=\alpha_{i}+\sum_{s=0}^{11} \beta_{i, s} y_{i, t-24-s}+\varepsilon_{i, t}$ each month, in which $y$ is (log) industrial production. The output gap is constructed as the difference between the most recently available data point at time $t\left(y_{t}\right)$ and the fitted value from the regression. GAP $P_{S}$ is a high-minus-low portfolio formed as $P_{5}-P_{1}$, after sorting currencies into five portfolios ranging from the lowest $\left(P_{1}\right)$ to the highest $\left(P_{5}\right)$ output gap. $L I N$ and $R N K$ take a position in all currencies with the weight determined by either the magnitude or relative size of the output gap. $G A P_{T S}$ is a $1 / \mathrm{N}$ time-series strategy long (short) currencies issued by countries with an output gap above (below) the US output gap. The three $C O M$ portfolios take 50-50 weights in $G A P_{T S}$ and the $G A P_{C S}, L I N$, and $R N K$ strategies. We report summary statistics for the annualized mean, which is then further split between the exchange rate $(f x)$ and interest rate $(i r)$ components, we also report the Sharpe ratio (Sharpe), skewness (skew), kurtosis (kurt), and maximum drawdown $(m d d)$. The superscripts $*, * *, * * *$ represent significance of the strategies' mean excess returns at the $10 \%, 5 \%$, and $1 \%$ significance levels using Newey and West (1987) corrected standard errors. The sample runs from December 1999 to January 2016.

Panel A: German Investor

\begin{tabular}{cccccccc}
\hline & GAP $_{\mathrm{CS}}$ & LIN & RNK & GAP $_{\mathrm{TS}}$ & COM $_{\mathrm{GAP}}$ & COM $_{\mathrm{LIN}}$ & $\mathrm{COM}_{\mathrm{RNK}}$ \\
\cline { 2 - 7 } mean (\%) & $5.61^{* * *}$ & $2.24^{* * *}$ & $3.88^{* * *}$ & $1.76^{* *}$ & $3.73^{* * *}$ & $2.05^{* * *}$ & $2.87^{* * *}$ \\
fx (\%) & 4.84 & 1.72 & 3.26 & 2.25 & 3.57 & 2.01 & 2.78 \\
ir (\%) & 0.77 & 0.52 & 0.62 & -0.49 & 0.16 & 0.03 & 0.09 \\
Sharpe & 0.79 & 0.76 & 0.72 & 0.50 & 0.80 & 0.74 & 0.73 \\
\hline
\end{tabular}

Panel B: Japanese Investor

\begin{tabular}{cccccccc}
\hline & $\mathrm{GAP}_{\mathrm{CS}}$ & $\mathrm{LIN}$ & $\mathrm{RNK}$ & $\mathrm{GAP}_{\mathrm{TS}}$ & $\mathrm{COM}_{\mathrm{GAP}}$ & $\mathrm{COM}_{\mathrm{LIN}}$ & $\mathrm{COM}_{\mathrm{RNK}}$ \\
\cline { 2 - 7 } mean (\%) & $4.49^{* * *}$ & $1.93^{* * *}$ & $3.40^{* * *}$ & $4.19^{* *}$ & $4.41^{* * *}$ & $3.13^{* * *}$ & $3.86^{* * *}$ \\
fx (\%) & 4.08 & 1.61 & 3.07 & 3.68 & 3.92 & 2.68 & 3.41 \\
ir (\%) & 0.41 & 0.32 & 0.33 & 0.51 & 0.49 & 0.44 & 0.45 \\
Sharpe & 0.66 & 0.68 & 0.67 & 0.61 & 0.82 & 0.77 & 0.80 \\
\hline
\end{tabular}

Panel C: British Investor

\begin{tabular}{cccccccc}
\hline & $\mathrm{GAP}_{\mathrm{CS}}$ & $\mathrm{LIN}$ & $\mathrm{RNK}$ & $\mathrm{GAP}_{\mathrm{TS}}$ & $\mathrm{COM}_{\mathrm{GAP}}$ & $\mathrm{COM}_{\mathrm{LIN}}$ & $\mathrm{COM}_{\mathrm{RNK}}$ \\
\cline { 2 - 7 } mean (\%) & $4.98^{* * *}$ & $2.27^{* * *}$ & $4.12^{* * *}$ & $1.51^{* *}$ & $3.26^{* * *}$ & $1.91^{* * *}$ & $2.83^{* * *}$ \\
fx (\%) & 4.51 & 1.87 & 3.70 & 1.24 & 2.87 & 1.55 & 2.47 \\
ir (\%) & 0.47 & 0.41 & 0.41 & 0.27 & 0.39 & 0.36 & 0.36 \\
Sharpe & 0.72 & 0.77 & 0.77 & 0.40 & 0.69 & 0.66 & 0.71 \\
\hline
\end{tabular}

Panel D: Swiss Investor

\begin{tabular}{cccccccc}
\hline & $\mathrm{GAP}_{\mathrm{CS}}$ & $\mathrm{LIN}$ & $\mathrm{RNK}$ & $\mathrm{GAP}_{\mathrm{TS}}$ & $\mathrm{COM}_{\mathrm{GAP}}$ & $\mathrm{COM}_{\mathrm{LIN}}$ & $\mathrm{COM}_{\mathrm{RNK}}$ \\
\cline { 2 - 7 } mean (\%) & $6.35^{* * *}$ & $2.32^{* * *}$ & $4.25^{* * *}$ & 0.66 & $3.55^{* * *}$ & $1.54^{* *}$ & $2.50^{* * *}$ \\
$f x(\%)$ & 5.43 & 1.76 & 3.59 & 1.21 & 3.35 & 1.51 & 2.42 \\
ir (\%) & 0.92 & 0.56 & 0.66 & -0.55 & 0.21 & 0.03 & 0.08 \\
Sharpe & 0.91 & 0.81 & 0.81 & $23^{0.14}$ & 0.73 & 0.48 & 0.59 \\
\hline \hline
\end{tabular}




\section{Table A9: Pricing Currency Portfolios Sorted on Output Gaps with Fama-MacBeth Estimation}

The table presents cross-sectional asset pricing results. We construct various two-factor linear SDF's that include the $D O L$ factor plus a second pricing factor, including 'slope' risk $\left(H M L_{F X}\right)$, global imbalance risk $(I M B)$, volatility risk $(V O L)$, and the $G A P_{C S}$ factor. In each model, we price five currency portfolios sorted on output gaps using real-time information. We report Fama-MacBeth estimates of factor loadings on the pricing kernel $(b$ 's $)$ and prices of factor risk $(\lambda ' s)$. The superscripts *, ${ }^{* *},{ }^{* * *}$ represent significance of the coefficients at the $10 \%, 5 \%$, and $1 \%$ significance levels using Newey and West (1987) corrected standard errors (reported in parentheses). We also report goodness-of-fit statistics for each model including the adjusted $R^{2}$ statistic, Root Mean Squared Pricing Error $(R M S E)$, and the Hansen-Jagannathan distance statistic $\left(H J_{\text {dist }}\right)$ with simulated $p$-values in brackets. The $H J_{d i s t}$ statistic measures the distance between the estimated pricing kernel and the efficient set of permissible pricing kernels. A $p$-value less than $5 \%$ indicates the null hypothesis that the pricing kernel is efficient can be rejected at the $95 \%$ confidence level. We provide full details of the pricing factors in Section 5. The sample runs from December 1999 to January 2016.

\begin{tabular}{cccccccc}
\hline \hline & \multicolumn{2}{c}{ SDF } & \multicolumn{2}{c}{ Risk } & \multicolumn{3}{c}{ Model Fit } \\
& \multicolumn{2}{c}{ Loadings $(b)$} & \multicolumn{2}{c}{ Prices $(\lambda)$} & \multicolumn{3}{c}{ Mod. } \\
& DOL & FAC & DOL & FAC & Adj.R ${ }^{2}$ & RMSE & HJ $_{\text {dist }}$ \\
\cline { 2 - 8 } DOL + HML & 0.22 & 0.19 & 0.02 & 0.03 & -0.78 & 1.69 & 0.22 \\
& $(0.26)$ & $(0.72)$ & $(0.02)$ & $(0.10)$ & & & {$[0.03]$} \\
DOL + IMB & -1.39 & 7.52 & 0.04 & 0.26 & -0.15 & 1.59 & 0.19 \\
& $(1.43)$ & $(5.78)$ & $(0.04)$ & $(0.20)$ & & & {$[0.61]$} \\
DOL + VOL & -3.21 & -40.5 & 0.03 & -0.03 & -0.19 & 1.51 & 0.21 \\
& $(2.86)$ & $(31.6)$ & $(0.03)$ & $(0.02)$ & & & {$[0.46]$} \\
DOL + GAP & 0.08 & $0.83^{* * *}$ & 0.02 & $0.05^{* * *}$ & 0.44 & 0.95 & 0.13 \\
& $(0.26)$ & $(0.29)$ & $(0.02)$ & $(0.02)$ & & & {$[0.34]$} \\
\hline \hline
\end{tabular}


Table A10: Asset Pricing using DOL, $\mathrm{HML}_{\mathrm{FX}}$, and $\mathrm{GAP}_{\mathrm{CS}}$ as Pricing Factors with Fama-MacBeth Estimation

The table presents cross-sectional asset pricing results for two sets of test portfolios. The SDF is constructed as a linear combination of $D O L$ and $H M L_{F X}$ (2 pricing factors, left-side) and $D O L, H M L_{F X}$, and $G A P_{C S}$ (3 pricing factors, right-side). In Panel B, we also include $H M L_{F X}$ and $G A P_{C S}$ as test assets. We report Fama-MacBeth estimates of factor loadings on the pricing kernel (b's) and prices of factor risk $(\lambda ' s)$. The superscripts *, ${ }^{* *},{ }^{* * *}$ represent significance of the coefficients at the $10 \%, 5 \%$, and $1 \%$ significance levels using Newey and West (1987) corrected standard errors (reported in parentheses). In addition, we report goodness-of-fit statistics for each model including the adjusted $R^{2}$ statistic, Root Mean Squared Pricing Error $(R M S E)$, and the Hansen-Jagannathan distance statistic $\left(H J_{\text {dist }}\right)$ with simulated $p$-values in brackets. The $H J_{\text {dist }}$ statistic measures the distance between the estimated pricing kernel and the efficient set of permissible pricing kernels. A $p$-value less than $5 \%$ indicates the null hypothesis that the pricing kernel is efficient can be rejected at the 95\% confidence level. The sample runs from December 1999 to January 2016.

Panel A: Excluding Pricing Factors as Test Portfolios

\begin{tabular}{|c|c|c|c|c|c|c|c|c|c|c|c|c|c|c|c|c|}
\hline \multirow[b]{3}{*}{ i } & \multicolumn{7}{|c|}{2 Pricing Factors $\left(\mathrm{DOL}+\mathrm{HML}_{\mathrm{FX}}\right)$} & \multicolumn{9}{|c|}{3 Pricing Factors $\left(\mathrm{DOL}+\mathrm{HML}_{\mathrm{FX}}+\mathrm{GAP}_{\mathrm{CS}}\right)$} \\
\hline & \multicolumn{2}{|c|}{ Loadings $(b)$} & \multicolumn{2}{|c|}{ Risk Prices $(\lambda)$} & \multicolumn{3}{|c|}{ Model Fit } & \multicolumn{3}{|c|}{ Loadings $(b)$} & \multicolumn{3}{|c|}{ Risk Prices $(\lambda)$} & \multicolumn{3}{|c|}{ Model Fit } \\
\hline & DOL & $\mathrm{HML}_{\mathrm{FX}}$ & DOL & $\mathrm{HML}_{\mathrm{FX}}$ & Adj. $R^{2}$ & DOL & $\mathrm{HJ}_{\text {dist }}$ & DOL & $\mathrm{HML}_{\mathrm{FX}}$ & $\mathrm{GAP}_{\mathrm{CS}}$ & DOL & $\mathrm{HML}_{\mathrm{FX}}$ & $\mathrm{GAP}_{\mathrm{CS}}$ & Adj. $R^{2}$ & RMSE & $\mathrm{HJ}_{\text {dist }}$ \\
\hline $\begin{array}{c}10 \text { TPs } \\
\text { (val, mom) }\end{array}$ & $\begin{array}{c}0.19 \\
(0.26)\end{array}$ & $\begin{array}{c}0.08 \\
(0.32)\end{array}$ & $\begin{array}{c}0.02 \\
(0.02)\end{array}$ & $\begin{array}{c}0.01 \\
(0.04)\end{array}$ & -0.35 & 1.32 & $\begin{array}{c}0.22 \\
{[0.81]}\end{array}$ & $\begin{array}{l}-0.31 \\
(0.36)\end{array}$ & $\begin{array}{c}0.43 \\
(0.41)\end{array}$ & $\begin{array}{c}2.57^{* *} \\
(1.01)\end{array}$ & $\begin{array}{c}0.02 \\
(0.03)\end{array}$ & $\begin{array}{c}0.07 \\
(0.05)\end{array}$ & $\begin{array}{c}0.14^{* *} \\
(0.06)\end{array}$ & 0.59 & 0.67 & $\begin{array}{c}0.16 \\
{[0.96]}\end{array}$ \\
\hline $\begin{array}{l}20 \text { TPs } \\
\text { (gap, car, } \\
\text { val, mom) }\end{array}$ & $\begin{array}{c}0.18 \\
(0.27)\end{array}$ & $\begin{array}{c}0.36 \\
(0.22)\end{array}$ & $\begin{array}{c}0.02 \\
(0.02)\end{array}$ & $\begin{array}{l}0.05^{*} \\
(0.03)\end{array}$ & 0.26 & 1.36 & $\begin{array}{c}0.33 \\
{[0.99]}\end{array}$ & $\begin{array}{l}-0.02 \\
(0.28)\end{array}$ & $\begin{array}{c}0.35 \\
(0.22)\end{array}$ & $\begin{array}{c}1.05^{* * *} \\
(0.32)\end{array}$ & $\begin{array}{c}0.02 \\
(0.02)\end{array}$ & $\begin{array}{l}0.06^{*} \\
(0.03)\end{array}$ & $\begin{array}{c}0.06^{* * *} \\
(0.02)\end{array}$ & 0.62 & 0.94 & $\begin{array}{c}0.30 \\
{[0.99]}\end{array}$ \\
\hline
\end{tabular}

Panel B: Including Pricing Factors as Test Portfolios

\begin{tabular}{|c|c|c|c|c|c|c|c|c|c|c|c|c|c|c|c|c|}
\hline & \multicolumn{7}{|c|}{2 Pricing Factors $\left(\mathrm{DOL}+\mathrm{HML}_{\mathrm{FX}}\right)$} & \multicolumn{9}{|c|}{3 Pricing Factors $\left(\mathrm{DOL}+\mathrm{HML}_{\mathrm{FX}}+\mathrm{GAP}_{\mathrm{CS}}\right)$} \\
\hline & \multicolumn{2}{|c|}{ Loadings $(b)$} & \multicolumn{2}{|c|}{ Risk Prices $(\lambda)$} & \multicolumn{3}{|c|}{ Model Fit } & \multicolumn{3}{|c|}{ Loadings $(b)$} & \multicolumn{3}{|c|}{ Risk Prices $(\lambda)$} & \multicolumn{3}{|c|}{ Model Fit } \\
\hline & DOL & $\mathrm{HML}_{\mathrm{FX}}$ & DOL & $\mathrm{HML}_{\mathrm{FX}}$ & Adj. $R^{2}$ & DOL & $\mathrm{HJ}_{\text {dist }}$ & DOL & $\mathrm{HML}_{\mathrm{FX}}$ & $\mathrm{GAP}_{\mathrm{CS}}$ & DOL & $\mathrm{HML}_{\mathrm{FX}}$ & $\mathrm{GAP}_{\mathrm{CS}}$ & $\operatorname{Adj} . R^{2}$ & RMSE & $\mathrm{HJ}_{\text {dist }}$ \\
\hline $\begin{array}{c}10 \text { TPs } \\
\text { (val, mom) }\end{array}$ & $\begin{array}{c}0.16 \\
(0.28)\end{array}$ & $\begin{array}{l}0.41^{*} \\
(0.22)\end{array}$ & $\begin{array}{c}0.02 \\
(0.02)\end{array}$ & $\begin{array}{c}0.06^{* *} \\
(0.03)\end{array}$ & 0.31 & 1.37 & $\begin{array}{c}0.23 \\
{[0.80]}\end{array}$ & $\begin{array}{l}-0.02 \\
(0.28)\end{array}$ & $\begin{array}{l}0.40^{*} \\
(0.21)\end{array}$ & $\begin{array}{c}0.97^{* * *} \\
(0.30)\end{array}$ & $\begin{array}{c}0.02 \\
(0.02)\end{array}$ & $\begin{array}{c}0.06^{* *} \\
(0.03)\end{array}$ & $\begin{array}{c}0.06^{* * *} \\
(0.02)\end{array}$ & 0.65 & 0.96 & $\begin{array}{c}0.19 \\
{[0.91]}\end{array}$ \\
\hline $\begin{array}{c}20 \text { TPs } \\
\text { (gap, car, } \\
\text { val, mom) }\end{array}$ & $\begin{array}{c}0.17 \\
(0.28)\end{array}$ & $\begin{array}{l}0.41^{*} \\
(0.22)\end{array}$ & $\begin{array}{c}0.02 \\
(0.02)\end{array}$ & $\begin{array}{c}0.06^{* *} \\
(0.03)\end{array}$ & 0.46 & 1.34 & $\begin{array}{c}0.69 \\
{[0.91]}\end{array}$ & $\begin{array}{c}0.00 \\
(0.28)\end{array}$ & $\begin{array}{l}0.40^{*} \\
(0.21)\end{array}$ & $\begin{array}{c}0.91^{* * *} \\
(0.30)\end{array}$ & $\begin{array}{c}0.02 \\
(0.02)\end{array}$ & $\begin{array}{c}0.06^{* *} \\
(0.03)\end{array}$ & $\begin{array}{c}0.05^{* * *} \\
(0.02)\end{array}$ & 0.74 & 0.92 & $\begin{array}{c}0.69 \\
{[0.98]}\end{array}$ \\
\hline
\end{tabular}


Table A11: Asset Pricing using DOL, IMB, and GAP ${ }_{\mathrm{CS}}$ as Pricing Factors

The table presents cross-sectional asset pricing results for two sets of test portfolios. The SDF is constructed as a linear combination of $D O L$ and $I M B$ (2 pricing factors, left-side) and $D O L, I M B$, and $G A P_{C S}$ (3 pricing factors, right-side). In Panel $\mathrm{B}$, we also include $I M B$ and $G A P_{C S}$ as test assets. We report Generalized Method of Moments (GMM) one-step estimates of factor loadings on the pricing kernel ( $b$ 's) and prices of factor risk $(\lambda ' s)$. The superscripts *, $* *, * * *$ represent significance of the coefficients at the $10 \%$, $5 \%$, and $1 \%$ significance levels using Newey and West (1987) corrected standard errors (reported in parentheses). In addition, we report goodness-of-fit statistics for each model including the adjusted $R^{2}$ statistic, Root Mean Squared Pricing Error $(R M S E)$, and the Hansen-Jagannathan distance statistic $\left(H J_{\text {dist }}\right)$ with simulated $p$-values in brackets. The $H J_{\text {dist }}$ statistic measures the distance between the estimated pricing kernel and the efficient set of permissible pricing kernels. A $p$-value less than $5 \%$ indicates the null hypothesis that the pricing kernel is efficient can be rejected at the $95 \%$ confidence level. The sample runs from December 1999 to January 2016.

\begin{tabular}{|c|c|c|c|c|c|c|c|c|c|c|c|c|c|c|c|c|}
\hline \multirow{4}{*}{$\begin{array}{c}10 \mathrm{TPs} \\
(\mathrm{val}, \mathrm{mom})\end{array}$} & \multicolumn{7}{|c|}{2 Pricing Factors (DOL + IMB) } & \multicolumn{9}{|c|}{3 Pricing Factors $\left(\mathrm{DOL}+\mathrm{IMB}+\mathrm{GAP}_{\mathrm{CS}}\right)$} \\
\hline & \multicolumn{2}{|c|}{ Loadings $(b)$} & \multicolumn{2}{|c|}{ Risk Prices $(\lambda)$} & \multicolumn{3}{|c|}{ Model Fit } & \multicolumn{3}{|c|}{ Loadings $(b)$} & \multicolumn{3}{|c|}{ Risk Prices $(\lambda)$} & \multicolumn{3}{|c|}{ Model Fit } \\
\hline & DOL & IMB & DOL & IMB & Adj. $R^{2}$ & DOL & $\mathrm{HJ}_{\text {dist }}$ & DOL & IMB & $\mathrm{GAP}_{\mathrm{CS}}$ & DOL & IMB & GAP $_{\mathrm{CS}}$ & Adj. $R^{2}$ & RMSE & $\mathrm{HJ}_{\text {dist }}$ \\
\hline & $\begin{array}{l}-0.13 \\
(0.45)\end{array}$ & $\begin{array}{l}2.04^{*} \\
(1.23)\end{array}$ & $\begin{array}{c}0.03 \\
(0.02)\end{array}$ & $\begin{array}{c}0.08^{* *} \\
(0.04)\end{array}$ & -0.03 & 1.20 & $\begin{array}{c}0.20 \\
{[0.92]}\end{array}$ & $\begin{array}{l}-0.27 \\
(0.42)\end{array}$ & $\begin{array}{c}1.26 \\
(1.48)\end{array}$ & $\begin{array}{l}1.85^{*} \\
(1.12)\end{array}$ & $\begin{array}{c}0.03 \\
(0.02)\end{array}$ & $\begin{array}{c}0.05 \\
(0.05)\end{array}$ & $\begin{array}{c}0.11^{* *} \\
(0.04)\end{array}$ & 0.47 & 0.80 & $\begin{array}{c}0.14 \\
{[0.98]}\end{array}$ \\
\hline $\begin{array}{c}20 \text { TPs } \\
\text { (gap, car, } \\
\text { val, mom) }\end{array}$ & $\begin{array}{l}-0.20 \\
(0.41)\end{array}$ & $\begin{array}{c}2.43^{* *} \\
(1.18)\end{array}$ & $\begin{array}{c}0.03 \\
(0.02)\end{array}$ & $\begin{array}{c}0.09^{* * *} \\
(0.03)\end{array}$ & 0.43 & 1.35 & $\begin{array}{c}0.41 \\
{[0.98]}\end{array}$ & $\begin{array}{l}-0.28 \\
(0.39)\end{array}$ & $\begin{array}{l}2.03^{*} \\
(1.19)\end{array}$ & $\begin{array}{c}0.93^{* *} \\
(0.38)\end{array}$ & $\begin{array}{c}0.03 \\
(0.02)\end{array}$ & $\begin{array}{c}0.08^{* *} \\
(0.02)\end{array}$ & $\begin{array}{c}0.06^{* * *} \\
(0.03)\end{array}$ & 0.64 & 1.04 & $\begin{array}{c}0.37 \\
{[0.99]}\end{array}$ \\
\hline \multicolumn{17}{|c|}{ Panel B: Including Pricing Factors as Test Portfolios } \\
\hline & \multicolumn{7}{|c|}{2 Pricing Factors $(\mathrm{DOL}+\mathrm{IMB})$} & \multicolumn{9}{|c|}{3 Pricing Factors $\left(\mathrm{DOL}+\mathrm{IMB}+\mathrm{GAP}_{\mathrm{CS}}\right)$} \\
\hline & \multicolumn{2}{|c|}{ Loadings $(b)$} & \multicolumn{2}{|c|}{ Risk Prices $(\lambda)$} & \multicolumn{3}{|c|}{ Model Fit } & \multicolumn{3}{|c|}{ Loadings $(b)$} & \multicolumn{3}{|c|}{ Risk Prices $(\lambda)$} & \multicolumn{3}{|c|}{ Model Fit } \\
\hline & DOL & IMB & DOL & IMB & Adj. $R^{2}$ & DOL & $\mathrm{HJ}_{\text {dist }}$ & DOL & $\mathrm{IMB}$ & $\mathrm{GAP}_{\mathrm{CS}}$ & DOL & IMB & $\mathrm{GAP}_{\mathrm{CS}}$ & Adj. $R^{2}$ & RMSE & $\mathrm{HJ}_{\text {dist }}$ \\
\hline $\begin{array}{c}10 \text { TPs } \\
\text { (val, mom) }\end{array}$ & $\begin{array}{c}0.05 \\
(0.31)\end{array}$ & $\begin{array}{c}1.36^{* * *} \\
(0.43)\end{array}$ & $\begin{array}{c}0.03 \\
(0.02)\end{array}$ & $\begin{array}{c}0.05^{* * *} \\
(0.02)\end{array}$ & 0.04 & 1.18 & $\begin{array}{c}0.20 \\
{[0.96]}\end{array}$ & $\begin{array}{l}-0.10 \\
(0.31)\end{array}$ & $\begin{array}{c}1.24^{* * *} \\
(0.43)\end{array}$ & $\begin{array}{c}0.96 * * * \\
(0.31)\end{array}$ & $\begin{array}{c}0.03 \\
(0.02)\end{array}$ & $\begin{array}{c}0.05 * * * \\
(0.02)\end{array}$ & $\begin{array}{c}0.06 * * * \\
(0.02)\end{array}$ & 0.48 & 0.85 & $\begin{array}{c}0.16 \\
{[0.99]}\end{array}$ \\
\hline $\begin{array}{c}20 \text { TPs } \\
\text { (gap, car, } \\
\text { val, mom) }\end{array}$ & $\begin{array}{l}-0.01 \\
(0.32)\end{array}$ & $\begin{array}{c}1.65^{* * *} \\
(0.56)\end{array}$ & $\begin{array}{c}0.04 \\
(0.02)\end{array}$ & $\begin{array}{c}0.06^{* * *} \\
(0.02)\end{array}$ & 0.36 & 1.41 & $\begin{array}{c}0.41 \\
{[0.99]}\end{array}$ & $\begin{array}{l}-0.13 \\
(0.32)\end{array}$ & $\begin{array}{c}1.47^{* * *} \\
(0.56)\end{array}$ & $\begin{array}{c}0.91^{* * *} \\
(0.32)\end{array}$ & $\begin{array}{c}0.04 \\
(0.02)\end{array}$ & $\begin{array}{c}0.06^{* * *} \\
(0.02)\end{array}$ & $\begin{array}{c}0.06^{* * *} \\
(0.02)\end{array}$ & 0.63 & 1.05 & $\begin{array}{c}0.47 \\
{[0.99]}\end{array}$ \\
\hline
\end{tabular}


Table A12: Asset Pricing using DOL, VOL, and GAP ${ }_{\mathrm{CS}}$ as Pricing Factors

The table presents cross-sectional asset pricing results for two sets of test portfolios. The SDF is constructed as a linear combination of $D O L$ and $V O L$ (2 pricing factors, left-side) and $D O L, V O L$, and $G A P_{C S}$ (3 pricing factors, right-side). In Panel B, we also include $V O L$ and $G A P_{C S}$ as test assets. We report Generalized Method of Moments (GMM) one-step estimates of factor loadings on the pricing kernel $\left(b^{\prime} s\right)$ and prices of factor risk $(\lambda ' s)$. The superscripts ${ }^{*},{ }^{* *},{ }^{* * *}$ represent significance of the coefficients at the $10 \%$, $5 \%$, and $1 \%$ significance levels using Newey and West (1987) corrected standard errors (reported in parentheses). In addition, we report goodness-of-fit statistics for each model including the adjusted $R^{2}$ statistic, Root Mean Squared Pricing Error $(R M S E)$, and the Hansen-Jagannathan distance statistic $\left(H J_{d i s t}\right)$ with simulated $p$-values in brackets. The $H J_{\text {dist }}$ statistic measures the distance between the estimated pricing kernel and the efficient set of permissible pricing kernels. A $p$-value less than $5 \%$ indicates the null hypothesis that the pricing kernel is efficient can be rejected at the $95 \%$ confidence level. The sample runs from December 1999 to January 2016.

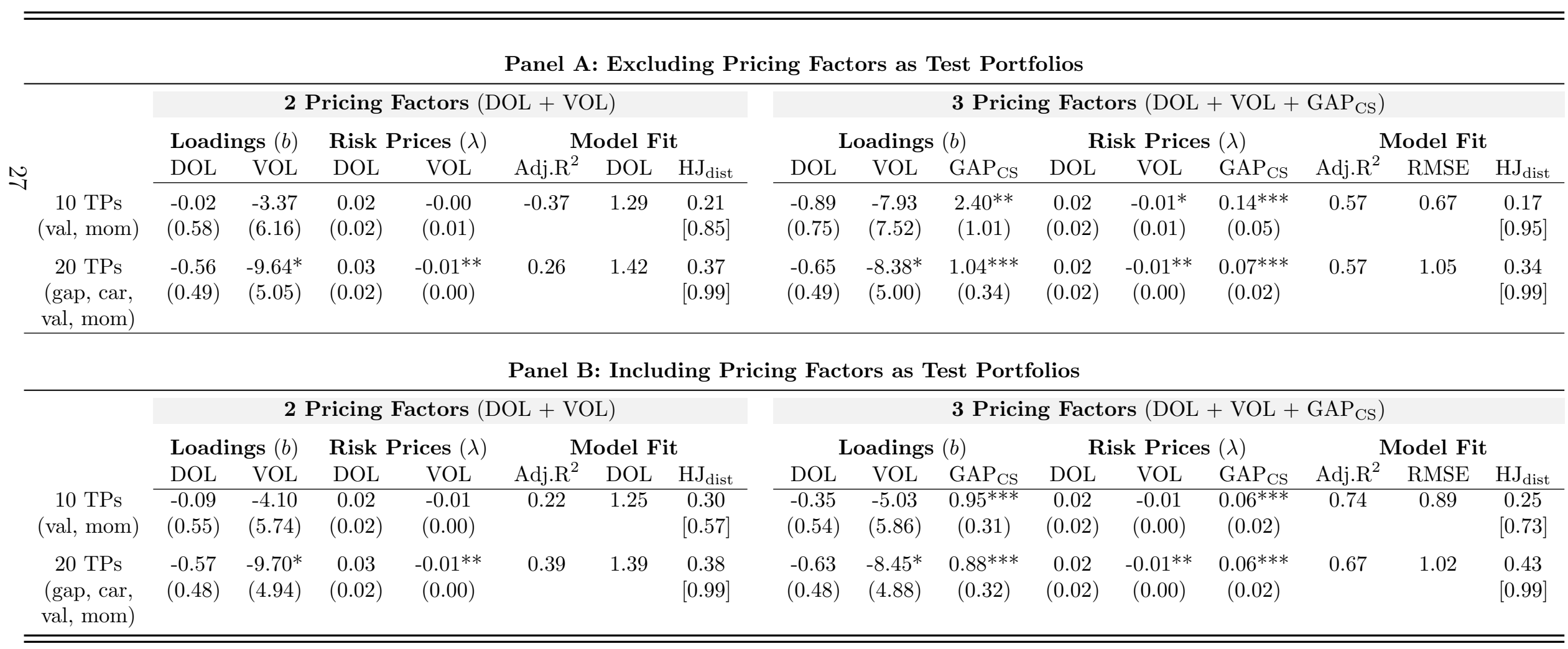


Table A13: Asset Pricing using DOL and GAP $_{\mathrm{CS}}$ as Pricing Factors

The table presents cross-sectional asset pricing results for two sets of test portfolios. The SDF is constructed as a linear combination of $D O L$ and $G A P_{C S}$. In Panel B, we include $G A P_{C S}$ as a test asset. We report Generalized Method of Moments (GMM) one-step estimates of factor loadings on the pricing kernel $(b ' s)$ and prices of factor risk $(\lambda$ 's). The superscripts *, **, *** represent significance of the coefficients at the $10 \%, 5 \%$, and $1 \%$ significance levels using Newey and West (1987) corrected standard errors. In addition, we report goodness-of-fit statistics for each model including the $R^{2}$ statistic and the Hansen-Jagannathan distance statistic $(H J)$ with simulated $p$-values in brackets. The $H J$ statistic measures the distance between the estimated pricing kernel and the efficient set of permissible pricing kernels. A $p$-value less than $5 \%$ indicates the null hypothesis that the pricing kernel is efficient can be rejected at the $95 \%$ confidence level. The sample runs from December 1999 to January 2016.

\begin{tabular}{|c|c|c|c|c|c|c|c|}
\hline \multicolumn{8}{|c|}{ Panel A: Excluding Pricing Factor as Test Portfolio } \\
\hline & \multicolumn{7}{|c|}{2 Pricing Factors $\left(\mathrm{DOL}+\mathrm{GAP}_{\mathrm{CS}}\right)$} \\
\hline & \multicolumn{2}{|c|}{ Loadings $(b)$} & \multicolumn{2}{|c|}{ Risk Prices $(\lambda)$} & \multicolumn{3}{|c|}{ Model Fit } \\
\hline & DOL & $\mathrm{GAP}_{\mathrm{CS}}$ & DOL & $\mathrm{GAP}_{\mathrm{CS}}$ & Adj. $R^{2}$ & RMSE & $\mathrm{HJ}_{\text {dist }}$ \\
\hline $\begin{array}{c}10 \text { TPs } \\
\text { (val, mom) }\end{array}$ & $\begin{array}{l}-0.15 \\
(0.33)\end{array}$ & $\begin{array}{l}1.96^{* *} \\
(0.87)\end{array}$ & $\begin{array}{c}0.02 \\
(0.02)\end{array}$ & $\begin{array}{l}0.11^{* *} \\
(0.05)\end{array}$ & 0.35 & 0.91 & $\begin{array}{c}0.17 \\
{[0.95]}\end{array}$ \\
\hline $\begin{array}{c}20 \text { TPs } \\
\text { (gap, car, } \\
\text { val, mom) }\end{array}$ & $\begin{array}{c}0.02 \\
(0.26)\end{array}$ & $\begin{array}{c}1.06^{* * *} \\
(0.29)\end{array}$ & $\begin{array}{c}0.02 \\
(0.02)\end{array}$ & $\begin{array}{c}0.06^{* * *} \\
(0.02)\end{array}$ & 0.31 & 1.31 & $\begin{array}{c}0.33 \\
{[0.99]}\end{array}$ \\
\hline
\end{tabular}

Panel B: Including Pricing Factor as Test Portfolio

\begin{tabular}{|c|c|c|c|c|c|c|c|}
\hline & \multicolumn{7}{|c|}{2 Pricing Factors $\left(\mathrm{DOL}+\mathrm{GAP}_{\mathrm{CS}}\right)$} \\
\hline & \multicolumn{2}{|c|}{ Loadings $(b)$} & \multicolumn{2}{|c|}{ Risk Prices $(\lambda)$} & \multicolumn{3}{|c|}{ Model Fit } \\
\hline & DOL & $\mathrm{GAP}_{\mathrm{CS}}$ & DOL & $\mathrm{GAP}_{\mathrm{CS}}$ & Adj. $R^{2}$ & RMSE & $\mathrm{HJ}_{\text {dist }}$ \\
\hline $\begin{array}{c}10 \text { TPs } \\
\text { (val, mom) }\end{array}$ & $\begin{array}{c}0.03 \\
(0.26)\end{array}$ & $\begin{array}{c}0.94^{* * *} \\
(0.29)\end{array}$ & $\begin{array}{c}0.02 \\
(0.02)\end{array}$ & $\begin{array}{c}0.05^{* * *} \\
(0.02)\end{array}$ & 0.46 & 1.00 & $\begin{array}{c}0.19 \\
{[0.89]}\end{array}$ \\
\hline $\begin{array}{c}20 \text { TPs } \\
\text { (gap, car, } \\
\text { val, mom) }\end{array}$ & $\begin{array}{c}0.04 \\
(0.26)\end{array}$ & $\begin{array}{c}0.93^{* * *} \\
(0.28)\end{array}$ & $\begin{array}{c}0.02 \\
(0.02)\end{array}$ & $\begin{array}{c}0.05^{* * *} \\
(0.02)\end{array}$ & 0.40 & 1.29 & $\begin{array}{c}0.42 \\
{[0.99]}\end{array}$ \\
\hline
\end{tabular}

